Portland State University

PDXScholar

$5-19-2021$

\title{
Preventing Sexual Violence Through Understanding Perceptions of Sexual Offenders
}

Judith G. Zatkin

Portland State University

Follow this and additional works at: https://pdxscholar.library.pdx.edu/open_access_etds

Part of the Psychology Commons

Let us know how access to this document benefits you.

\section{Recommended Citation}

Zatkin, Judith G., "Preventing Sexual Violence Through Understanding Perceptions of Sexual Offenders" (2021). Dissertations and Theses. Paper 5698.

https://doi.org/10.15760/etd.7570

This Dissertation is brought to you for free and open access. It has been accepted for inclusion in Dissertations and Theses by an authorized administrator of PDXScholar. Please contact us if we can make this document more accessible: pdxscholar@pdx.edu. 
Preventing Sexual Violence Through Understanding Perceptions of Sexual Offenders

by

Judith G. Zatkin

A dissertation submitted in partial fulfillment of the requirements for the degree of

Doctor of Philosophy

in

Applied Psychology

Dissertation Committee:
Keith Kaufman, Chair
Greg Townley
Joel Steele
Melissa Thompson

Portland State University

2021 
PREVENTION AND PERCEPTIONS

\section{Abstract}

In this dissertation, I present three complete manuscripts. I utilize social and community psychological theory, as well as criminological theory to better understand those who perpetrate sexual violence in two domains: child sexual abuse and college campus sexual assault. All three studies are conducted with an eye toward the prevention of sexual violence. In the first study, I conduct a complete psychometric analysis of the Modus Operandi Questionnaire, a comprehensive quantitative tool that examines offending patterns and tactics of those who commit child sexual abuse (Chapter II). An updated factor structure for this tool is presented, as well as recommendations for future use for both researchers and treatment providers. One finding of note is that particularly violent tactics are rarely used by offenders, who instead opt for more subtle, manipulative grooming tactics. This defies common beliefs and perceptions about offenders.

Therefore, the second study I present examines how policy and media have impacted public perceptions of sexual offenders (Chapter III). This systematic literature review supports a cyclical relationship between myths about offenders, policy, and media, which leads to a false understanding about the nature of sexual assault. Finally, I conduct a third study which aims to understand if myths about sexual offending and offenders extend to a campus setting (Chapter IV). This vignette-based experiment manipulates both the student status of the offender and the type of sexual assault committed to see if perceptions of deserved punishment and blame attribution shift. Results show no differences between perceptions of student and non-student offenders, suggesting that myths about offenders do span across context. 


\section{Dedication}

To those who know that the best journeys are not linear and who have the courage to wander. 
PREVENTION AND PERCEPTIONS

\section{Acknowledgments}

Where to start? I am positive that I would not be writing this without the support of my community. This dissertation represents all of the ideas we have shared, and I am so grateful to each and every person who has been a part of my wandering journey.

To my advisor, Dr. Keith Kaufman: thank you for sticking with me, thank you for pushing me to be my best, and thank you for knowing that sometimes, a trip to Harry Potter World is exactly what is needed for research productivity.

To Dr. Joel Steele: Thank you for always telling me that I have the makings of a methodologist, even when I was crying over multivariate statistics. Thank you for being an exceptional listener and pushing me to keep going. And, thank you for seeing the teacher in me, and helping me to cultivate those skills.

To Dr. Greg Townley: Your positive attitude is such a breath of fresh air and is needed in any academic setting. Kindness matters. Thank you for always being genuinely proud of my accomplishments, and for never making me chase you down for an email response.

To Dr. Melissa Thompson: The perspective that you brought to this project strengthened it immensely. I am so grateful for your support, and the stability, pragmatism, and intellect you brought as an "outside" member.

To Dr. Eric Mankowski: Your mentorship has been essential to my graduate school success, and my chosen career path. You knew before I knew that teaching was my calling, and I am so grateful that you did not let me forget that. Thank you for your immense guidance as I took on the academic job market. 
PREVENTION AND PERCEPTIONS

To Dr. Hayley Tews: I sometimes wonder how I got lucky enough to end up with a graduate student mentor as wonderful, strong, steady, and kind as you. Thank you for being an exceptional role model and an even better friend.

To Dr. Kate Sackett Kerrigan: I do not have the words to describe what your support and friendship have meant to me over the last seven (what) years. I will leave it at this: I am so grateful that we were able to take this graduate school journey together. I cannot imagine this journey with anyone else as my "partner in crime."

To my peers and colleagues at Portland State University, Linfield University, and The University of Washington, Tacoma: I have been so lucky to work with exceptional, brilliant, kind people who have shown me what academia SHOULD look like. There are too many of you to name but know that your impact has helped me to get this dissertation to the finish line.

To my parents and my sister: Thank you for supporting me from afar, and for pushing me to keep going, even though academia is unfamiliar. Thank you for countless phone calls, tickets to visit, gestures of financial and emotional support, and just believing that I could do this.

And, to my partner, AJ—I love you, and thank you for making me dinner when I work too much and forget to eat. I could not have done this without you, and I am so excited to see where our journey takes us. 


\section{Table of Contents}

Abstract

\section{CHAPTER I. INTRODUCTION}

Sexual Violence Prevalence and Incidence.......................................

Impact of Sexual Violence...................................................2

Preventing Sexual Violence..................................................4

Rational Choice Theory and Modus Operandi.................................. 6

Attribution Theory and Perceptions of Sexual Violence............................... 8

The Present Investigation: An Overview...................................... 11

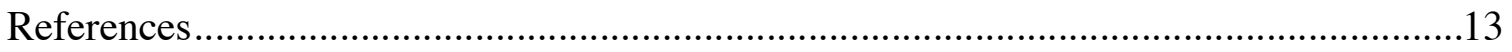

CHAPTER II. MANUSCRIPT I. AN UPDATED FACTOR STRUCTURE OF THE MODUS OPERANDI QUESTIONNAIRE

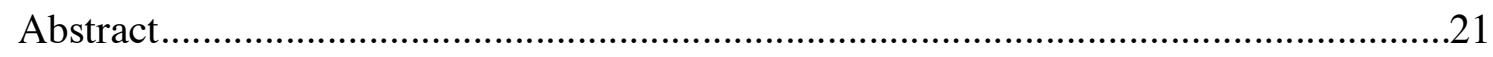

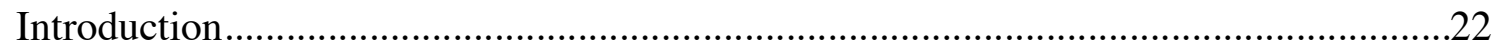

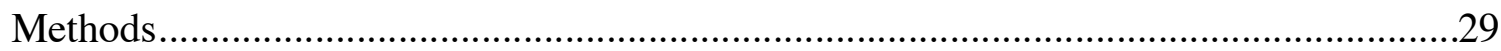

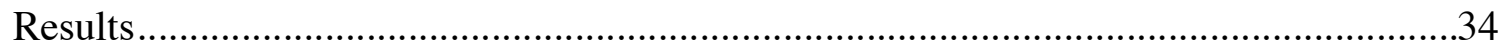

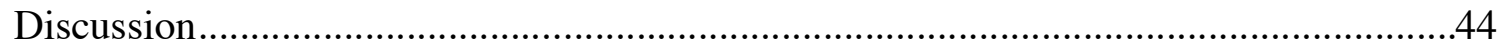

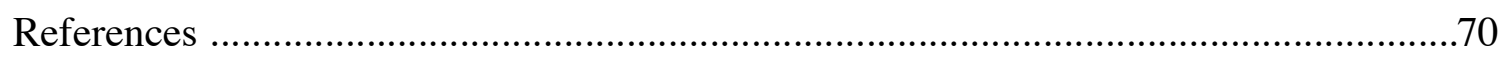


PREVENTION AND PERCEPTIONS

CHAPTER III. THE RELATIONSHIP BETWEEN POLICY, MEDIA, AND

PERCEPTIONS OF SEXUAL OFFENDERS BETWEEN 2007 AND 2017: A

\section{REVIEW OF THE LITERATURE}

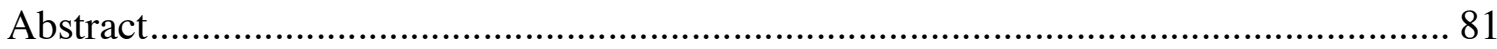

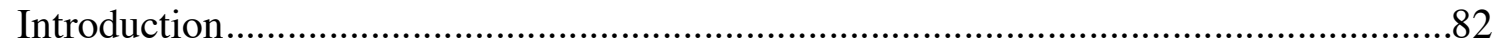

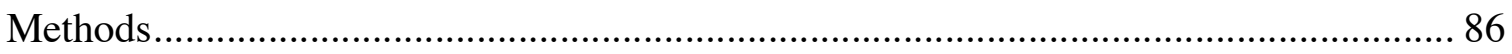

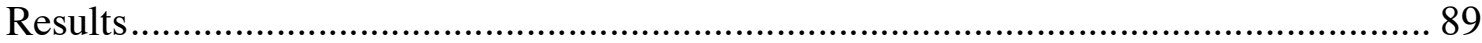

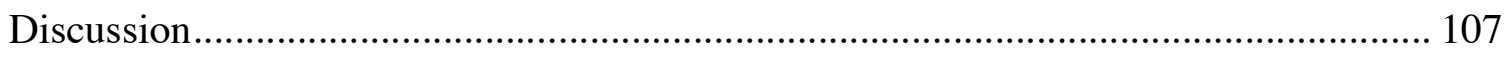

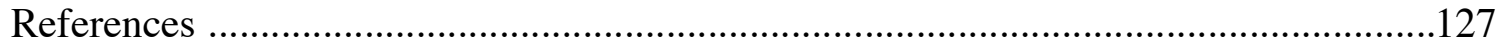

CHAPTER IV: THE IMPACT OF STUDENT STATUS AND ASSAULT TYPE ON SEXUAL ASSAULT BLAME ATTRUBUTIONS

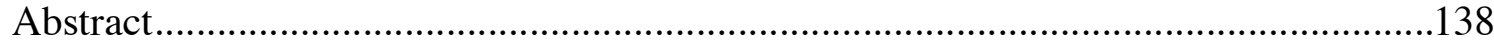

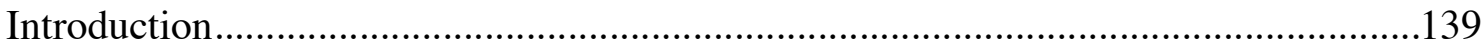

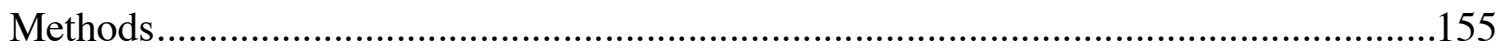

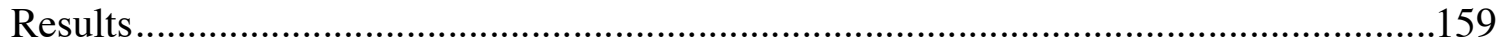

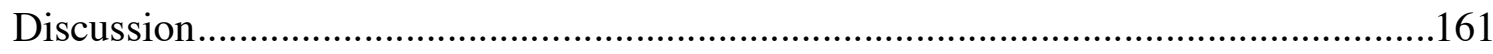

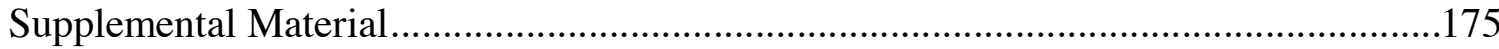

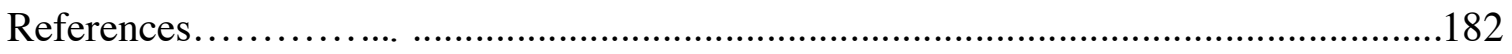

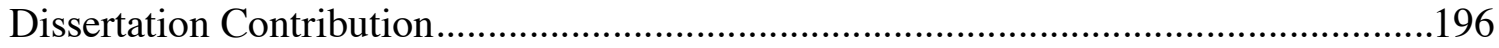

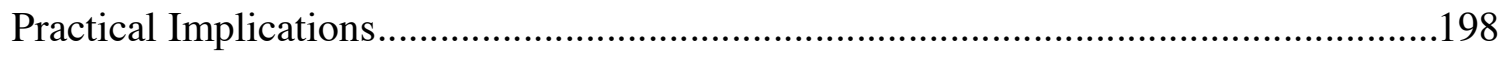

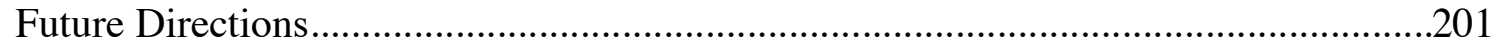

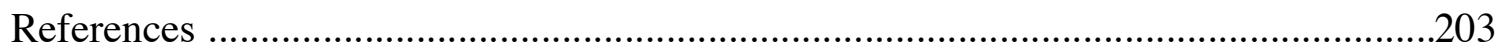


PREVENTION AND PERCEPTIONS

\section{List of Tables}

\section{Chapter II}

Table 1. Low Endorsement MOQ Items...........................................................50

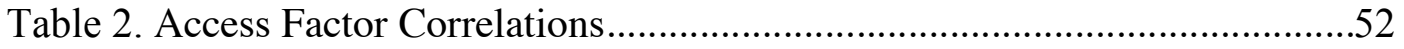

Table 3. Accessing Exploratory Factor Loadings.............................................53

Table 4. Trust Factor Correlations.................................................................... 55

Table 5. Gaining Trust Exploratory Factor Loadings...................................... 56

Table 6. Cooperation Factor Correlations........................................................ 58

Table 7. Gaining Cooperation Exploratory Factor Loadings................................. 59

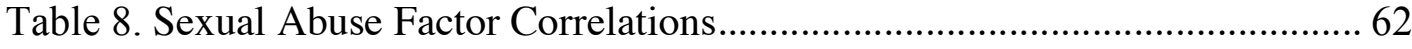

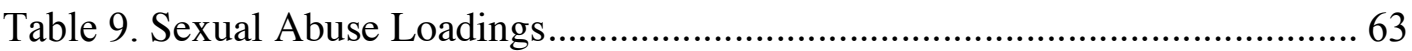

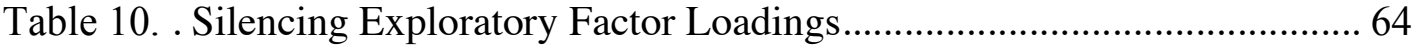

\section{Chapter III}

Table 1. Coding Scheme for Findings.............................................................. 117

Table 2. Offender Perceptions Articles ............................................................... 117

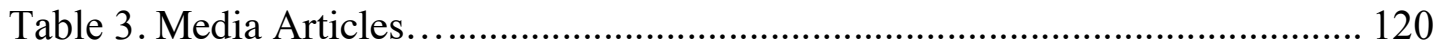

Table 4. Policy Articles..................................................................................... 122

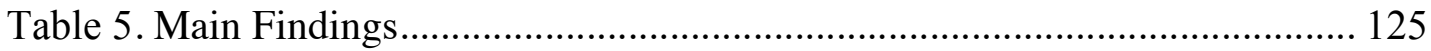

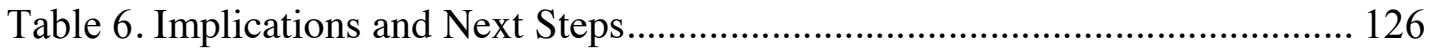

\section{Chapter IV}

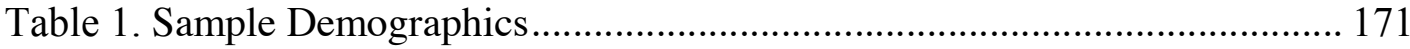

Table 2. Correlations between Dependent Variables....................................... 171 


\section{List of Figures}

\section{Chapter II}

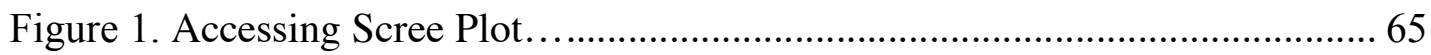

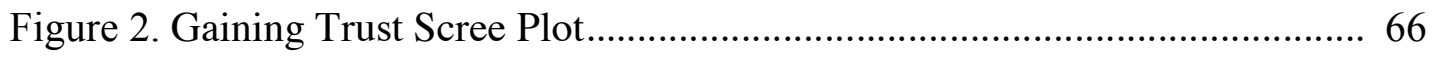

Figure 3 Gaining Cooperation Scree Plot................................................................... 67

Figure 4. Sexual Abuse Scree Plot.......................................................................... 68

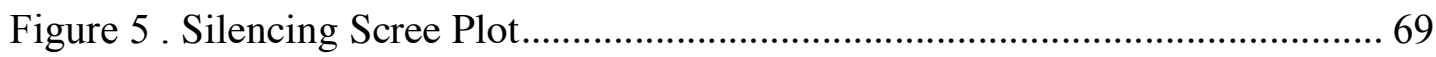

\section{Chapter IV}

Figure 1 . Estimated Marginal Means for Jail Variable.......................................... 172

Figure 2 . Estimated Marginal Means for Registration Variable............................... 173

Figure 3 . Estimated Marginal Means for Counseling Variable ................................. 173

Figure 4. Estimated Marginal Means for Victim Blaming Variable........................ 174 
PREVENTION AND PERCEPTIONS

\section{Chapter I. Introduction}

This dissertation examines the importance of preventing the perpetration of sexual assault in two domains: child sexual abuse (CSA) and college campus assault. Although sexual violence extends beyond these domains, these two play a significant role in the societal impact of sexual violence. The guiding frameworks in this document utilized to best understand sexual violence perpetration are Rational Choice Theory (RCT; Cornish \& Clarke, 1986), Modus Operandi (MO), and Attribution Theory. This chapter first highlights sexual violence prevalence and incidence, as well as the impact of sexual violence on victims. It then provides the theoretical framework for the dissertation as a whole. Finally, it provides an overview of the three studies which comprise this dissertation and indicates what they each contribute to the prevention literature.

\section{Sexual Violence Prevalence and Incidence}

Due to the broad array of definitions used to measure incidence and prevalence of CSA, as well as a lack of abuse reporting, it is difficult to pinpoint the exact scope of the problem. However, even with these issues, a number of indicators elucidate that CSA is far too common an occurrence. A meta-analysis that examined 100 international studies and designed to better understand the epidemiology of CSA, found that $7.9 \%$ of men and $19.7 \%$ of women worldwide are sexually abused in some fashion prior to turning 18 years of age (Pereda et al., 2009). Prevalence rates in the United States are $7.5 \%$ for men and $25.3 \%$ for women (Pereda et al., 2009). Baker, Connaughton \& Zhang (2010) indicated that only between $10 \%$ and $35 \%$ of CSA incidents are ever reported, which 
means that current incidence rates are likely too low. Overall, child sexual abuse is a pervasive societal problem that impacts many people.

Similarly, evidence suggests that college-aged individuals are at particularly high risk for experiencing sexual violence relative to the general population (Krebs et al., 2016). Recent studies have found that between 17 and 42 percent of female students and 7 to 28 percent of male students have experienced a sexual assault, with even more students experiencing an act of attempted sexual violence during college (Krebs et al., 2016; Mellins et al., 2017; Sutherland et al., 2014). Moreover, campus sexual assault policy has been largely overlooked and under-prepared for by U.S. institutions of higher education (Cook, et al., 2011). While all college students are at an elevated risk for experiencing sexual violence, particular subgroups have been identified for even greater risk of victimization in this context. Students of color, young students, LGBT students, and low socioeconomic status students are at the highest risk for sexual violence (Coulter et al., 2017; Fedina et al, 2018; Mellins et al., 2017). The potential negative impacts of sexual violence on victims are well-documented (Melssen, 2013; Sit \& Schuller, 2018; Cook \& Fox, 2012), and in conjunction with these statistics indicate a pervasive and impactful problem for colleges and universities nationwide.

\section{Impact of Sexual Violence on Victims}

The frequency of sexual violence is striking, but must also be considered in consort with the impact of adverse consequences of victimization. Of course, the experience of victimization will differ across individuals, but the literature demonstrates that most victims do experience negative consequences to some degree. 
In terms of child sexual abuse (CSA), short-term consequences can be both physical and psychological. Injuries after an attack are common (Wolfe et al., 2003), as well as feelings of low self-esteem, shame, anger, and grief. (Fater \& Mullaney, 2000; Isley et al., 2008; Shakeshaft, 2004). Cognitively, some victims have trouble with intrusive memories about their abuse, as well as difficulty remembering specific aspects of the experience (Isley et al., 2008). Finally, victims may have difficulties with interactions that extend to their friendships and intimate relationships, particularly if their perpetrator was someone that they trusted and looked up to (Wolfe et al., 2003).

CSA victims can experience negative symptoms throughout their lifetime, lasting well into adulthood. For example, they may struggle interpersonally with difficulty developing appropriate relationships and other types of intimacy problems (Wolfe et al., 2006; Uliando \& Mellor, 2012). CSA victimization can also include an array of longterm consequences, such as poor academic performance (Shakeshaft, 2004), disrespect for authority (Isley et al., 2008), domestic violence perpetration, and involvement with the criminal justice system (Wolfe et al., 2006). Finally, mental health issues such as sleep disorders, psychiatric disorders, depression, panic disorder, PTSD, and alcohol dependence are common for victims of CSA (Fitzpatrick et al., 2010; Fater \& Mullaney, 2000; Shakeshaft, 2004).

Those victimized on college campuses may face a parallel set of negative outcomes. Similar to CSA victims, college-aged victims/survivors can experience physical outcomes such as injury and Sexually Transmitted Infections (STIs) (Campbell et al., 2003; Fisher et al., 2000). Psychological consequences also range from short- to 
long-term. Many victims experience PTSD or depression, as well as non-clinical, but still disorienting, psychological consequences (Sochting et al., 2004; Smith et al., 2003). Other negative outcomes can include: eating disorders, anxiety disorders, and suicidal ideation (Campbell et al., 2009; Gidycz, et al., 2008; Kaura \& Lohnman, 2007). Finally, survivors of campus sexual assault can face negative situational outcomes, such as poor academic achievement, drug and alcohol abuse, and risk of future victimization (Combs et al., 2014; Fisher et al., 2000).

The prevalence and impact of these negative consequences of sexual victimization underscores the importance of prevention. The next section will outline prevention theory as it pertains to sexual abuse and provide a foundation for the current studies.

\section{Preventing Sexual Violence}

The Center for Disease Control's (CDC) Public Health Model of Prevention is the overarching theoretical framework for this dissertation (Centers for Disease Control and Prevention, 2004). The CDC's approach focuses on community and societal health above the health of any one individual. The most recent CDC Public Health Model is based on a four-step approach to violence prevention. These steps include: (1) Defining the problem; (2) Identifying risk and protective factors; (3) Developing and testing prevention strategies; and (4) Assuring widespread adoption (Centers for Disease Control and Prevention, 2004).

The CDC model also separates prevention into three levels: Primary/ Universal, Secondary/ Selected, and Tertiary/ Indicated. These levels provide an indication of 
"when" the program will address the problem, "who" will be targeted, and "what" the program will focus upon.

The "when" refers to: Primary interventions, which occur before the problem; Secondary interventions, which involve immediate responses directly after the sexual violence; and Tertiary interventions, which include the long-term responses after the sexual violence has occurred. The literature has also defined these three in a different fashion as well Primary (before the problem occurs); Secondary (addressing high risks factor know to be associated with the problem, but still before); and Tertiary (after the abuse has occurred) (Rogers, Green \& Kaufman 2010).

The "who" is defined by the CDC as Universal Interventions, which are programs directed toward entire populations; Selected Interventions, which are programs directed toward those at highest risk for perp or victimization; and Indicated Interventions, which are programs directed toward those who have already been victimized or who have offended. Universal prevention programming focuses on teaching everyone in a population about consent and healthy sexual relationships as a means to avoid perpetration behaviors before they begin. Selected prevention programs capitalize on known risk factors for offending, such as use of child pornography, and create programming to prevent contact offenses. Indicated preventions work to stop offender recidivism through a means such as group therapy.

The "what" adds to this idea, describing the focus of a specific program. Individual level interventions asses the root of the problem as being within specific individuals and target those individuals for intervention. Relationship level interventions 
assess the problem as being within a dyadic or small group relationship and target interventions at the group level. Community level interventions assess the problem as being within a community, such as a neighborhood or organization and target interventions toward communities as a whole. Finally, Societal level interventions assess the problem as being rooted in macro-level factors, such as gender inequality or economic inequality and these interventions target these higher-order factors (Centers for Disease Control and Prevention, 2004).

In order to design prevention programming, it is essential to understand a fourth layer - the "how." The next section will define and describe both Rational Choice Theory (RCT) and offender Modus Operandi (MO), as well as their relation to each other. Following will be a discussion of the ways in which these frameworks provide a foundation for our understanding of how offenders commit acts of sexual abuse.

\section{Rational Choice Theory and Modus Operandi}

Rational Choice Theory (RCT) assumes that people who commit crimes do so because they see it as an effective way to achieve a desired benefit (Cornish \& Clarke, 1986). The commission of crimes, through this model, is not perceived as random, but as a calculated choice made by an individual. RCT suggests that before an individual commits a crime, they engage in a cost-benefit analysis to consider what will need to happen to achieve a criminal goal, as well as the potential for adverse outcomes if they are caught. If the costs for committing the crime are perceived as too high, the potential perpetrator may be less likely to commit that crime (Pratt, 2008). 
Decisions made to commit a crime may also be limited by situational factors, such as time available to commit the crime, or individual factors, such as the offender's cognitive abilities (Cornish \& Clarke, 1987). Even with context in mind, the minimization of risks and maximization of benefits holds true. It is important to note that most crimes do not involve a single action on the part of the perpetrator. Instead, they reflect a complex array of behaviors leading to the commission of a crime. For example, offenders of child sexual abuse often engage in a series of grooming behaviors prior to abusing a victim (Kaufman et al., 1998). RCT was developed to allow for a dynamic analysis of the elements involved in criminal behavior, viewing it as a process that takes situational factors into account (Cornish \& Clarke, 1987). Beyond the initial choice to commit a crime, offenders continue to make choices throughout the commission of the crime based on situational factors that will minimize risks and maximize benefits. Finally, as individuals commit more crimes over time, they get better at understanding the relative impact that various decisions will have on their success, given a particular set of circumstances. As such, they may become more sophisticated in adjusting their actions to achieve the best possible outcome (Leclerc et al., 2009). In this way, their criminal behaviors become more refined and their decision-making becomes more experience based. Homicide (De Souza \& Miller, 2012), assault (Reynald \& Elffers, 2009; Schreck \& Fisher, 2004), burglary (Groff, 2007), cybercrime (Yar, 2005), domestic violence (Mannon, 1997), sexual offenses involving adults (Beauregard et al., 2007), and the perpetration of child sexual abuse (Leclerc et al., 2010) have all been successfully explained utilizing the RCT framework. Rational Choice Theory has also greatly 
informed research on the perpetration of sexual violence, as it is easily applied to this phenomenon.

RCT's assumption that offenders continually make decisions across the offending process, from first deciding to engage in a criminal act, through the commission of the crime, and including how to minimize detection following perpetration, is also clearly reflected in offenders' "modus operandi" or their pattern of perpetration. Modus operandi is an observable phenomenon defined as a pattern of perpetration that facilitates the commission of CSA, as well as minimizing the perpetrator's chances of being detected as an offender (Kaufman et al., 1998; Kaufman et al., 2010).

Examining $\mathrm{MO}$ as a pattern or a process allows for a better understanding of the typical tactics that perpetrators use to commit acts of sexual violence. Seeing these crimes as deliberate choices, and not misunderstandings or mistakes, should make it clear that the commission of an act of sexual violence is clearly the responsibility of the perpetrator. However, as evident in the sexual assault literature, it has not been unusual for victims to be blamed for their own assaults, rather than placing responsibility where it belongs, with the perpetrator. The next section will explore attribution theory, and how it helps explain who has typically been blamed for sexual assault.

\section{Attribution Theory and Perceptions of Sexual Violence}

Attribution theory views individuals as motivated to discover an underlying cause of a behavior, and to make sense of the behaviors of those around them (Heider, 1958; Kelley, 1973; Weiner, 2006). An attribution, then, is the reason that individuals construct to explain the behavior of another person (Reeder, 2013). Attributions tend to vary along 
three dimensions. The first is whether an action is seen as internal (because of the person) or external (because of the situation). The second evaluates if an action occurs frequently, or if it is a one-time event. Finally, whether the cause of an action was under the control of an individual or not is considered. In large part, the determination of an attribute reflects a balance between the role of the individual and their context.

Attribution theory is often used to better understand why responsibility for sexual assault is often placed on survivors. Unlike many other crimes, survivors of sexual assault often have blame attributed to them for their attack (Grubb \& Turner, 2012; Whatley, 1996). This aligns with the "fundamental attribution error," which suggests that individuals overestimate the impact of choices a survivor makes, and underestimate the impact of context on the occurrence of a crime. Of course, a survivor of a sexual crime should never be blamed. This is supported by RCT, which states that offenders make clear choices to commit a crime, and rely on opportunistic contexts to avoid getting caught.

Despite continued victim blaming, perpetrators are generally assigned higher levels of responsibility or blame as compared to their victims, when a sexual assault occurs (Gerber et al., 2004; Landstrom et al., 2016). What is unclear is the role of context in determining how blame is attributed to perpetrators. The next section discusses how these theories intersect in campus and community context.

\section{Campus and Community Contexts: Do Myths Apply?}

In understanding sexual violence prevention, and the theories that support it, what is apparent is that context matters. Offenders make choices based on their contexts, we 
attribute blame while taking context into account, and prevention must be tailored to context to be most impactful. Logically, this would mean that the way we perceive sexual offenders is impacted by the situation in which they offend. Yet, empirical evidence supports that perceptions of sexual offenders vary little across contexts (Kernsmith et al., 2009; Sample \& Kadleck, 2008). Society see people who sexually offend as dangerous, mentally ill monsters who will continue offending under any circumstances (King \& Roberts, 2015; Levenson et al., 2007).

In practice, however, some offenders do seem to be demonized more than others. In particular, older men who commit acts of child sexual abuse seem to be the prototypical sexual offender - the most demonized and punished, as well as the basis for policies and perceptions surrounding perpetrators (Burchfield et al., 2014; KatzSchiavone et al., 2008). On the other hand, juvenile offenders seem to have an easier time, as there is more of a belief that they can change (Brown et al., 2008). There has also been ample public discourse surrounding campus sexual assault, with both calls for leniency and punitive action toward the campus perpetrator (Krebs et al., 2009; Mouilso et al., 2012).

With this in mind, this dissertation attempts to determine more about how perceptions of those who sexually offend shift across context. First, it examines the actual perpetration patterns of the most demonized group that myths are based upon, perpetrators of child sexual abuse. Then, it explores the most prevalent myths surrounding sexual offenders thorough a systematic literature review. Finally, it uses an 
experimental framework to look further into the campus context, as a comparison to child sexual abuse. The next section provides and overview of these three studies.

\section{The Present Investigation: An Overview}

This dissertation is comprised of three studies which explore what we know about perpetrator offending patterns, how these patterns inform perceptions of perpetrators, and how these perceptions impact blame attribution. All three studies are designed to generate findings that would enhance the prevention of sexual violence as their ultimate impact.

Study One is a psychometric analysis of the Modus Operandi Questionnaire, which is the most comprehensive tool available to examine the perpetration patterns of individuals who commit CSA (Kaufman, 2004). One major finding from this study is that offenders are more likely to engage in subtle, seemingly non-violent behaviors to groom their victims, as opposed to obviously violent tactics.

The understanding of CSA MO leads to questions about whether adverse perceptions of perpetrators match the actual perpetration behaviors. In other words, is public fear of sexual offenders warranted? Study Two utilizes a systematic literature review to analyze policy, media, and public perception surrounding those who commit CSA. This study finds that societal perceptions of sexual offenders are based on four main myths: 1 . Sexual offenders are strangers to their victims; 2 . Sexual violence poses the greatest public safety risk as compared to other crimes 3 . Sex offenders are a relatively homogeneous group; and 4. It is impossible to rehabilitate a sexual offender. 
Study Three utilizes the myths found in Study Two as a framework to examine another sub-type of sexual offenders: those who offend on college campuses. This study discusses how campus perpetration of sexual assault does and does not conform to common perpetrator myths. Further, it utilizes an experimental, vignette-based framework to more deeply examine how crime location and severity can impact how an offender is perceived. The major finding in this study is that we may not perceive college student offenders differently than non-student offenders.

Taken together, these three studies help to explore perceptions of sexual offenders across three methodologies: a psychometric analysis, a systematic literature review, and an experiment. Study One identifies how typical offending patterns differ from common perceptions. Study Two explores pervasive myths about sexual offenders. Finally, Study Three examines whether the campus context might shift myths. 
PREVENTION AND PERCEPTIONS

\section{References}

Baker III, T. A., Connaughton, D. P., \& Zhang, J. J. (2010). An examination of immunity statutes regarding the liability of recreational youth sport organizations for the pedophilic actions of coaches, administrators, and officials. ICHPER--SD Journal of Research in Health, Physical Education, Recreation, Sport \& Dance, 5(1).

Beauregard, E., Proulx, J., Rossmo, K., Leclerc, B., \& Allaire, J. F. (2007). Script a nalysis of the hunting process of serial sex offenders. Criminal justice and behavior, 34(8), 1069-1084.

Brown, S., Deakin, J., \& Spencer, J. (2008). What people think about the management of sex offenders in the community. The Howard Journal of Crime and Justice, 47(3), 259-274.

Burchfield, K., Sample, L. L., \& Lytle, R. (2014). Public interest in sex offenders: A perpetual panic. Criminology, Criminal Justice, Law \& Society, 15 (96).

Campbell, R., Dworkin, E., \& Cabral, G. (2009). An ecological model of the impact of sexual assault on women's mental health. Trauma, Violence, \& Abuse, 10(3), 225-246.

Combs, J. L., Jordan, C. E., \& Smith, G. T. (2014). Individual differences in personality predict externalizing versus internalizing outcomes following sexual assault. Psychological Trauma: Theory, Research, Practice, and Policy, 6(4), 375.

Cook, S. L., Gidycz, C. A., Koss, M. P., \& Murphy, M. (2011). Emerging issues in the measurement of rape victimization. Violence against women, 17(2), 201-218. 
Cornish, D., \& Clarke, R. (1986). Situational prevention, displacement of crime and rational choice theory. Situational crime prevention: From theory into practice, 116.

Cornish, D. B., \& Clarke, R. V. (1987). Understanding crime displacement: An application of rational choice theory. Criminology, 25(4), 933-948.

Cornish, D. B., \& Clarke, R. V. (2002). Crime as a rational choice. Criminological theories: Bridging the past to the future, 77-96.

Coulter, R. W., Mair, C., Miller, E., Blosnich, J. R., Matthews, D. D., \& McCauley, H. L. (2017). Prevalence of past-year sexual assault victimization among undergraduate students: Exploring differences by and intersections of gender identity, sexual identity, and race/ethnicity. Prevention Science, 18(6), 726-736.

De Souza, E., \& Miller, J. (2012). Homicide in the brazilian favela: Does opportunity make the killer?. British Journal of Criminology, 52(4), 786-807.

Fitzpatrick, M., Carr, A., Dooley, B., Flanagan-Howard, R., Flanagan, E., Tierney, K., ... \& Egan, J. (2010). Profiles of adult survivors of severe sexual, physical and emotional institutional abuse in Ireland. Child Abuse Review, 19(6), 387-404.

Fisher, B. S., \& Sloan III, J. J. (2003). Unraveling the fear of victimization among college women: Is the "shadow of sexual assault hypothesis" supported?. Justice Quarterly, 20(3), 633-659.

Fater, K., \& Mullaney, J. A. (2000). The lived experience of adult male survivors who allege childhood sexual abuse by clergy. Issues in Mental Health Nursing, 21(3), 281-295. 
Fedina, L., Holmes, J. L., \& Backes, B. L. (2018). Campus sexual assault: A systematic review of prevalence research from 2000 to 2015. Trauma, violence, \& abuse, 19(1), 76-93.

Gerber, G. L., Cronin, J. M., \& Steigman, H. J. (2004). Attributions of blame in sexual assault to perpetrators and victims of both genders. Journal of Applied Social Psychology, 34(10), 2149-2165.

Gidycz, C. A., Orchowski, L. M., King, C. R., \& Rich, C. L. (2008). Sexual victimization and health-risk behaviors: A prospective analysis of college women. Journal of interpersonal violence, 23(6), 744-763.

Grubb, A., \& Turner, E. (2012). Attribution of blame in rape cases: A review of the impact of rape myth acceptance, gender role conformity and substance use on victim blaming. Aggression and Violent Behavior, 17(5), 443-452.

Heider, F. (1958). The psychology of interpersonal relations Wiley. New York.

Isely, P.J., Isley, P., Freiburger, J. and McMackin, R. 2008. In their own voices: A qualitative study of men abused as children by catholic clergy. Journal of Child Sexual Abuse, 17(3-4): 201-215

Katz-Schiavone, S., Levenson, J. S., \& Ackerman, A. R. (2008). Myths and facts about sexual violence: Public perceptions and implications for prevention. Journal of Criminal Justice and Popular Culture, 15(3), 291-311.

Kaufman, K. L., Hilliker, D. R., \& Daleiden, E. L. (1996). Subgroup differences in the modus operandi of adolescent sexual offenders. Child Maltreatment, 1(1), 17-24.

Kaufman, K.L., McCrady., F., Homlberg, J., Rotzien, A., Orts, K., \& Hilliker, E. (1997). 
Factor structure of the behaviors of offenders as measured by the modus operandi questionnaire. Poster session presented at the $16^{\text {th }}$ Annual Research and Treatment Conference of The Association for the Treatment of Sexual Abusers, Arlington, VA.

Kaufman, K. L., Holmberg, J. K., Orts, K. A., McCrady, F. E., Rotzien, A. L., Daleiden, E. L., \& Hilliker, D. R. (1998). Factors influencing sexual offenders' modus operandi: An examination of victim-offender relatedness and age. Child Maltreatment, 3(4), 349-361.

Kaufman, K. L., Mosher, H., Carter, M., \& Estes, L. (2006). Empirically based situational prevention model for child sexual abuse (From Situational Prevention of Child Sexual Abuse, P 101-144, 2006, Richard Wortley and Stephen Smallbone, eds.--See NCJ-215297).

Kaufman, K., Hayes, A., \& Knox, L. A. (2010). The situational prevention model: Creating safer environments for children and adolescents.

Kaura, S. A., \& Lohman, B. J. (2007). Dating violence victimization, relationship satisfaction, mental health problems, and acceptability of violence: A comparison of men and women. Journal of Family Violence, 22(6), 367-381.

Kelley, H. H. (1973). The processes of causal attribution. American psychologist, 28(2), 107.

Kernsmith, P. D., Craun, S. W., \& Foster, J. (2009). Public attitudes toward sexual offenders and sex offender registration. Journal of Child Sexual Abuse, 18(3), 2 90-301. 
King, L. L., \& Roberts, J. J. (2017). The complexity of public attitudes toward sex crimes. Victims \& Offenders, 12(1), 71-89.

Krebs, C. P., Lindquist, C. H., Warner, T. D., Fisher, B. S., \& Martin, S. L. (2007). The campus sexual assault (CSA) study. Washington, DC: National Institute of Justice, US Department of Justice.

Landström, S., Strömwall, L. A., \& Alfredsson, H. (2016). Blame attributions in sexual crimes: Effects of belief in a just world and victim behavior. Nordic Psychology, 68(1), 2-11.

Leclerc, B., Proulx, J., \& Beauregard, E. (2009). Examining the modus operandi of sexual offenders against children and its practical implications. Aggression and violent behavior, 14(1), 5-12.

Leclerc, B., Wortley, R., \& Smallbone, S. (2010). Investigating mobility patterns for $\mathrm{r}$ epetitive sexual contact in adult child sex offending. Journal of Criminal Justice, 38(4), 648-656.

Mannon, J. M. (1997). Domestic and intimate violence: An application of routine activities theory. Aggression and Violent Behavior, 2(1), 9-24.

Mellins, C. A., Walsh, K., Sarvet, A. L., Wall, M., Gilbert, L., Santelli, J. S., ... \& Bah, K. (2017). Sexual assault incidents among college undergraduates: Prevalence and factors associated with risk. PLoS one, 12(11), e0186471.

Melssen, M. C. (2013). Sources: Sexual Violence and Abuse: An Encyclopedia of Prevention, Impacts, and Recovery. Reference \& User Services Quarterly, 52(4), 354-354. 
Mouilso, E. R., Fischer, S., \& Calhoun, K. S. (2012). A prospective study of sexual assault and alcohol use among first-year college women. Violence and victims, 27(1), 78-94.

Pereda, N., Guilera, G., Forns, M., \& Gómez-Benito, J. (2009). The prevalence of child sexual abuse in community and student samples: A meta-analysis. Clinical psychology review, 29(4), 328-338.

Pratt, T.C. (2008). Rational choice theory, crime control policy, and criminological relevance. Criminology \& Public Policy, 7(1), 43-52

Rogers, D., Green, J., \& Kaufman, K. (2010). Using theory to strengthen prevention practice. The prevention of sexual violence: A practitioner's sourcebook, 55-84.

Reeder, G. D. (2013). Attribution as a gateway to social cognition.

Reynald, D. M., \& Elffers, H. (2009). The future of newman's defensible space theory linking defensible space and the routine activities of place. European Journal of Criminology, 6(1), 25-46.

Sample, L. L., \& Kadleck, C. (2008). Sex offender laws: Legislators' accounts of the need for policy. Criminal Justice Policy Review, 19(1), 40-62.

Schreck, C. J., \& Fisher, B. S. (2004). Specifying the influence of family and peers on violent victimization extending routine activities and lifestyles theories. Journal of interpersonal violence, 19(9), 1021-1041.

Shakeshaft, C. (2004). Educator sexual misconduct: A synthesis of existing literature. PPSS 2004-09. US Department of Education 
Sit, V., \& Schuller, R. A. (2018). Understanding support providers' views of "helpful" responses to sexual assault disclosures: The impacts of self-blame and physical resistance. Journal of interpersonal violence, 33(8), 1236-1259.

Smith, P. H., White, J. W., \& Holland, L. J. (2003). A longitudinal perspective on dating violence among adolescent and college-age women. American journal of public health, 93(7), 1104-1109.

Söchting, I., Fairbrother, N., \& Koch, W. J. (2004). Sexual assault of women: Prevention efforts and risk factors. Violence against women, 10(1), 73-93.

Sutherland, J. L., Amar, A. F., \& Sutherland, M. A. (2014). Victimization and perpetration of sexual violence in college-aged men and women. Journal of Forensic Nursing, 10(3), 153-159

Uliando, A., \& Mellor, D. (2012). Maltreatment of children in out-of-home care: A review of associated factors and outcomes. Children and youth services review, 34(12), 2280-2286.

Weiner, B. (2010). Attribution theory. The Corsini encyclopedia of psychology, 1-2.

Whatley, M. A. (1996). Victim characteristics influencing attributions of responsibility to rape victims: A meta-analysis. Aggression and Violent Behavior, 1(2), 81-95.

Wolfe, D. A., Francis, K. J., \& Straatman, A. L. (2006). Child abuse in religiouslyaffiliated institutions: Long-term impact on men's mental health. Child Abuse \& Neglect, 30(2), 205-212.

Wolfe, D. A., Jaffe, P. G., Jetté, J. L., \& Poisson, S. E. (2003). The impact of child abuse in community institutions and organizations: Advancing professional and 
scientific understanding. Clinical Psychology: Science and Practice, 10(2), 179191

Yar, M. (2005). The novelty of 'cybercrime: An assessment in light of routine activity theory. European Journal of Criminology, 2(4), 407-427. 
PREVENTION AND PERCEPTIONS

\title{
Chapter II. An Updated Factor Structure for the Modus Operandi Questionnaire
}

\author{
Abstract. \\ Child sexual abuse is a pervasive crime that has numerous negative short- and \\ long-term impacts on its victims, as well as negative impacts for society. Modus \\ Operandi (MO) is defined as a pattern of perpetration utilized by those who commit CSA \\ to successfully abuse a child without detection. Understanding how CSA is perpetrated \\ through MO is essential, as this construct influences both prevention of CSA, and \\ treatment for victims and perpetrators. The Modus Operandi Questionnaire (Kaufman, \\ 1991; MOQ) is the first and most comprehensive measurement tool for CSA MO, and is \\ utilized by both researchers and clinicians. This study provides an up-to-date factor \\ analysis of the MOQ, breaking the measure into five stage-based scales (i.e.; Accessing \\ the victim, Gaining the victim's trust, Gaining the victim's cooperation, Sexual Abuse, \\ and Silencing after the abuse). Each stage-based scale was analyzed through Exploratory \\ Factor Analysis to determine structure. The results of this study determined reliable \\ factors within all five scales, and show a structure that can be utilized to further inform \\ research, treatment, and prevention of CSA.
}


PREVENTION AND PERCEPTIONS

\section{Introduction}

Child sexual abuse (CSA) is a pervasive public health issue that negatively impacts the lives of victims and their families. Due to the numerous negative effects of CSA, it is imperative that perpetrators of this serious crime are studied in a manner that fosters the development of effective prevention efforts. Modus operandi, or the way in which perpetrators commit their crimes, is a useful lens for gaining insight into how CSA perpetrators operate. Modus operandi is a common concept in criminological research and has been measured in a variety of ways, including through the collection of archival data, interview-based data, and self-report surveys. The Modus Operandi Questionnaire (MOQ; Kaufman, 1994) is the only self-report measure that accounts for the full scope of CSA offenders' modus operandi. To enhance the measurement of child sexual abuse offenders' modus operandi, this study examines the factor structure and reliability of the MOQ by conducting an Exploratory Factor Analysis, as well as indices of internal consistency reliability.

\section{Modus Operandi in the Literature}

Definition. Modus operandi is an observable phenomenon defined as a pattern of perpetration that facilitates the commission of CSA, as well as minimizing the perpetrator's chances of being detected as an offender (Kaufman et al., 1998; Kaufman et al., 2010). In defining MO as a pattern or a process, it follows that it includes behaviors prior to, during, and after the commission of CSA (Kaufman, 1998). Understanding the ways in which offenders commit their crimes has been useful in informing prevention, as well as intervention strategies for both CSA offenders and victims. 
PREVENTION AND PERCEPTIONS

Early Use. Initially, modus operandi was studied as a means of understanding how to best prevent CSA. This was in response to what was perceived as ineffective prevention programming as a result of an anecdotal understanding of how CSA is committed (Berliner \& Conte, 1990). These early descriptive studies (Berliner \& Conte, 1990; Budin \& Johnson, 1989; Christiansen \& Blake, 1990; Conte, Wolf, \& Smith, 1989; Lang \& Frenzel, 1988) are integral in that they highlight the importance of modus operandi as a critical factor for understanding the dimensions that underlie CSA and provide directions for its prevention. At the time, however, studies in this area were lacking in methodological rigor. They did not rely on any specific definition of modus operandi, they utilized small samples of participants, and they were predominately qualitative in nature. In fact, early research in this area did not include the use of a reliable or valid measure of MO. It is this gap that led to the development of Kaufman's (1989) Modus Operandi Questionnaire.

The Modus Operandi Questionnaire (MOQ). The MOQ (Kaufman, 1989) is the first reliable and valid quantitative measure of $\mathrm{MO}$ to examine the full spectrum of offender-victim interactions from an offender's strategies to access a victim through their efforts to their victim's silence following the onset of sexually abusive behaviors. Specifics regarding the development and validation of the MOQ will be covered in the next section, but it is important to acknowledge the impact that this measure had on the CSA literature overtime. Beyond providing a reliable quantitative mechanism with which to measure $\mathrm{MO}$, the questionnaire has helped organize thinking about $\mathrm{MO}$ by presenting it as a temporal, stage-based process. The MOQ tracks offenders' grooming 
and abusive interactions with CSA victims and includes: (1) Accessing the victim; (2) Gaining the victim's trust; (3) Gaining the victim's cooperation in abusive acts (i.e., through bribes and threats); (4) Detailing the victim's abuse; and (5) Maintaining the victim's silence after onset of the abuse. Each stage in the MO process, and the situational factors that influence these stages, informs decisions made throughout the progression of the crime (Leclerc, Proulx, \& Beauregard, 2009). These stages had been uncovered in past exploratory research, but a measure that encompasses the entire MO process was an important contribution to the field. Even in studies where the MOQ itself was not utilized, it set the foundation for the understanding of $\mathrm{MO}$ in the literature (Leclerc, Proulx, \& Beauregard, 2009). This scale introduced new discussions about MO in relation to a variety of situational variables, such as offender age (Kaufman et al., 1998), victim age and gender (Kaufman, Hilliker, \& Daledien, 1996; Leclerc, Carpentier, \& Proulx, 2006), and offender-victim relationship (Kaufman et al., 1996). MO has also been utilized in relation to understanding victim behavior (Van Gijn \& Lamb, 2013) and has been utilized in the context of organizational CSA (Colton, Roberts, \& Vanstone, 2012; Firestone, Moulden, \& Wexler, 2009; Leclerc, Proulx, \& McKibben, 2005; Leclerc \& Cale, 2015; Sullivan, Beech, Craig, \& Gannon, 2010). Though not all of these studies utilize the MOQ, it is evident that the measure has significantly influenced the field, shaping how MO is conceptualized in general as well as the ways in which it is categorized into critical subcomponents.

History of the MOQ. The MOQ was constructed largely in response to criticism that child sexual abuse prevention programming was based almost entirely on anecdotal 
evidence and clinical case studies (Conte, Wolfe \& Smith, 1989). At the time, the literature included mostly descriptive studies with minimal generalizability due to small sample sizes and an over-reliance on qualitative methodologies (Kaufman et al., 1997). In response to these concerns, Dr. Keith Kaufman created the first version of the Modus Operandi Questionnaire in 1989. This initial measure was designed for completion by adults who sexually offend against children, with a parallel version developed in 1992 for use with adolescents (AMOQ). Both versions of the questionnaire included sub-scales based on a similar sequence of temporal MO stages beginning with efforts to identify potential victims and progressing through strategies intended to silence victims following abuse onset. These stages included: accessing the victim, gaining the victim's trust, bribes and enticements to gain cooperation in abusive acts, threats and coercion to gain cooperation in abusive acts, characteristics of the abusive acts, and strategies (i.e., appetitive and coercive) to maintain victim silence. In the mid-1990s, the MOQ and AMOQ were combined into a single assessment measure for use with both adolescent and adult offenders. Combining these very similar measures was also supported by evidence that both adult and juvenile offenders' MO varied across temporal stages (Kaufman et al., 1997).

Once combined, the resulting measure was examined to determine if it reflected a comprehensive means of gathering MO information from child sexual offenders. More specifically, the MOQ was compared to a highly detailed structured MO interview to determine its effectiveness in describing the full scope of offenders' MO (Kaufman et al., 1996). Findings revealed that the MOQ was as or more effective than the structured 
interview in describing perpetrators' offending behaviors for the majority of MOQ areas (e.g., accessing victims, grooming victims), with one exception. The structured interview was found to yield more $\mathrm{MO}$ information regarding their use of threats and coercion intended to gain cooperation in abusive acts. Of significance is the fact that this study established the utility of the MOQ as a pencil-and-paper based self-report measure for obtaining MO related information. Moreover, it documented the MOQ's superiority over interview approaches for most MO dimensions. This study, as well as those that followed closely in time (Kaufman et al., 1998; Kaufman, et al., 1997) expanded on the MOQ's content validity and encouraged the use of this measure for large-scale research on CSA offenders.

MOQ Description. The MOQ differs from other scales in that it was created to bridge the gap between descriptive and predictive research. It is intended to be utilized to examine the various temporal dimensions that, as a whole, constitute the full continuum of CSA MO behaviors. While the questionnaire has a large number of items (i.e., 339), it reflects six subscales of more moderate length. Items are behaviorally specific (e.g., "Giving them [the victim] alcohol;" "Saying you will take them places") and meant to be analyzed within the context of each MOQ scale's particular temporal stage (e.g., accessing victims, gaining their trust, gaining cooperation in sexually abusive acts). It should be noted that for most of the MO stages, the offenders' goals are qualitatively different (e.g., accessing a victim vs. gaining cooperation in abusive acts vs. maintaining victim silence following abuse onset). Moreover, the ability to engage in many later MO stages is directly dependent upon offenders' successful navigation of earlier stages in the 
PREVENTION AND PERCEPTIONS

process (i.e., the ability to groom and later abuse a victim is dependent on success in accessing the victim in the first place). The broad range of behaviors included in the MOQ at each stage ensures the ability to fully describe very different patterns of offender MO. For example, one offender may use "pro-social" MO strategies, such as showering a victim with gifts and compliments, to gain cooperation in abusive acts, while another may rely on more threatening MO strategies to accomplish the same end. Since clinical and research evidence suggests that the MOQ stages reflect critical, real world temporal dimensions in a CSA offending process, the psychometric focus on the MOQ has always been at the level of examining the scales within each temporal stage. As such, the MOQ may be seen as a series of scales that reflect the CSA MO process as it unfolds over time. Conceptualizing the measure in this manner has allowed for its clinical use as well as its frequent inclusion in research studies of CSA (Kaufman et al., 1997; LeClerc et al., 2009).

Changes In The MOQ Over Time. The MOQ has evolved over time to better meet clinical and research needs. Yet, its content has remained relatively consistent since its inception. For example, only a few items have been added or changed. In large part, these items were adjusted to accommodate the integration of adult and adolescent versions of the questionnaire and to a lesser degree to reflect changes in CSA offenders' MO over time. The most substantial change to the MOQ has been an adjustment in its response format. Initially, participants rated how often they used each specific MO strategy on a 7-point Likert scale ( $1=$ not at all; $7=$ almost always). Later this was reduced to a 4 -point Likert scale $(0=$ never; $4=$ almost always $)$. This change was 
prompted by recognition that respondents rarely used the full range of the measure's seven Likert scale anchors. Finally, it should be noted that while some MOQ scales have been factor analyzed (e.g., Exploratory Factor Analysis) multiple times (e.g., Gaining Victim's Trust), others have never been analyzed in this way (e.g., Accessing Victims).

Purpose of Study. The purpose of this study is to elucidate the factor structure of the MOQ to enhance the utility of this unique measure as both a research tool and as a clinical assessment device to guide offender treatment planning. A few changes were made to update the MOQ for use in this psychometric study. First, the Bribes and Enticement and Threats and Coercion sections were presented together to more clearly reflect the fact that both types of strategies can be engaged in at the same point in time in the grooming process. These combined MO sections are referred to as the new "Strategies to Gain Cooperation" scale.

Finally, as suggested by Leclerc, Proulx, and Beauregard (2009), previously unexamined sections of the MOQ will be analyzed. This includes sections pertaining to offenders' efforts to access victims, relating to the victim prior to abuse, and characteristics of the sexual abuse itself. Including these scales will contribute to a fuller understanding of behaviors across the MO continuum and will encourage additional research regarding these previously neglected dimensions.

A fresh psychometric analysis of the MOQ could help prompt much needed research into the relationship between $\mathrm{MO}$ and other variables critical to encouraging more effective CSA prevention and offender treatment. For example, additional information could be gleaned about the relationship between $\mathrm{MO}$ and situational risk 
factors, attachment, sexual history, and sexual fantasy in juvenile as well as adult offenders.

\section{Methods}

\section{Participants}

The data used for this study are part of a larger, ongoing investigation on CSA offending conducted by Dr. Keith Kaufman and his colleagues. Modus operandi information is one part of a broader array of offender data collecting with CDC funding, which also included victim and juvenile offender supervision and cultural data (supported by CDC Grant R49/CCR016517-01). This study focuses exclusively on the behaviors of adolescent and adult sexual offenders within the larger dataset.

The study sample includes 854 male adolescent and adult offenders who were recruited from correctional facilities and outpatient treatment programs in nine states. Of the 854 participants, 360 were adult offenders (i.e., their offense was committed after they were at least 18 years of age). Juveniles offenders were defined as those who committed their offenses prior to the age of 18 years of age. At the time of measures' completion, the average age of the adult offenders was just over 40 years $(M=40.43$, $\mathrm{SD}=11.82$ ) and the average age for juvenile offenders was close to 17 years of age $(M=16.77, \mathrm{SD}=2.27)$. Finally, $56 \%$ of the participants committed an intra-familial offense (i.e., the victim either lived with or was related to the offender).

\section{Design}

This study examined the psychometric properties and factor structure of the Modus Operandi Questionnaire (MOQ; Kaufman, 2004). It utilized a cross-sectional and 
non-experimental approach, as participants only completed the MOQ once, in one sitting at their correctional facility. Data from this measure was analyzed both to identify the MOQ's factor structure (i.e., Exploratory Factor Analysis) and assess its reliability.

\section{Measures}

The MOQ is a 339-item self-report questionnaire developed with input from CSA offenders, victims, law enforcement professionals, and treatment professionals. It examines offenders' modus operandi across seven temporal stages of the CSA process which include: (1) Where they found and had time alone with the children they abuse; (2) How they gained the trust of the children they abuse; (3) Grooming strategies utilized prior to the onset of the sexual abuse; (4) Characteristics of the sexual abuse itself; (5) Strategies for engaging victims in sexually abusive behaviors (i.e., Bribes and enticements as well as threats and coercion); and (6) Strategies to maintain victim silence following the onset of sexual abuse.

Participants who had more than one victim were asked to respond to the MOQ for their victim or victims in one of four groups that would yield the most MO information. This decision was guided by a set of four questions, asking how many male and female victims each participant offended against in two different age groups (i.e., under 12 years of age and 12 to 17 years of age). The group with the most victims was the group that the participant was instructed to think about when responds to the questionnaire. Of course, if the participant only had one victim, he responded for that victim. Each MO strategy on the questionnaire was responded to in terms of frequency of use with the 
target victim or victim group. Participants used a 4-point Likert scale to respond to each strategy. Response options ranged from 0 (never) to 3 (almost always).

\section{Procedure}

All participants were recruited from a correctional facility or an outpatient treatment center. CSA offender status was determined based on the crime for which a person was incarcerated. All individuals who had been incarcerated for committing any type of CSA were invited to participate in the study. Participants over the age of 18 completed informed consent forms, which ensured anonymity and confidentiality. Incarcerated participants under the age of 18 were considered to be under the legal custody of the facility and as such, consent forms were completed by their administrators. Minor participants were also asked to complete assent forms prior to their participation. Participants were informed that their involvement was completely voluntary and that they could stop the process at any point in time. All consent/assent forms and procedures were approved by both the correctional facility and the university Institutional Review Board.

Prior to survey completion, potential participants were screened for reading ability and comprehension, as well as significant mental disabilities. This involved having facility staff identify offenders who had reading and/or comprehension difficulties. If a participant was deemed appropriate for participation, and gave consent, he was given the paper and pencil questionnaires to be completed in one sitting.

\section{Data Analyses}

The statistical analysis of each MOQ temporal scale was composed of two parts. First, an Exploratory Factor Analysis was conducted separately to establish each of the 
MOQ scale's structure. Once established, reliability statistics were calculated for each scale.

As each MO temporal stage in the CSA offense process is qualitatively different from other stages, no attempt was made to factor analyze the MOQ as a whole. Instead, the two-part analysis process for this study was repeated for each of the five temporal scales. The scales analyzed are: (1) Accessing the victim (items 49-81; 84-111); (2) Gaining the Victim's Trust (items 118-158; 161-168); (3) Gaining the Victim's Cooperation (items 218-264; 265-298); (4) The Sexual Abuse (items 175-193; 195-204); and (5) Silencing after the Abuse (items 300-337). For the sake of this analysis, a number of items were removed prior to analysis. The items that are not included were removed due to their open-ended nature, or due to very low endorsement (i.e., less than five percent (5\%). This is relevant for questions in the "Accessing" stage that are left out due to only being answered by extra-familial offenders.

Although past EFAs have been conducted on the MOQ, they were not used to restrict the factors that can be found in this analysis. In particular, there are two changes that were made to the structure of the MOQ data entered into the EFA to enhance the utility of the model. First, the two gaining cooperation scales (i.e., the use of "Bribes and enticements" and the use of "Threats and coercion") were combined to allow for a more robust examination of the factor structure for all of the gaining cooperation items. This was also done to ensure that MO strategies utilized at the same relative point in time in the offending process were analyzed together. Second, while the original version of the MOQ used a 7-point Likert scale, this was amended to a 4-point Likert scale due to 
limited endorsement of some of the item response categories on the original, longer Likert scale. Past EFA work is useful for comparison purposes, but was not utilized to restrict factors for any of the new analyses.

Descriptive Tests. Prior to conducting inferential analyses, descriptive tests were conducted to examine the normality of the data within each scale, as well as how frequently each item within each MOQ scale had been endorsed. All of the items on the MOQ were found to be of low base-rate in nature, due to the large number of MO items and the diversity of offenders' MO patterns. In fact, only 46 of the 339 had a mean above 1 on the 4-point Likert Scale, indicating positive skew. Many items had such low endorsement rates that over $95 \%$ of the sample indicate that they never used this tactic. These items, listed in Table 1, were removed from further analyses.

Exploratory Factor Analyses. Next, an Exploratory Factor Analysis using SPSS software was conducted for each of the five temporal MOQ scales. The majority of existing studies reflect a 10:1 participant to item ratio or less, with about one-sixth of the studies having a 2:1 ratio or less (Costello \& Osborne, 2009). With 854 participants, and the largest scale being 79 items, the MOQ is beyond a 10:1 ratio of participants to items. For each stage-based scale, the first EFA was conducted with no constraints on the number of factors retained, and utilized an oblique rotation. This decision is based on past exploratory factor work on the MOQ (Kaufman et al., 1997). Results were interpreted first by extracting factors with an eigen value above 1.0 (Kaiser's Criteria, 1959). This initial solution was used to test more parsimonious, constrained solutions for the MO strategies in each MOQ temporal stage. Consideration in the final solution was 
given primarily to the percentage of variance explained by factor solutions, followed by interpretable factors, and Scree plots. Solutions were judged as competent if they explained a majority of the variance (at least $50.1 \%$ ), were parsimonious, and were made up of easily interpretable factors.

Once factors were extracted, loadings and cross-loadings were examined. Following Tabachnik and Fidell's (2001) guidelines, items that reached a .3 loading were considered to have successfully loaded on a particular factor. Cross-loaded items (i.e., those loading on two different factors above .3) are considered part of the factor onto which they load more strongly. Loaded items were examined qualitatively, and factors were named based on items with the largest loadings, as well as an examination of low loadings (Gorsuch, 1990). This process was repeated for each of the five temporal MO scales.

Reliability. Finally, reliability statistics were calculated for each of the five overall temporal stage-based MOQ scales and EFA factor analysis derived sub-scales. Cronbach's (1951) alpha is a method typically used for measuring subscale's internal consistency reliability when the scale has used a Likert-type response format. Alpha is a "weighted standard variations mean obtained by dividing the total number of items in the scale, by the general variance" (Thorndike et al., 1991). As alpha is utilized most often in psychological research, it was the reliability index of choice $\mathrm{n}$ for this study.

\section{Results}

The following result section is organized by stage, moving from assessing victims to maintaining silence after an offense. Each MOQ section is discussed separately. 
PREVENTION AND PERCEPTIONS

Offenders' Access To Victims. The best EFA model for the 53 items on the Accessing Victims scale was a five-factor model, which explains $41.99 \%$ of the scale's variance. Seven items did not load strongly onto any of the five factors, and were removed from further analyses. A Scree Plot for this scale is provided in Figure 1, and correlations between the factors can be seen as Table 2 .

The first factor is made up of 14 items, which describe ways in which perpetrators build relationships with their victims as a way of accessing them. Therefore, this factor was named "Relationship Building." All items on this factor, as well as their loadings, are presented in Table 3.

The next factor on the Access scale is made up of eight items that describe the use of violence to access victims. Accordingly, this factor is called "Violence." Sample items include "hurt them" and "get angry or violent with them." Interestingly, as seen in Table 3 , all of the loadings on this factor are negative. This could be due to the underlying factors actually reflecting "non-violence," or as a result of the oblique rotation utilized for the factor analysis. According to Tabachnick and Fidell (2001), an oblique rotation can sometimes reverse the direction of the dimension, as well as the signs of that dimension. These negative loadings should be considered in future interpretations of this subscale and may indicate a unique set of offenders who endorse items on this scale.

The third factor on this scale is composed of 12 items that reflect offenders taking the victims to various locations as a means to access them. Accordingly, the factor is titled "Taken Places." All items on this factor, as well as their loadings, can be seen on Table 3. 
The fourth factor related to accessing victims is composed of 10 items that describe a perpetrator engaging in care-taking behaviors to access their victims. It is likely that this factor describes behaviors used by intra-familial offenders, or other types of guardians. The scale is called "Caretaking," and includes items such as "tuck them into bed," and "give them a bath." All items on this factor, as well as their loadings, are presented on Table 3.

The final factor on the Accessing scale is made up of two items, both of which are related to cigarettes and alcohol. Of note is that all other items that had to do with giving victims drugs, across all scales, were removed due to extremely low endorsement rates (Table 1). However, this scale was titled "Cigarettes and Alcohol," and included the items "Give them cigarettes" and Give them alcohol." The loadings for these two items are provided in Table 3.

Finally, reliability statistics were calculated for each of the Accessing Victims subscales. The Chronbach's alpha for each subscale is as follows: Relationship Building (.879); Violence (.861); Going Places (.877); Caretaking (.788); and Cigarettes and Alcohol (.466). This indicates that with the exception of the Cigarettes and Alcohol scales, all scales have good internal consistency.

Gaining Trust. A six-factor solution offered the best result for the 47 items included in the EFA for the Gaining Trust MOQ scale. This solution explains $53.43 \%$ of the scale's variance. Four items did not load strongly onto any factors, and were removed from further analyses. A Scree Plot for this analysis can be seen as Figure 2, and correlations between factors are displayed in Table 4. 
PREVENTION AND PERCEPTIONS

The first factor determined by the EFA is made up of 12 items that describe the perpetrator treating their victims with kindness. As such, the factor is called "Kindness," and is made up of items such as "give them a lot of attention," and "do what they like to do.” All items on this factor, as well as their loadings, are displayed in Table 5.

The next Gaining Trust factor is composed of 9 items that describe perpetrators' efforts to establish themselves as trustworthy through associations with other individuals known to the victim. Therefore, the factor is named "Trust By Association," and is made up of items such as "say you know one of their friends," and "have their friend say to trust you." All items on this factor, as well as their loadings, are provided in Table 5.

The third factor is composed of three items, all having to do with cigarettes and alcohol. Therefore, the factor is named "Cigarettes and Alcohol." An example item is "give them cigarettes," and loadings for all three items are provided in Table 5.

The next Gaining Trust factor is made up of nine items that describe bribing the victims with gifts or privileges to gain their trust and was named "Bribes." It is important to point out that much like the Violence factor on the Accessing scale, all of the factor loadings here are strong, but negative. Again, this could have to do with the oblique rotation (Tabachnik \& Fidell, 2001), but it could also be that offenders who used visible trust-gaining strategies, such as bribes, are different than those that use more interpersonal strategies that can only be seen by the victim. Either way, it will be referred to as the "Bribes" scale. Sample items include "give them toys," and "give money to others in their family." All items on this factor, as well as their loadings, are presented in Table 5 . 
The fifth factor on the gaining trust scale, named "Manipulation," is made up of three items that involve manipulating the victim in order to gain their trust and all items as well as their loadings are presented in Table 5. Example items include "act like someone they like or trust," and "pretend to be their friend before sexual abuse."

The final factor, is composed of seven items, describes behaviors reflecting the perpetrator's attempts to treat the victim as a peer or an equal (see Table 5 for items and loadings). Consequently, the factor was named "Treat Like A Peer," and includes items such as "treat them like adults," and "tell them personal things." There is one crossloaded item on this factor, which also loads onto the "Kindness" factor (.367). It loads onto this factor slightly more strongly (.413), so will remain here.

The final step for this stage of the data analysis was the calculation of reliability statistics. The scales and their associated alpha were determined to be as follows: Kindness (.917); Trust By Association (.867); Cigarettes and Alcohol (.856); Bribes (.87); Manipulation (.648); and Treat Like A Peer (.838). Overall, with the exception of the Manipulation, the scales show strong internal consistency reliability.

Gaining Cooperation. A six-factor solution was best for the 54 items included in the EFA of the Gaining Cooperation in sexually abusive acts scale. This solution explains $52.39 \%$ of the scale's variance. One item did not load strongly onto any factors and was removed from further analyses. A Scree Plot for this analysis can be seen as Figure 3 and correlations between factors are presented in Table 6.

The first factor for this scale is made up of six items that describe perpetrators using manipulative strategies to convince their victims to participate in abusive sexual 
activity and was named "Manipulation". It should be noted that since EFAs were conducted separately on each of the five MOQ scales, it makes sense to use the same name for subscales that have similar item content. This subscale includes such items as, "say you will love them more if they do this with you," and "say you will make up things to tell on them." Interestingly, this scale is made up of both items from the "bribes" and "threats" to gain cooperation in sexually abusive behavior sections of the MOQ, which were combined in this study into the Cooperation scale. This implies that there is an overlap between the two formerly separated sections. Two items on this factor are also cross-loaded. The item, "say you will teach them something" also loads onto the "Desensitization" factor (.351), and the item "say you will make things up to tell on them" also loads onto the Violence factor (.342). However, both items load more strongly onto this factor, so they were kept on this subscale. All items on this factor, as well as their loadings, are presented in Table 7.

The second factor on the Gaining cooperation scale, called "Violence," is made up of 10 items that are all indicators of violent or coercive behavior. Sample subscale items include "use force to make them do sexual things," and "say you will hurt their mother." All of the items on this factor come from the Threats section of the MOQ. All items on this factor, as well as their loadings, are provided in Table 7.

The third factor is made up of seven items describing behaviors such as purchasing "sexual" clothing items (e.g., bathing suits or underwear), taking nude images, or exposing victims to nude images (i.e., named "Use of Pornography"). This subscale covers both exposure to and the making of pornography. It includes items such 
as "take pictures or videos of them with their clothes off," and "have them watch you do sexual things with adults." All of the items on this factor come from the Bribes and Enticements to Gain Cooperation in Sexually Abusive Acts section of the MOQ. All items on this factor, as well as their loadings, are presented in Table 7.

The fourth subscale, "Bribes," on the Gaining cooperation scale is composed of items indicating that the offender will give something to the victim in exchange for their cooperation in abusive sexual activity. Sample items for this subscale include "give them money just after sexual abuse" and "say you will take them places." There is one crossloaded item on this scale, "say you will spend more time with them." This item also loads onto the "Manipulation" factor (.313), but loads more strongly onto this factor (.467). All of the items on this factor come from the Bribes section of the MOQ. All items on this factor, as well as their loadings, are provided in Table 7.

The fifth subscale, "Desensitization," is composed of 12 items that describe actions the perpetrator takes to desensitize the victim to sexual contact. includes items such as "touch them non-sexually," and "get them curious about sex." Three items crossload onto the "Manipulation" factor, which are "get them curious about sex" (.318); "say how special they are to be doing this with you" (.339); and "talk more and more about sex" (.335). All three load more strongly onto the Desensitization factor $(.483, .344$, and .343 , respectively). However, the closeness of these loadings indicates that the items, particularly the latter two, could be a good fit for either factor. The three items, however, were maintained on the Desensitization factor for this analysis. All of the items on this 
factor come from the Bribes section of the MOQ. All items on this factor, as well as their loadings, are provided in Table 7.

The last subscale, "Directed Participation in Sexually Abusive Acts," was composed of eight items that describe ways in which perpetrators direct victims to engage in sexual activity with both the perpetrator and other individuals. This subscale also includes items involving the use of cigarettes and alcohol. Sample items include, "have them join in on sex between you and another child" and "have them do sexual things with other children." All of the items on this factor come from the Bribes section of the MOQ. All items on this factor, as well as their loadings, are provided in Table 7.

Finally, reliability statistics were calculated for each factor, using Cronbach's alpha, as follows: Manipulation (.775); Violence (.852); Use of Pornography (.799); Bribes (.907); Desensitization (.906); and Participation (.795). This indicates either good to very good internal consistency reliability, depending on the scales, with Bribes and Desensitization standing out as particularly good.

Stage 4: Sexual Abuse. A five-factor solution was best for the 26 items included in the EFA of the Sexual abuse stage-based scale. This solution explains $52.52 \%$ of the scale's variance. Two items did not load strongly onto any factors, and were removed from further analyses. A Scree Plot for this analysis is presented in Figure 4, and correlations between factors can be seen on Table 8 .

The first factor on the Sexual abuse scale is made up of six items that describe actions that perpetrators have victims do to them. For this reason, the factor is titled "Self-serving Sexual Behavior," and includes items such as "masturbate you for a while," 
and "touch your penis." One item on this factor, "rub them against you," is cross-loaded onto the "sexual touch" factor (.350). It is included onto this factor because it loads more strongly (.474),. All items on this factor, as well as their loadings, can be seen on Table 9 .

The second factor on this scale is made up of five items that indicate abuse of a female victim. The factor is therefore named "Abuse of A Female Victim," and includes items such as "put your penis into their vagina," and "put your finger into their vagina." One item on this factor, "touch their breasts or nipples," cross-loads onto the sexual touch factor (.362), but is retained on the Abuse of A Female Victim factor as it loads here more strongly (.401). All items on this factor, as well as their loadings, can be seen on Table 9.

The third factor on the Sexual abuse scale is made up of two items that both describe the perpetrator anally penetrating the victim. As such, the factor is named "Anal Penetration." It includes the items, "try to put your penis into their anus" and "put your penis into their anus." Both of these items and their loadings can be seen on Table 9 .

The fourth factor on the Sexual abuse scale is made up of six items that describe non-penetrative sexual touch. It is therefore called "Sexual Touch" and includes items such as, "rub them sexually with them knowing" and "touch their vagina or penis." All items on this factor, as well as their loadings, can be seen on Table 9 .

The final factor on this scale is made up of five items that describe abusive acts related to buttocks, which include both the victim doing something to the buttocks of the perpetrator and the perpetrator doing something to the buttocks of the victim. For this reason, the factor is called "Buttock Related Abuse." Example items include, "touch 
PREVENTION AND PERCEPTIONS

your buttocks" and "put their penis into your anus." All items on this factor, as well as their loadings, can be seen on Table 9 .

Finally, reliability statistics were calculated for each factor in the model, utilizing Cronbach's alpha: Self-serving Abuse (.852); Abuse of a Female Victim (.764); Anal Penetration (.854); Sexual Touch (.753); and Buttock Related Abuse (.670). All reliability statistics indicate decent reliability, with the final factor, Buttock Related Abuse, being less reliable than the other scales.

Stage Five: Silencing. A two-factor solution was best for the 23 items included in the EFA of the Silencing stage-based scale. This solution explains $51.74 \%$ of the scale's variance. All items included loaded onto one of the two factors. The correlation between the two factors is .580. A Scree Plot for this analysis can be seen as Figure 5.

The first of the two factors that make up the Silencing stage is made up of 11 items that describe perpetrators threatening to remove benefits of positive aspects of the relationship if the victim tells anyone about the abuse, as well as bribes. As such, the factor is named "Bribes and Removal of Benefits," and example items include "say you cannot go places together if anyone knew," and "say you will give them privileges if they do not tell." All items on this factor, as well as their loadings, can be seen on Table 10.

The second factor on the Silencing scale is made up of 12 items that describe more threatening behaviors that perpetrators use to silence their victims. Therefore, the factor is named "Threats to Silence" and includes items such as, "hurt them as a warning" and "hope they thought you would get them in trouble." All items on this factor, as well as their loadings, can be seen on Table 10 . 
PREVENTION AND PERCEPTIONS

Finally, reliability statistics for both factors were calculated. The Bribes factor has an alpha of .923 , and the Threats factor has an alpha of .859. This indicates that both factors are reliable.

\section{Discussion}

Results from this study are promising. All five scales analyzed produced clean factor solutions that explained large portions of the variance within each scale. Further, the scales and sub-scales produced show high reliability, meaning that this scale can be well utilized in future research. The best use of the MOQ, however, is as a tool for clinicians. This section will discuss the importance of the MOQ as a clinical tool, review limitations of the study, and provide future directions for the utilization of the MOQ as a research tool.

\section{The MOQ as a Clinical Tool}

The MOQ has long been utilized as a clinical tool for sexual offender treatment providers to assess perpetrators' modus operandi and to contribute to the development of their individualized treatment plan (i.e., since the mid-1990s). Workshops have been provided around the country by MOQ creator, Dr. Kaufman, to train treatment providers on the clinical use of the MOQ (Kaufman \& Daleiden, 1995; Kaufman, Hilliker, \& Daleiden, 1995; Kaufman \& Uncapher, 1995; Kaufman, Daleiden, Hilliker, \& Wallace, 1995). In this capacity, the MOQ was intended both to identify the breadth of MO strategies previously used by a particular offender as well as to summarize the types of MO approaches that characterize an offender's perpetration. The heterogeneity of sex offending requires that the MOQ reflect the breadth of possible MO behaviors. The fact 
PREVENTION AND PERCEPTIONS

that the MOQ represents a measure that broadly samples the domain of MO behaviors lends itself to use in identifying previously used patterns of behaviors that can be used in treatment planning that utilizes relapse prevention approaches (Marques et al., 2005) and/or the development of safety plans (e.g., to increase safety when returning juvenile sex offenders to their home and community (Veneziano et al. ; 2000). In both cases, a knowledge of early steps in a particular perpetrator's past offending process can help identify observable "red flags" reflecting movement toward re-offense that can be shared with parents, family members, probation/parole officers, and other guardians to increase safety and minimize the chances of reoffending (i.e., relapse). This underscores the importance of maintaining the MOQ to reflect the breadth of MO items (i.e., including low base-rate behaviors such as use of violence) for clinical purposes.

At the same time, the MOQ's clinical utility also relies on the ability to identify salient patterns that characterize an offender's modus operandi and suggests the need for particular clinical treatment directions. For example, an offender's reliance on more threatening or violent $\mathrm{MO}$ strategies may reflect their need for anger management training or therapy to address the role of violence in their sexual arousal. Alternatively, a reliance on bribes and enticements to access younger victims may reflect a need to develop better peer appropriate social and dating skills. With this in mind, factor analytic based MOQ subscales can offer a clinician the ability to quickly identify areas of concern.

The EFAs conducted in this study reflect a strong data-driven factor structure for the MOQ. Moreover, this factor structure is largely consistent with a previous EFA of 
the MOQ with a different participant pool (Kaufman et al., 1997) and also boasts scales with strong internal consistency reliability (i.e., based on this study's findings). As such, findings from this study provide additional support for the continued use of the MOQ as a clinical measure for identifying factor-based patterns of offenders' modus operandi. It may be beneficial for future studies to examine the extent to which the MOQ is found to be helpful by clinicians and the specific ways in which MOQ scales are useful in suggesting particular treatment needs.

\section{Limitations}

The MOQ has is limited in regard to its self-report, retrospective nature. Even though anonymity has been assured, the sensitive nature of the MOQ items may lead to biased self-report. This could have particular relevance for any crime related information that has not been previously reported to the justice system. In fact, Kaufman and his colleagues found a propensity for juvenile sexual offenders to under-report more violent MO behaviors (Kaufman et al., 1993). Research on offenders provides mixed information on whether they are impacted by social desirability when responding to questionnaires (Tan \& Grace, 2008). This study would have benefitted from a measure of social desirability, to help understand honesty of responses.

The MOQ items also ask participants to recall an offense (or offenses) that may have happened quite a few years ago. As a result, they may have difficulties accurately recalling particular aspects of their MO behaviors. However, since offending behaviors are typically a focus of their treatment, there is reason to believe that their salient nature and clinical focus on such behaviors in treatment may make this less of a concern. 
Another limitation of the study is related to the type of sample collected. The MOQ in this study was only administered to convicted sex offenders. Therefore, results may only be generalizable to that population. This may mean that the resulting factor structure may not be appropriate for use with non-convicted offenders, who may use very different MO tactics than convicted offenders. Given the challenges associated with collecting data from non-identified (i.e., non-convicted) offenders it is difficult to know if or in what ways their MOQ data may differ from the current study sample.

The length of the MOQ may also represent a study limitation. At 339 items, the MOQ takes a fair amount of time to complete and original study participants also completed a number of other measures at the same time. This length may have led to fatigue, which could have been a factor impacting how participants completed the MOQ. However, even though the measure was long, participants were given a break during the data collection and a snack halfway through the process.

\section{Future Directions as a Research Tool}

This study provides important information as to how the MOQ can be utilized as a research tool. To strengthen the scale, future research could conduct confirmatory analyses on new samples of offenders to examine theoretical fit of the proposed MOQ EFA structure. Replications of this nature will help determine if consideration should ultimately be given to creating separate versions of the MOQ based on key offender subgroups, as well as consideration of item deletion. Enhancing the fit of the data will provide a measure that is reliable and valid for empirical use. 
PREVENTION AND PERCEPTIONS

Future studies on the MOQ could also delve into Item Response Theory (IRT) as a means to analyze the scale at an item level. The use of IRT could better develop the psychometric characteristics of the MOQ, which would strengthen the overall measure. Studies could also examine relationships between scales reflecting the MO temporal stages, examining if high levels of a specific tactic in one stage predict high levels of a similar or related tactic in succeeding stages. For example, future studies may examine whether the use of a high frequency of threats in the gaining cooperation stage predicts the use of a high frequency of threats in the victim silencing stage. It could also be useful to see if specific MO strategies predict how violent the act of sexual abuse will be across temporal stages. Finally, cluster analysis work could be conducted to see if there are identifiable offender profiles across the MO process. This may have particular implications for planning offender treatment or placing offenders into groups containing perpetrators with similar issues to foster a more intensive focus on issues relevant to all group members.

An up to date factor analysis of the MOQ is a valuable contribution to the work done on situational factors that influence offending, as well as situational prevention. Differences in MO could be analyzed in conjunction with reported situational variables that made the abuse easier or more difficult to understand the full crime commission process, as suggested by Leclerc, Proulx, \& Beauregard (2009). The MOQ could also be adapted, as necessary, to best fit the process of different types of offenders, such as organizational offenders, or offenders who use the internet to access 
their victims. This would align with work that is being done in these areas on MO, such as internet offending (Elliott \& Beech, 2009; Kloess et al., 2015).

Overall, this study has the potential to re-integrate the MOQ into offender research and to help clinicians continue to understand how to best treat their clients. It further quantifies an area of research that has long relied on interview-based data, allowing for both researchers and clinicians to compare the offending patterns of individuals to those tactics most commonly used by perpetrators as a group. Understanding these patterns on a broader level can help to inform widespread prevention efforts. 


\section{Table 1.}

Low Endorsement MOQ Items

\begin{tabular}{|c|c|c|}
\hline Item & Stage-based Scale & $\begin{array}{l}\text { "Never" } \\
\text { Percentage }\end{array}$ \\
\hline Give them drugs & Access & 95.3 \\
\hline Tell them you'd hurt their friend if they didn't go & Access & 95.7 \\
\hline Tell them you'd hurt their pet if they didn't go & Access & 96.6 \\
\hline Let them see you had a weapon & Access & 95.3 \\
\hline Hurt their pet & Access & 97.5 \\
\hline Hurt some other animal & Access & 97.8 \\
\hline Hurt a member of their family & Access & 95.4 \\
\hline Threaten them with a weapon & Access & 96.1 \\
\hline Give them drugs & Gaining Trust & 95.9 \\
\hline Give them drugs just after sexual abuse & Gaining Cooperation & 95.6 \\
\hline $\begin{array}{l}\text { Show them pictures or videos of you having sex with } \\
\text { other adults }\end{array}$ & Gaining Cooperation & 95.4 \\
\hline $\begin{array}{l}\text { Have them watch children do sexual things with each } \\
\text { other }\end{array}$ & Gaining Cooperation & 95.3 \\
\hline $\begin{array}{l}\text { Show them pictures or videos of you having sex with } \\
\text { kids }\end{array}$ & Gaining Cooperation & 97.9 \\
\hline Have them join in sex between you and another adult & Gaining Cooperation & 96.3 \\
\hline $\begin{array}{l}\text { Have them take pictures or videos of you doing sexual } \\
\text { things with kids }\end{array}$ & Gaining Cooperation & 98.4 \\
\hline Have them take pictures or videos of you having sex & Gaining Cooperation & 98.1 \\
\hline $\begin{array}{l}\text { Show them media with adults doing sexual things with } \\
\text { kids }\end{array}$ & Gaining Cooperation & 96.6 \\
\hline Show them media with naked children & Gaining Cooperation & 95.7 \\
\hline $\begin{array}{l}\text { Show them media with kids doing sexual things } \\
\text { together }\end{array}$ & Gaining Cooperation & 96.2 \\
\hline Show them media with animals doing sexual things & Gaining Cooperation & 97.9 \\
\hline $\begin{array}{l}\text { Show them media of people doing sexual things with } \\
\text { animals }\end{array}$ & Gaining Cooperation & 98.5 \\
\hline Put a weapon where they could see it & Gaining Cooperation & 95.4 \\
\hline Tell them you had a weapon & Gaining Cooperation & 96.1 \\
\hline Say you will tie them up & Gaining Cooperation & 96.4 \\
\hline Say you will hurt them with a gun & Gaining Cooperation & 97.9 \\
\hline Say you will hurt them with a knife & Gaining Cooperation & 96.5 \\
\hline Say you will hurt them with another object & Gaining Cooperation & 97.9 \\
\hline Say you will hurt their father & Gaining Cooperation & 97 \\
\hline Say you will hurt their friends or relatives & Gaining Cooperation & 97.1 \\
\hline Say you will hurt their pet & Gaining Cooperation & 97.1 \\
\hline Say you will kill them & Gaining Cooperation & 95.2 \\
\hline Say you will kill their sibling & Gaining Cooperation & 97.2 \\
\hline Say you will kill their mother & Gaining Cooperation & 96.9 \\
\hline Say you will kill their father & Gaining Cooperation & 97.3 \\
\hline Say you will kill their friends or relatives & Gaining Cooperation & 97.5 \\
\hline Say you will kill their pet & Gaining Cooperation & 97.1 \\
\hline Get them drunk & Gaining Cooperation & 95.2 \\
\hline Get them high with drugs & Gaining Cooperation & 96.5 \\
\hline Get them high with prescription drugs & Gaining Cooperation & 97.5 \\
\hline Tie them up & Gaining Cooperation & 96.7 \\
\hline
\end{tabular}


Low Endorsement MOQ Items

\begin{tabular}{lll}
\hline Item & Stage-based Scale & $\begin{array}{l}\text { "Never" } \\
\text { Percentage }\end{array}$ \\
\hline Hurt a pet in front of them & Gaining Cooperation & 98 \\
Hurt their friends & Gaining Cooperation & 98.1 \\
Hurt a family member in front of them & Gaining Cooperation & 97.3 \\
Urinate or defecate on them & Sexual Abuse & 98 \\
Have them urinate or defecate on you & Sexual Abuse & 98.9 \\
Have them hurt you as part of sexual acts & Sexual Abuse & 98.6 \\
Say you would tie them up & Silencing & 96.7 \\
Say you would hurt them with a gun & Silencing & 97.1 \\
Say you would hurt them with a knife & Silencing & 96.7 \\
Say you would hurt them with another object & Silencing & 97.4 \\
Say you would hurt their siblings & Silencing & 96.2 \\
Say you would hurt their mother & Silencing & 95.5 \\
Say you would hurt their father & Silencing & 96.6 \\
Say you would hurt their friends or relatives & Silencing & 97.1 \\
Say you would hurt their pet & Silencing & 97.7 \\
Say you would kill their siblings & Silencing & 97.5 \\
Say you would kill their mother & Silencing & 97.1 \\
Say you would kill their father & Silencing & 97.7 \\
Say you would kill their friends or relatives & Silencing & 98.2 \\
Say you would kill their pet & Silencing & 98.1 \\
Hurt a friend in front of them as a warning & Silencing & 98 \\
\hline
\end{tabular}


Table 2.

\begin{tabular}{lrrrrr}
\multicolumn{6}{l}{ Access Factor Correlations } \\
\hline \multicolumn{1}{c}{1} & 2 & 3 & \multicolumn{1}{l}{4} & \multicolumn{1}{l}{5} \\
\hline 1. & - & & & & \\
2 & -.322 & - & & & \\
3 & .314 & -.238 & - & & \\
4 & .299 & -.078 & .363 & - & \\
5 & .227 & -.140 & .320 & .212 & - \\
\hline
\end{tabular}

Note. 1. Relationship Building; 2. Violence; 3. Going Places;

4. Caretaking; 5. Cigarettes and alcohol 
Table 3.

Accessing Exploratory Factor Loadings

\begin{tabular}{|c|c|c|c|c|c|}
\hline & 1 & 2 & 3 & 4 & 5 \\
\hline tell them you will do something fun & .692 & .065 & .021 & .027 & .018 \\
\hline $\begin{array}{l}\text { threaten with ending of privileges or } \\
\text { rewards }\end{array}$ & .625 & -.179 & -.110 & .038 & .044 \\
\hline $\begin{array}{l}\text { telling them they'd get special } \\
\text { rewards or privileges }\end{array}$ & .617 & -.001 & -.091 & .088 & .068 \\
\hline give them toys or candy & .595 & -.013 & -.022 & .110 & .037 \\
\hline tell them you can be trusted & .576 & .014 & .093 & .083 & -.039 \\
\hline $\begin{array}{l}\text { tell the you won't spend time with } \\
\text { them if they didn't go }\end{array}$ & .560 & -.197 & .035 & -.072 & .038 \\
\hline $\begin{array}{l}\text { tell them you are older and they } \\
\text { should do what you say }\end{array}$ & .560 & -.244 & .108 & .009 & -.105 \\
\hline $\begin{array}{l}\text { tell them they would get in trouble if } \\
\text { they didn't go }\end{array}$ & .555 & -.330 & .072 & -.097 & -.022 \\
\hline defend them from bullies & .455 & .031 & .083 & .193 & .092 \\
\hline $\begin{array}{l}\text { tell them you would get in trouble if } \\
\text { they didn't go }\end{array}$ & .453 & -.287 & .061 & -.068 & -.007 \\
\hline give them money & .384 & -.012 & -.063 & .226 & .241 \\
\hline tell them parents said to go with you & .340 & -.180 & .197 & -.009 & .001 \\
\hline watch t.v. with them & .330 & .101 & .185 & .300 & -.063 \\
\hline $\begin{array}{l}\text { pretend to be someone they like or } \\
\text { trust }\end{array}$ & .329 & -.110 & .187 & -.134 & -.007 \\
\hline $\begin{array}{l}\text { being at home of friend or relative } \\
\text { with permission }\end{array}$ & .152 & -.003 & .083 & .084 & .126 \\
\hline $\begin{array}{l}\text { tell them you would hurt them if they } \\
\text { didn't go }\end{array}$ & .051 & -.747 & .002 & -.043 & .104 \\
\hline hurt them & -.026 & -.738 & .036 & .004 & .037 \\
\hline use physical force to make them go & -.004 & -.730 & .009 & -.079 & .026 \\
\hline get angry or violent with them & .089 & -.667 & .098 & .044 & -.090 \\
\hline $\begin{array}{l}\text { tell them you had hurt others or had a } \\
\text { bad temper }\end{array}$ & .165 & -.616 & -.121 & .145 & -.047 \\
\hline $\begin{array}{l}\text { tell them you'd hurt their family if } \\
\text { they didn't go }\end{array}$ & -.040 & -.532 & .081 & -.032 & .245 \\
\hline $\begin{array}{l}\text { hoping they thought you'd hurt them } \\
\text { if they didn't go }\end{array}$ & .199 & -.481 & -.098 & .081 & .034 \\
\hline $\begin{array}{l}\text { let them see you angry or violent with } \\
\text { another person }\end{array}$ & .253 & -.442 & .011 & .178 & -.068 \\
\hline take them to parks & .078 & .005 & .797 & -.082 & -.066 \\
\hline go to playground & .076 & -.065 & .745 & -.091 & -.133 \\
\hline go to shopping mall & -.098 & -.030 & .744 & -.005 & -.026 \\
\hline take them to the movies & -.008 & .034 & .655 & .033 & .051 \\
\hline take them to school & -.065 & -.025 & 641 & .126 & -.081 \\
\hline take them to the video arcade & .006 & -.086 & .561 & -.015 & .081 \\
\hline take them camping & -.028 & -.011 & .510 & .091 & .088 \\
\hline go for car ride with them & .056 & .107 & .454 & .197 & .112 \\
\hline be together for a holiday & .177 & .034 & .373 & .295 & -.050 \\
\hline go swimming with them & .105 & .049 & .360 & .221 & .160 \\
\hline take them on overnight trips alone & -.034 & .020 & .330 & .164 & .223 \\
\hline take them places during the day alone & .149 & .126 & .329 & .147 & .216 \\
\hline
\end{tabular}


Accessing Exploratory Factor Loadings

\begin{tabular}{|c|c|c|c|c|c|}
\hline & 1 & 2 & 3 & 4 & 5 \\
\hline go to isolated or out of the way place & .097 & -.083 & .281 & -.099 & .251 \\
\hline $\begin{array}{l}\text { letting them see you with other } \\
\text { children }\end{array}$ & .213 & .085 & .274 & .060 & .071 \\
\hline having a pet to show and play with & .195 & -.118 & .230 & -.095 & .123 \\
\hline tuck them in bed & .094 & .001 & .080 & .669 & -.050 \\
\hline give them a bath & .011 & -.107 & .049 & .572 & .015 \\
\hline take a bath/shower with them & -.019 & -.059 & .019 & .519 & .106 \\
\hline being at home with permission & .021 & .085 & -.012 & .502 & .010 \\
\hline being home alone due to time & .014 & .046 & -.081 & .498 & -.013 \\
\hline difference with parent or spouse & & & & & \\
\hline let them sleep in my bed & .049 & .050 & 139 & 492 & .059 \\
\hline sneak into their bedroom at night & .109 & -.045 & -.005 & .478 & .025 \\
\hline baby-sit & .221 & .065 & -.068 & .455 & -.049 \\
\hline have sole custody & -.125 & -.173 & .056 & 348 & -.072 \\
\hline $\begin{array}{l}\text { let them stay up after parent had gone } \\
\text { to bed }\end{array}$ & .298 & .041 & .072 & .316 & .139 \\
\hline have them baby-sit for own children & -.013 & -.030 & .055 & .268 & .039 \\
\hline take them out of school & -.157 & -.201 & .207 & .242 & .094 \\
\hline $\begin{array}{l}\text { see them on weekend visit (if } \\
\text { divorced or separated) }\end{array}$ & .010 & -.012 & .101 & .175 & .035 \\
\hline give them cigarettes & .034 & .024 & -.046 & -.067 & .683 \\
\hline give them alcohol & -.065 & -.106 & -.047 & .025 & .618 \\
\hline
\end{tabular}

Note. 1. Relationship Building; 2. Violence; 3. Going Places; 4. Caretaking; 5. Cigarettes and Alcohol. All loadings above .3 are bolded 
Table 4.

Trust Factor Correlations

\begin{tabular}{lrrrrrr}
\hline & 1 & \multicolumn{1}{c}{2} & 3 & 4 & 5 & 6 \\
\hline 1 & - & & & & & \\
2 & .267 & - & & & & \\
3 & .109 & .255 & - & & & \\
4 & -.455 & -.431 & -.189 & - & & \\
5 & .217 & .269 & .152 & -.091 & - & - \\
6 & .494 & .366 & .267 & -.442 & .164 & - \\
\hline
\end{tabular}

Note. 1. Kindness; 2. Trust by Association; 3. Cigarettes and Alcohol; 4. Bribes; 5. Manipulation; 6. Treat like a Peer 
Table 5.

Gaining trust exploratory factor loadings

\begin{tabular}{|c|c|c|c|c|c|c|}
\hline Item & 1 & 2 & 3 & 4 & 5 & 6 \\
\hline give them a lot of attention & .790 & .049 & .011 & -.073 & -.050 & .015 \\
\hline spend a lot of time with them & .784 & .069 & .019 & -.074 & -.101 & -.045 \\
\hline play with them & .741 & .069 & -.042 & -.081 & .008 & .008 \\
\hline do what they like to do & .725 & .120 & .022 & -.108 & -.005 & .005 \\
\hline touch them non-sexually & .589 & .041 & -.095 & -.086 & -.049 & .260 \\
\hline $\begin{array}{l}\text { let them decide what you will do } \\
\text { together }\end{array}$ & .450 & .102 & .032 & -.118 & -.068 & .262 \\
\hline tell them they're special & .435 & .098 & -.044 & -.220 & -.087 & .322 \\
\hline $\begin{array}{l}\text { try to form real friendships before } \\
\text { sexual abuse }\end{array}$ & .430 & .058 & .091 & .001 & -.003 & .198 \\
\hline $\begin{array}{l}\text { imagine sexual abuse before it } \\
\text { began }\end{array}$ & .384 & -.013 & .028 & .037 & .272 & .188 \\
\hline $\begin{array}{l}\text { trick them into feeling safe with } \\
\text { you }\end{array}$ & .382 & .050 & .010 & -.134 & .278 & .137 \\
\hline $\begin{array}{l}\text { began sexual abuse before } \\
\text { mentioning sex }\end{array}$ & .364 & -.061 & .033 & .088 & .176 & -.017 \\
\hline be like a parent before sexual abuse & .334 & .054 & -.026 & -.137 & -.091 & .281 \\
\hline $\begin{array}{l}\text { protect them from people who } \\
\text { might hurt them }\end{array}$ & .325 & .127 & -.010 & -.291 & -.168 & .256 \\
\hline say you know one of their friends & .016 & .849 & .066 & .072 & -.002 & -.067 \\
\hline say you know one of their parents & .084 & .818 & -.058 & .073 & -.063 & -.066 \\
\hline say you know one of their relatives & .051 & .771 & .006 & .040 & -.112 & -.045 \\
\hline $\begin{array}{l}\text { have another child talk about } \\
\text { having fun with you }\end{array}$ & -.074 & .614 & .084 & .005 & .200 & .030 \\
\hline $\begin{array}{l}\text { let them see you with another child } \\
\text { they know }\end{array}$ & .143 & .564 & .026 & -.079 & -.058 & .019 \\
\hline have their friend say to trust you & -.043 & .508 & .107 & -.034 & .162 & .112 \\
\hline $\begin{array}{l}\text { say they shouldn't talk to strangers, } \\
\text { but you're ok }\end{array}$ & -.028 & .481 & -.011 & -.111 & .077 & .076 \\
\hline offer to help them & .068 & .346 & -.047 & -.224 & .220 & .102 \\
\hline $\begin{array}{l}\text { talk to them about another abuser } \\
\text { they know }\end{array}$ & -.031 & .319 & .117 & -.024 & .102 & .107 \\
\hline give them cigarettes & .023 & .012 & .964 & -.002 & -.068 & -.125 \\
\hline let them smoke cigarettes & .020 & .061 & .893 & .026 & -.010 & -.079 \\
\hline give them beer or liquor & -.077 & -.042 & .626 & -.024 & -.044 & .086 \\
\hline show them pornography & .104 & .106 & .168 & -.054 & .110 & .055 \\
\hline give them toys & .223 & -.002 & -.047 & -.755 & .110 & -.235 \\
\hline give them money & -.079 & -.033 & .176 & -.716 & .013 & .050 \\
\hline give them candy or fav food & .255 & .004 & -.012 & -.704 & .151 & -.175 \\
\hline give them privileges or rewards & .186 & -.057 & .001 & -.629 & .020 & .112 \\
\hline give them other gifts & -.058 & -.016 & .039 & -.562 & .023 & .102 \\
\hline $\begin{array}{l}\text { let them see you give something to } \\
\text { another child }\end{array}$ & -.023 & .273 & .056 & -.441 & -.037 & .001 \\
\hline $\begin{array}{l}\text { give money to others in their } \\
\text { family }\end{array}$ & -.081 & .163 & .021 & -.436 & -.170 & .139 \\
\hline take them places & .301 & .082 & .120 & -.378 & -.085 & .107 \\
\hline stick up for them against their & .071 & .137 & .036 & -.364 & .008 & .284 \\
\hline
\end{tabular}

friends 
PREVENTION AND PERCEPTIONS

Gaining trust exploratory factor loadings

\begin{tabular}{|c|c|c|c|c|c|c|}
\hline Item & 1 & 2 & 3 & 4 & 5 & 6 \\
\hline $\begin{array}{l}\text { let them do something else they } \\
\text { aren't supposed to }\end{array}$ & .217 & -.068 & .240 & -.266 & .138 & .180 \\
\hline act like someone they like or trust & -.077 & .280 & -.031 & -.137 & .431 & .021 \\
\hline ask them for help & -.031 & .343 & .015 & .001 & .379 & .043 \\
\hline $\begin{array}{l}\text { pretend to be friends before sexual } \\
\text { abuse }\end{array}$ & .247 & .092 & .029 & -.041 & .322 & .125 \\
\hline $\begin{array}{l}\text { test them for secrecy before sexual } \\
\text { abuse }\end{array}$ & .129 & .034 & .000 & -.238 & .269 & .151 \\
\hline treat them like adults & .153 & .001 & .071 & -.176 & -.124 & .533 \\
\hline $\begin{array}{l}\text { pretend to be romantically involved } \\
\text { before sexual abuse }\end{array}$ & -.010 & .018 & .082 & -.015 & .146 & .508 \\
\hline say loving, caring things to them & .367 & .079 & -.086 & -.206 & -.050 & .413 \\
\hline stick up for them against a parent & .073 & .096 & -.018 & -.362 & -.143 & .404 \\
\hline tell them personal things & .257 & .090 & .034 & -.168 & .044 & .360 \\
\hline tell them only you love them & .008 & .164 & -.052 & -.232 & .098 & .341 \\
\hline talk like their age & .135 & .174 & .102 & -.105 & .095 & .316 \\
\hline $\begin{array}{l}\text { talk to them about sex before } \\
\text { sexual abuse }\end{array}$ & .044 & -.002 & .027 & .062 & .017 & .218 \\
\hline
\end{tabular}

Note. 1. Kindness; 2. Trust by Association; 3. Cigarettes and Alcohol; 4. Bribes;

5. Manipulation; 6. Treat like a Peer. Loadings above .3 are bolded. 
PREVENTION AND PERCEPTIONS

Table 6

\begin{tabular}{lrrrrrr}
\multicolumn{6}{l}{ Cooperation Factor Correlations } \\
\hline Factor & 1 & 2 & 3 & 4 & 5 & 6 \\
\hline 1 & - & & & & & \\
2 & .211 & - & & & & \\
3 & .175 & .206 & - & & & \\
4 & .247 & .214 & .333 & - & & \\
5 & .325 & .056 & .254 & .452 & - & - \\
6 & .270 & .340 & .406 & .189 & .171 & - \\
\hline
\end{tabular}

Note. 1. Manipulation; 2. Violence; 3. Use of Pornography; 4. Bribes; 5. Desensitization; 6. Participation 
Table 7.

Gaining Cooperation Factor Loadings

\begin{tabular}{|c|c|c|c|c|c|c|}
\hline \multicolumn{7}{|l|}{ Item } \\
\hline & 1 & 2 & 3 & 4 & 5 & 6 \\
\hline $\begin{array}{l}\text { say you will love them } \\
\text { more if they do this } \\
\text { with you }\end{array}$ & .546 & .029 & .119 & .311 & .160 & $\overline{-.091}$ \\
\hline $\begin{array}{l}\text { say they don't love } \\
\text { you if they don't do } \\
\text { sex things }\end{array}$ & .506 & .100 & .086 & .203 & .115 & -.012 \\
\hline $\begin{array}{l}\text { say you will 'teach' } \\
\text { them something }\end{array}$ & .427 & .030 & .057 & .149 & .351 & .003 \\
\hline $\begin{array}{l}\text { say you will make up } \\
\text { things to tell on them }\end{array}$ & .423 & .342 & .047 & .146 & -.128 & .065 \\
\hline $\begin{array}{l}\text { say you will tell on } \\
\text { them about having } \\
\text { sexw/ you }\end{array}$ & .400 & .235 & .050 & .084 & -.036 & .035 \\
\hline $\begin{array}{l}\text { tell them their friends } \\
\text { have already had sex }\end{array}$ & .358 & .011 & .191 & .131 & .065 & .227 \\
\hline $\begin{array}{l}\text { say you will hit them } \\
\text { if they don't do it }\end{array}$ & -.115 & .825 & -.077 & .036 & .034 & .049 \\
\hline hurt them & -.092 & .742 & -.093 & -.025 & .059 & .107 \\
\hline $\begin{array}{l}\text { use force to make } \\
\text { them do sex things }\end{array}$ & .010 & .707 & -.055 & -.054 & .058 & -.018 \\
\hline $\begin{array}{l}\text { make them feel like } \\
\text { there is nothing to do } \\
\text { to stop it }\end{array}$ & .055 & .663 & .001 & .072 & .117 & -.141 \\
\hline $\begin{array}{l}\text { say you will hurt their } \\
\text { siblings }\end{array}$ & -.006 & .611 & .199 & -.027 & -.067 & .131 \\
\hline $\begin{array}{l}\text { say you will hurt their } \\
\text { mother }\end{array}$ & -.053 & .602 & .136 & -.054 & -.023 & .163 \\
\hline say you will kill them & -.106 & .555 & .088 & .044 & -.062 & .037 \\
\hline $\begin{array}{l}\text { hope they thought } \\
\text { you'd hurt them }\end{array}$ & .197 & .477 & -.026 & .061 & .023 & -.038 \\
\hline $\begin{array}{l}\text { hope they thought } \\
\text { you'd hurt a family } \\
\text { member }\end{array}$ & .159 & .459 & .079 & -.069 & .026 & .124 \\
\hline $\begin{array}{l}\text { hope they thought } \\
\text { you'd get them in } \\
\text { trouble }\end{array}$ & .286 & .376 & -.014 & .070 & .065 & -.028 \\
\hline $\begin{array}{l}\text { buy them bathing } \\
\text { suits }\end{array}$ & -.105 & .061 & .700 & .143 & .045 & -.066 \\
\hline
\end{tabular}


PREVENTION AND PERCEPTIONS

buy them underwear

or sleepwear

talk pics or vids of

them with clothes off show them pics or vids of you with

clothes off

take pics or vids of

them with clothes on

have them watch you

do sex things with

adults

show them media w/

adults doing sex

things $\mathrm{w} /$ kids

say you would hire

them for a job

give them money just

after sexual abuse

give them toys just

after sexual abuse

give them money

sometimes

give them gifts

sometimes

give them candy just

after sexualx abuse

give them privileges

or rewards just after

sexual abuse

say you will take

them places

give them other gifts

just after sexual

abuse

say you will spend

more time with them

buy them other

clothes

give non-sexual

attention

touch them non-

sexually

say nice things about

them

say loving things

touch them more and

more

start sexual abuse like

no big thing

get them curious

about sex
$-.106 \quad .003$

.159

.109

$-.134$

.104

$-.007$

.623

$-.122$

.028

.052

.205

.082

.573

$-.114$

$-.066$

.072

$-.07$

$-.022$

.550

.006

.135

.050

.005

.041

.403

$-.026$

$-.023$

.184

.198

.094

.373

$-.106$

$-.085$

.183

.04

$-.048$

.286

.149

$-.036$

.205

$-.01$

.004

$-.034$

.850

$-.113$

.117

.104

.119

$-.082$

.746

$-.048$

$-.014$

$-.11$

$-.034$

.054

.686

.140

.125

$-.105$

.004

.035

.671

.270

.026

.141

.068

$-.063$

.655

.041

.036

.140

$-.012$

$-.057$

.537

.245

.076

.271

.005

.034

.537

.176

.033

.002

.000

.178

.470

.014

$-.041$

.313

$.054 \quad .044$

.467

.216

$-.021$

$-.157$

$-.067$

.413

.449

.152

$-.095$

$-.167$

.072

.003

$-.017$

.828

$-.014$

$-.129$

.075

.089

.038

.798

$-.086$

$-.078$

.026

.066

.131

.787

$-.048$

.002

.016

.108

.133

.694

$-.086$

.148

.061

.029

.025

.568

.100

.100

.082

$-.075$

$-.025$

.557

.108

.318

$-.126$

$-.025$

.057

.483

.213 


\begin{tabular}{|c|c|c|c|c|c|c|}
\hline $\begin{array}{l}\text { get them sexually } \\
\text { excited }\end{array}$ & .237 & -.120 & .030 & .013 & .472 & .245 \\
\hline $\begin{array}{l}\text { start sexual abuse } \\
\text { when they were } \\
\text { upset }\end{array}$ & .107 & .052 & .077 & .139 & .404 & .135 \\
\hline $\begin{array}{l}\text { say how special they } \\
\text { are to be doing this } \\
\text { with you }\end{array}$ & .339 & -.054 & .089 & .275 & .344 & -.007 \\
\hline $\begin{array}{l}\text { talk more and more } \\
\text { about sex }\end{array}$ & .335 & -.106 & .026 & .031 & .343 & .280 \\
\hline $\begin{array}{l}\text { wear less clothes and } \\
\text { tell child to wear less }\end{array}$ & .151 & -.031 & .232 & .088 & .332 & .098 \\
\hline $\begin{array}{l}\text { have them join in sex } \\
\text { between you and } \\
\text { another kid }\end{array}$ & -.017 & .027 & -.038 & -.031 & .097 & .733 \\
\hline $\begin{array}{l}\text { have them watch you } \\
\text { do sexual things with } \\
\text { other kids }\end{array}$ & -.015 & .073 & -.028 & -.085 & .131 & .641 \\
\hline $\begin{array}{l}\text { have their friend, who } \\
\text { you've been sexual } \\
\text { involved with, say it's } \\
\text { ok }\end{array}$ & .075 & .005 & .056 & .049 & .026 & .589 \\
\hline $\begin{array}{l}\text { have them do sexual } \\
\text { things with other } \\
\text { children }\end{array}$ & .018 & .063 & .064 & -.029 & .027 & .554 \\
\hline $\begin{array}{l}\text { give them beer or } \\
\text { liquor just after } \\
\text { sexual abuse }\end{array}$ & -.133 & .104 & .054 & .167 & -.101 & .442 \\
\hline $\begin{array}{l}\text { give them cigarettes } \\
\text { just after sexual } \\
\text { abuse }\end{array}$ & -.069 & .099 & .046 & .168 & -.113 & .405 \\
\hline $\begin{array}{l}\text { show them media w/ } \\
\text { naked adults }\end{array}$ & .236 & -.056 & .089 & .034 & .109 & .332 \\
\hline $\begin{array}{l}\text { talk about another } \\
\text { abuser with whom } \\
\text { they've been involved }\end{array}$ & -.016 & .071 & .179 & .075 & .023 & .308 \\
\hline
\end{tabular}

Note. 1. Manipulation; 2. Violence; 3. Use of Pornography; 4. Bribes;

5. Desensitization; 6. Participation. Loadings above .3 are bold 
Table 8 .

Sexual Abuse Factor Correlations

\begin{tabular}{lrrrrr}
\hline Factor & 1 & 2 & 3 & 4 & 5 \\
\hline 1 & - & & & & \\
2 & .276 & - & & & \\
3 & .234 & .140 & - & & \\
4 & .570 & .342 & .115 & - & \\
5 & .388 & .173 & .308 & .249 & - \\
\hline
\end{tabular}

Note. 1. Self-serving Abuse; 2. Abuse of a Female; 3. Anal Penetration; 4. Sexual Touch; 5. Buttock Related Abuse 
Table 9.

Sexual Abuse Loadings

\begin{tabular}{|c|c|c|c|c|c|}
\hline Item & 1 & 2 & 3 & 4 & 5 \\
\hline masturbate you for awhile & .800 & -.047 & .036 & .047 & -.012 \\
\hline $\begin{array}{l}\text { put their mouth or tongue on } \\
\text { your penis }\end{array}$ & .777 & .046 & .035 & -.127 & .039 \\
\hline touch your penis & .757 & .033 & .010 & -.008 & -.129 \\
\hline $\begin{array}{l}\text { masturbate you to } \\
\text { ejaculation/orgasm }\end{array}$ & .603 & -.007 & .006 & .023 & .101 \\
\hline rub them against you & .474 & -.017 & .023 & .350 & .021 \\
\hline $\begin{array}{l}\text { put your mouth or tongue on } \\
\text { their vagina or penis }\end{array}$ & .375 & .060 & -.083 & 288 & .183 \\
\hline $\begin{array}{l}\text { put your penis into their } \\
\text { vagina }\end{array}$ & .019 & .773 & .168 & -.048 & -.072 \\
\hline $\begin{array}{l}\text { try to put your penis into their } \\
\text { vagina }\end{array}$ & .098 & .760 & .141 & .060 & -.179 \\
\hline put your finger in their vagina & -.030 & .610 & -.084 & .162 & .048 \\
\hline put an object in their vagina & .014 & 411 & -.017 & -.056 & .212 \\
\hline touch their breasts/nipples & .057 & .401 & -.121 & .362 & -.071 \\
\hline $\begin{array}{l}\text { try to put your penis into their } \\
\text { anus }\end{array}$ & .101 & .033 & .761 & .143 & .110 \\
\hline put your penis into their anus & .043 & .132 & .693 & .065 & .153 \\
\hline $\begin{array}{l}\text { rub them sexually with them } \\
\text { knowing }\end{array}$ & -.012 & -.009 & .038 & .738 & -.043 \\
\hline touch their buttocks & .052 & .037 & .108 & .638 & -.028 \\
\hline touch their vagina or penis & .015 & .100 & -.130 & .567 & .116 \\
\hline $\begin{array}{l}\text { rub your penis against their } \\
\text { bodies }\end{array}$ & .263 & .081 & .171 & .468 & -.099 \\
\hline $\begin{array}{l}\text { rub against them sexually w/o } \\
\text { them knowing }\end{array}$ & -.021 & -.007 & .076 & 435 & .007 \\
\hline $\begin{array}{l}\text { masturbate them (not to } \\
\text { ejaculation/orgasm) }\end{array}$ & .211 & -.015 & -.107 & .371 & .227 \\
\hline $\begin{array}{l}\text { put their finger or object in } \\
\text { your anus }\end{array}$ & -.007 & -.069 & .006 & .021 & .598 \\
\hline put their penis in your anus & .112 & -.193 & .177 & .031 & .472 \\
\hline $\begin{array}{l}\text { put their finger or object into } \\
\text { their anus }\end{array}$ & -.055 & .100 & .232 & .016 & .406 \\
\hline touch your butt & .293 & -.012 & .083 & .123 & .330 \\
\hline put your mouth on their anus & .075 & .043 & .055 & .158 & .303 \\
\hline $\begin{array}{l}\text { masturbate them to } \\
\text { ejaculation/orgasm }\end{array}$ & .157 & .115 & -.100 & .158 & .202 \\
\hline
\end{tabular}

Note. 1. Self-serving Abuse; 2. Abuse of a Female; 3. Anal Penetration; 4. Sexual Touch; 5. Buttock related abuse. 
Table 10.

Silencing Exploratory Factor Loadings

\begin{tabular}{|c|c|c|}
\hline & Bribes & Threats \\
\hline $\begin{array}{l}\text { say you cannot go places together if } \\
\text { anyone knew }\end{array}$ & .861 & -.036 \\
\hline $\begin{array}{l}\text { say you will take them places if they don't } \\
\text { tell }\end{array}$ & .856 & -.072 \\
\hline $\begin{array}{l}\text { say you cannot buy but them things if } \\
\text { anyone knew }\end{array}$ & .852 & -.067 \\
\hline $\begin{array}{l}\text { say you will spend more time together if } \\
\text { they don't tell }\end{array}$ & .837 & -.002 \\
\hline $\begin{array}{l}\text { say you will love them more if they don't } \\
\text { tell }\end{array}$ & .789 & .040 \\
\hline $\begin{array}{l}\text { say you will give privileges of if they don't } \\
\text { tell }\end{array}$ & .772 & .012 \\
\hline say they would not get to see you anymore & .718 & .036 \\
\hline $\begin{array}{l}\text { say you cannot spend time together if } \\
\text { anyone knew }\end{array}$ & .652 & -.010 \\
\hline say you would get in trouble if they told & .579 & .039 \\
\hline say that you would not love them anymore & .477 & .337 \\
\hline hope they wouldn't want to lose you & .425 & .218 \\
\hline $\begin{array}{l}\text { say their parents wouldn't love them } \\
\text { anymore (sex) }\end{array}$ & .050 & .713 \\
\hline hope they thought you would hurt them & -.131 & .699 \\
\hline $\begin{array}{l}\text { hope they thought you would get them in } \\
\text { trouble }\end{array}$ & .038 & .681 \\
\hline hope they thought it was their fault & .037 & .662 \\
\hline say people would think they are gay & -.037 & .573 \\
\hline hurt them as warning & -.098 & .524 \\
\hline $\begin{array}{l}\text { say you would tell on them about bad } \\
\text { behaviors }\end{array}$ & .312 & .493 \\
\hline take away love or affection as warning & .246 & .481 \\
\hline $\begin{array}{l}\text { say you would tell on them about their } \\
\text { sexual activity }\end{array}$ & .290 & .472 \\
\hline $\begin{array}{l}\text { hope their family didn't talk about sexual } \\
\text { things }\end{array}$ & .084 & .437 \\
\hline say they would get in trouble if they told & .346 & .366 \\
\hline $\begin{array}{l}\text { say their parents would not love them } \\
\text { anymore (told) }\end{array}$ & .142 & .366 \\
\hline
\end{tabular}


Figure 1.

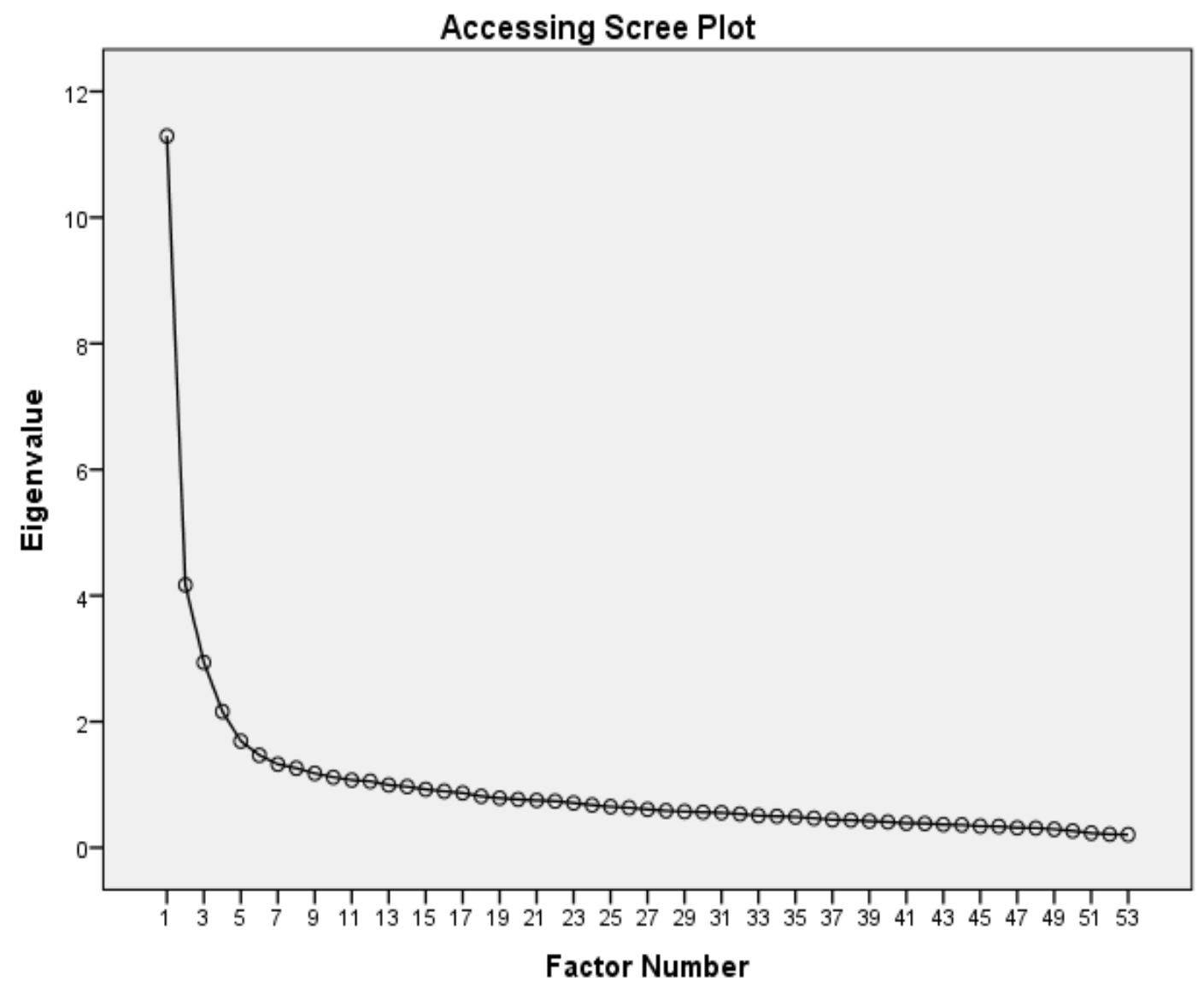


Figure 2.

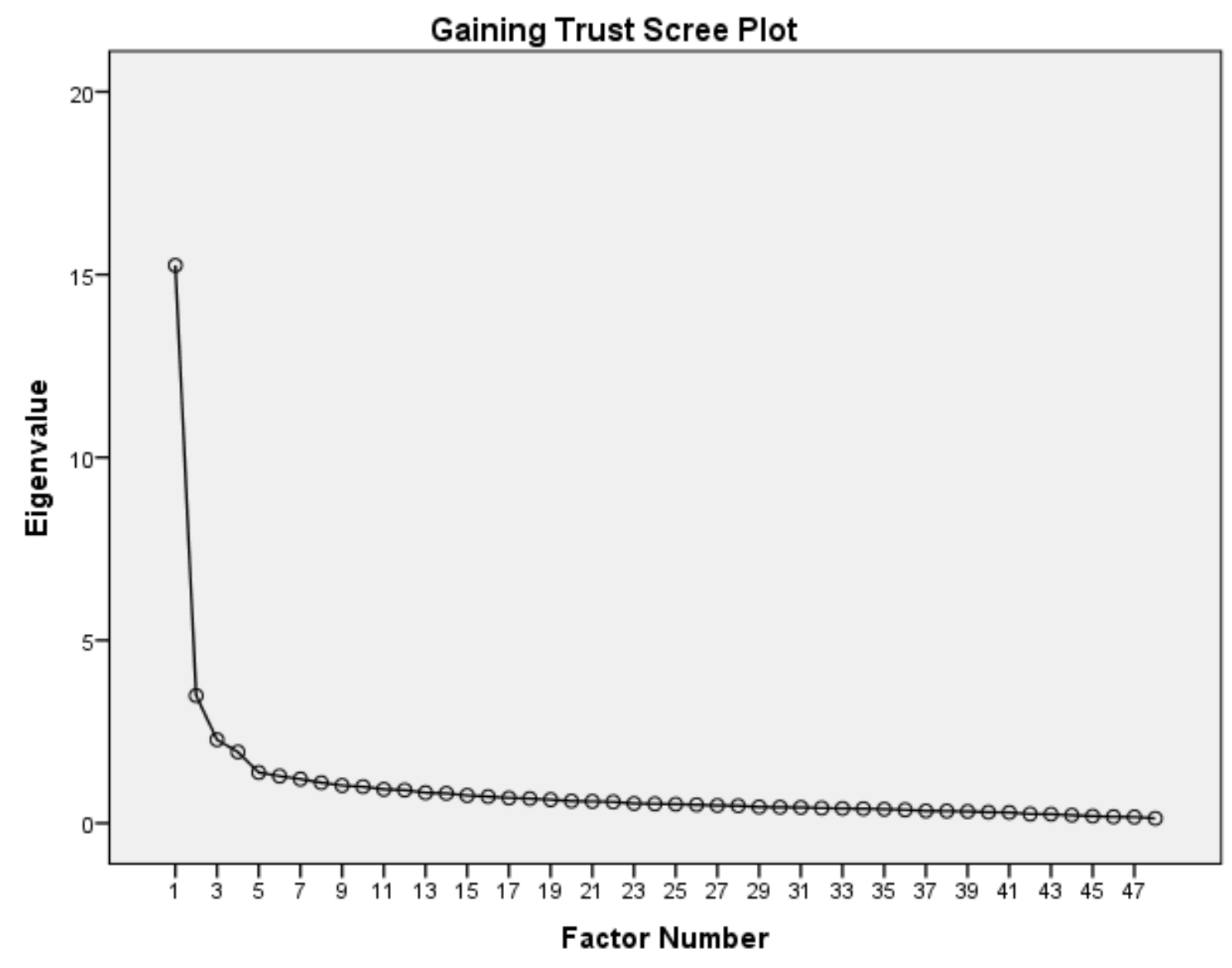


Figure 3.

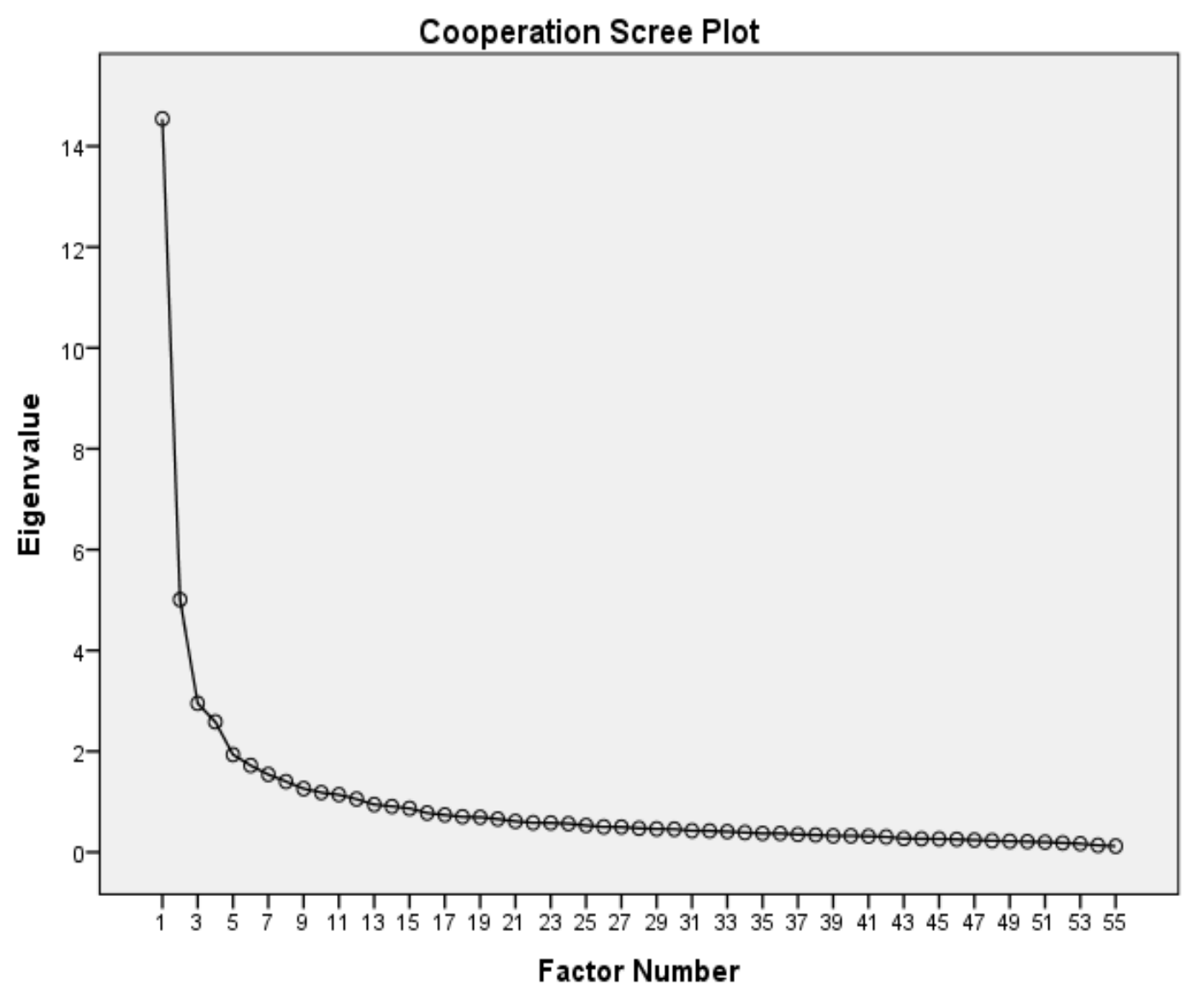


Figure 4.

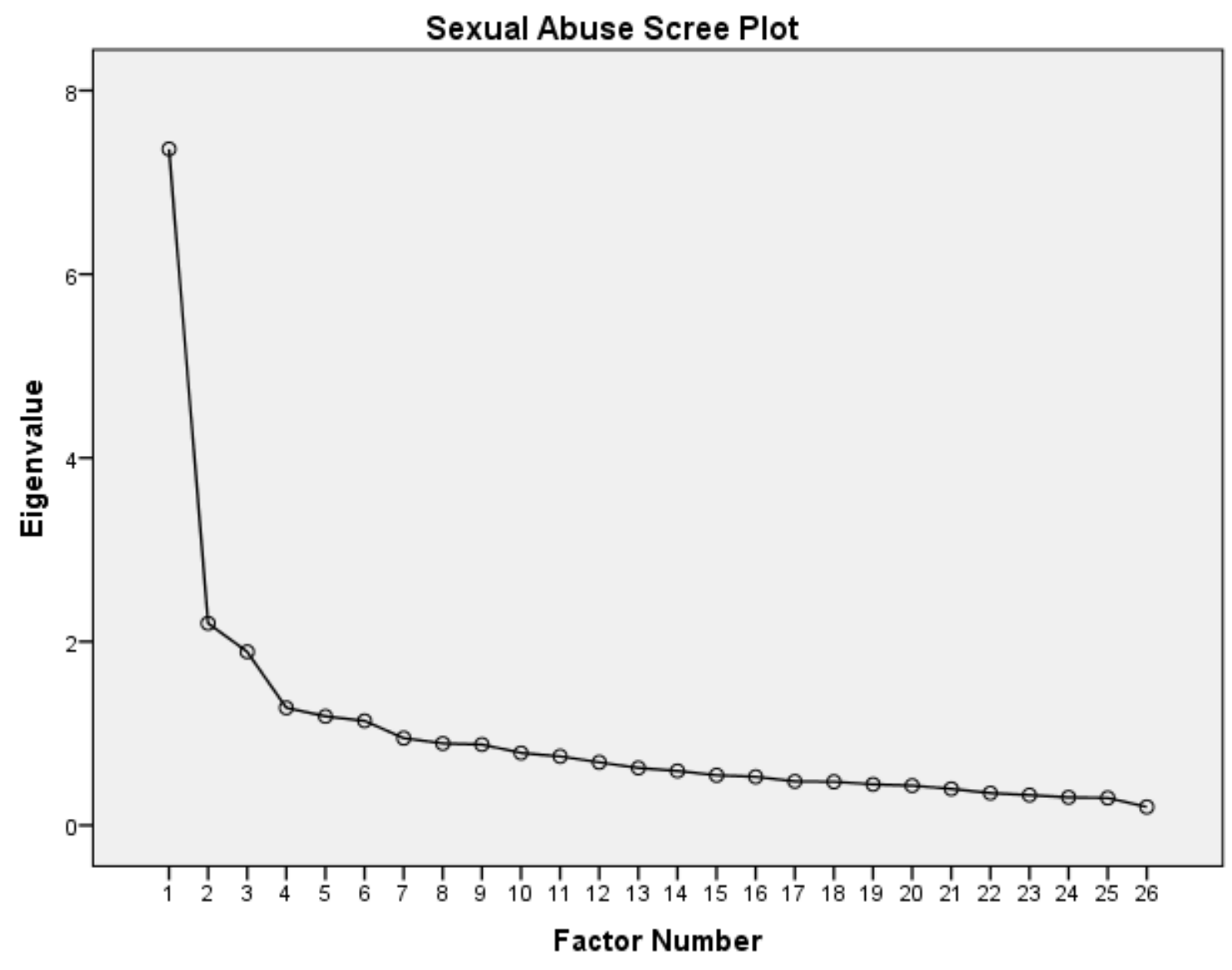


Figure 5.

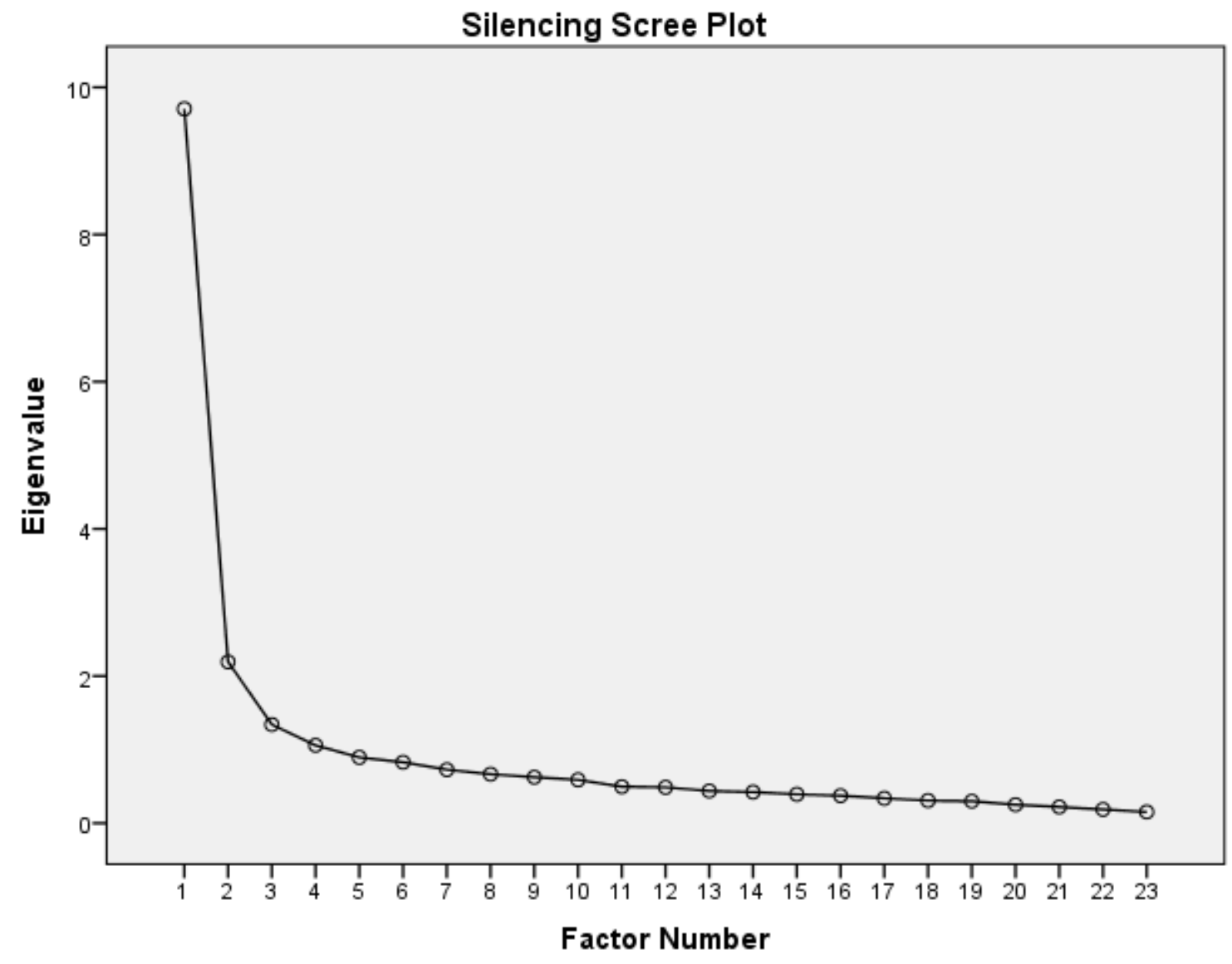




\section{References}

Akaike, H. (1974). A new look at the statistical model identification. IEEE transactions on automatic control, 19(6), 716-723.

Baker III, T. A., Connaughton, D. P., \& Zhang, J. J. (2010). An examination of immunity statutes regarding the liability of recreational youth sport organizations for the pedophilic actions of coaches, administrators, and officials. The ICHPER-SD Journal of Research in Health, Physical Education, Recreation, Sport \& Dance, 5(1), 54.

Beauregard, E., Rossmo, D. K., \& Proulx, J. (2007). A descriptive model of the hunting process of serial sex offenders: A rational choice perspective. Journal of Family Violence, 22(6), 449-463.

Bentler, P. M. (1990). Comparative fit indexes in structural models. Psychological bulletin, 107(2), 238.

Bentler, P. M., \& Bonett, D. G. (1980). Significance tests and goodness of fit in the analysis of covariance structures. Psychological bulletin, 88(3), 588.

Berliner, L., \& Conte, J. R. (1990). The process of victimization: The victims' perspective. Child abuse \& neglect, 14(1), 29-40.

Budin, L. E., \& Johnson, C. F. (1989). Sex abuse prevention programs: Offenders' attitudes about their efficacy. Child Abuse \& Neglect, 13(1), 77-87.

Butchart, A., Harvey, A. P., Mian, M., \& Furniss, T. (2006). Preventing child maltreatment: a guide to taking action and generating evidence.

Carr, A., Dooley, B., Fitzpatrick, M., Flanagan, E., Flanagan-Howard, R., \& Tierney, K. 
PREVENTION AND PERCEPTIONS

(2010). Adult adjustment of survivors of institutional child abuse in Ireland. Child Abuse \& Neglect, 34(7), 477-489.

Centers for Disease Control and Prevention (2004). Sexual violence prevention: beginning the dialogue. Atlanta, GA: Centers for Disease Control and Prevention; 2004.

Centers for Disease Control and Prevention, National Center for Injury Prevention and Control (2007). Preventing Child Sexual Abuse Within Youth-serving Organizations: Getting Started on Policies and Procedures.

Colton, M., Roberts, S., \& Vanstone, M. (2012). Learning lessons from men who have sexually abused children. The Howard Journal of Criminal Justice, 51(1), 79-93.

Conte, J. R., Wolf, S., \& Smith, T. (1989). What sexual offenders tell us about prevention strategies. Child abuse \& neglect, 13(2), 293-301.

Cornish, D. B. (1994). The procedural analysis of offending and its relevance for situational prevention. Crime prevention studies, 3, 151-196.

Cornish, D., \& Clarke, R. (1986). The reasoning criminal: Rational choice perspective on offending. New York: Springer.

Cornish, D. B., \& Clarke, R. V. (1987). Understanding crime displacement: An application of rational choice theory. Criminology, 25(4), 933-948.

Cornish, D. B., \& Clarke, R. V. (2002). Crime as a rational choice. Criminological Theories: Bridging the Past to the Future, 77-96.

Cornish, D. B., \& Clarke, R. V. (2003). Opportunities, precipitators and criminal 
PREVENTION AND PERCEPTIONS

decisions: A reply to Wortley's critique of situational crime prevention. Crime prevention studies, 16, 41-96.

Costello, Anna B. \& Jason Osborne (2005). Best practices in exploratory factor analysis: Four recommendations for getting the most from your analysis. Practical Assessment Research \& Evaluation, 10(7).

Cronbach, L. J. (1951). Coefficient alpha and the internal structure of tests. psychometrika, 16(3), 297-334.

Crosson-Tower, C. (2005). Extrafamilial sexual abuse, misuse and exploitation. Allyn \& Bacon/Longman.

Cuevas, C. A., Finkelhor, D., Clifford, C., Ormrod, R. K., \& Turner, H. A. (2010). Psychological distress as a risk factor for re-victimization in children. Child Abuse \& Neglect, 34(4), 235-243.

Cusson, M. (1993). Situational deterrence: Fear during the criminal event. Crime prevention studies, 1, 55-68.

Desai, S., Arias, I., Thompson, M. P., \& Basile, K. C. (2002). Childhood victimization and subsequent adult revictimization assessed in a nationally representative sample of women and men. Violence and victims, 17(6), 639-653.

De Souza, E., \& Miller, J. (2012). Homicide in the brazilian favela: Does opportunity make the killer?. British Journal of Criminology, 52(4), 786-807.

Elliott, I. A., \& Beech, A. R. (2009). Understanding online child pornography use: Applying sexual offense theory to internet offenders. Aggression and Violent Behavior, 14(3), 180-193. 
Fater, K., \& Mullaney, J. A. (2000). The lived experience of adult male survivors who allege childhood sexual abuse by clergy. Issues in Mental Health Nursing, 21(3), 281-295.

Firestone, P., Moulden, H. M., \& Wexler, A. F. (2009). Clerics who commit sexual offenses: Offender, offense, and victim characteristics. Journal of child sexual abuse, 18(4), 442-454.

Fischer, D. G., \& McDonald, W. L. (1998). Characteristics of intrafamilial and extrafamilial child sexual abuse. Child Abuse \& Neglect, 22(9), 915-929.

Gönültaş, B. M., \& Sahin, B. (2016). Event locations in extra-familial child sexual molestation cases the istanbul example. International Journal of Offender Therapy and Comparative Criminology, $0306624 X 16673373$.

Gorsuch, R. L. (1990). Common factor analysis versus component analysis: Some well and little known facts. Multivariate Behavioral Research, 25(1), 33-39.

Groff, E. R. (2007). Simulation for theory testing and experimentation: An example using routine activity theory and street robbery. Journal of Quantitative Criminology, 23(2), 75-103.

Harris, J. A. (1995). Confirmatory factor analysis of the aggression questionnaire. Behaviour Research and Therapy, 33(8), 991-993.

Hu, L. T., \& Bentler, P. M. (1999). Cutoff criteria for fit indexes in covariance structure analysis: Conventional criteria versus new alternatives. Structural equation modeling: a multidisciplinary journal, 6(1), 1-55.

Isely, P.J., Isley, P., Freiburger, J. and McMackin, R. 2008. In their own voices: A 
PREVENTION AND PERCEPTIONS

qualitative study of men abused as children by catholic clergy. Journal of Child Sexual Abuse, 17(3-4): 201-215.

James, J., \& Proulx, J. (2016). The modus operandi of serial and nonserial sexual murderers: A systematic review. Aggression and Violent Behavior, 31, 200-218.

Kaiser, H. F. (1959). Computer program for varimax rotation in factor analysis. Educational and psychological measurement, 19(3), 413-420.

Kaufman, K. L. (1989). Modus operandi questionnaire. Children's Hospital, Columbus, Ohio.

Kaufman, K. L. (1994). Modus Operandi Questionnaire (revised version). Columbus, OH: Children's Hospital.

Kaufman, K. L., Wallace, A. M., Johnson, C. F., \& Reeder, M. L. (1995). Comparing female and male perpetrators' modus operandi: Victims' reports of sexual abuse. Journal of Interpersonal Violence, 10(3), 322-333.

Kaufman, K., Hilliker, D., \& Daleiden, E. (November, 1995). Clinical applications of the Adolescent Modus Operandi Questionnaire. Fourteenth Annual Research \& Treatment Conference of The Association for the Treatment of Sexual Abusers. New Orleans, LA.

Kaufman, K., \& Daleiden, E. (July, 1995). Assessing adolescent sexual offenders' modus operandi: An approach to enhancing treatment planning. Texas Council on $\underline{\text { Sex Offender Treatment Annual Conference. Austin, TX. }}$

Kaufman, K. \& Uncapher, S. (June, 1995). Enhancing treatment planning through the assessment of adolescent sex offenders' Modus Operandi. State-wide 
PREVENTION AND PERCEPTIONS

"Reclaim Ohio" Conference, Department of Youth Services. Columbus, OH.

Kaufman, K., Daleiden, E., Hilliker, D., \& Wallace, A. (June, 1995). Assessing

adolescent sexual offenders' "Modus Operandi". Annual meeting of the American Professional Society on the Abuse of Children. Tucson, AZ.

Kaufman, K. L., Hilliker, D. R., \& Daleiden, E. L. (1996). Subgroup differences in the modus operandi of adolescent sexual offenders. Child Maltreatment, 1(1), 17-24.

Kaufman, K.L., McCrady., F., Homlberg, J., Rotzien, A., Orts, K., \& Hilliker, E. (1997). Factor structure of the behaviors of offenders as measured by the modus operandi questionnaire. Poster session presented at the $16^{\text {th }}$ Annual Research and Treatment Conference of The Association for the Treatment of Sexual Abusers, Arlington, VA.

Kaufman, K. L., Holmberg, J. K., Orts, K. A., McCrady, F. E., Rotzien, A. L., Daleiden, E. L., \& Hilliker, D. R. (1998). Factors influencing sexual offenders' modus o perandi: An examination of victim-offender relatedness and age. Child Maltreatment, 3(4), 349-361.

Kaufman, K. L., Mosher, H., Carter, M., \& Estes, L. (2006). Empirically based situational prevention model for child sexual abuse (From Situational Prevention of Child Sexual Abuse, P 101-144, 2006, Richard Wortley and Stephen Smallbone, eds.--See NCJ-215297).

Kaufman, K., Hayes, A., \& Knox, L. A. (2010). The situational prevention model: Creating safer environments for children and adolescents.

Kline, R. B. (2011). Principles and practice of structural equation modeling. New 
PREVENTION AND PERCEPTIONS

York: Guilford Press Google Scholar.

Kloess, J. A., Seymour-Smith, S., Hamilton-Giachritsis, C. E., Long, M. L., Shipley, D., \& Beech, A. R. (2015). A Qualitative analysis of offenders' modus operandi in sexually exploitative interactions with children online. Sexual abuse: a journal of research and treatment, 1079063215612442.

Lacoste, J., \& Tremblay, P. (2003). Crime and innovation: A script analysis of patterns in check forgery. Crime prevention studies, 16, 169-196.

Lang, R. A., \& Frenzel, R. R. (1988). How sex offenders lure children. Annals of Sex Research, 1(2), 303-317.

McGrath, R. J., Lasher, M. P., Cumming, G. F., Langton, C. M., \& Hoke, S. E. (2014). Development of vermont assessment of sex offender risk-2 (VASOR-2) Reoffense Risk Scale. Sexual Abuse, 26(3), 271-290.

Leclerc, B., \& Cale, J. (2015). Weapon use and sexual abuse outcomes: A multivariate and conjunctive analysis of sexual offenses against women. Security Journal, 28(1), 54-70.

Leclerc, B., Carpentier, J., \& Proulx, J. (2006). Strategies adopted by sexual offenders to involve children in sexual activity. In R. Wortley \& S. Smallbone (Eds.), Situational prevention of child sexual abuseCrime Prevention Studies, Vol. 19. (pp. 251-270). Monsey, N.Y.: Criminal Justice Press.

Leclerc, B., Proulx, J., \& Beauregard, E. (2009). Examining the modus operandi of sexual offenders against children and its practical implications. Aggression and violent behavior, 14(1), 5-12. 
Leclerc, B., Proulx, J., \& McKibben, A. (2005). Modus operandi of sexual offenders working or doing voluntary work with children and adolescents. Journal of Sexual Aggression, 11(2), 187-195.

Leclerc, B., Smallbone, S., \& Wortley, R. (2015). Prevention nearby: The influence of the presence of a potential guardian on the severity of child sexual abuse. Sexual Abuse, 27(2), 189-204.

Leclerc, B., Wortley, R., \& Smallbone, S. (2010). An exploratory study of victim resistance in child sexual abuse: Offender modus operandi and victim characteristics. Sexual Abuse, 22(1), 25-41.

Leclerc, B., \& Felson, M. (2016). Routine activities preceding adolescent sexual abuse of younger children. Sexual Abuse, 28(2), 116-131.

Leclerc, B., \& Wortley, R. (2015). Predictors of victim disclosure in child sexual abuse: Additional evidence from a sample of incarcerated adult sex offenders. Child abuse \& neglect, 43, 104-111.

Mannon, J. 1997. Domestic and Intimate Violence: An application of routine activities theory. Aggression and Violent Behavior 2(1):9-24.

Marques, J. K., Wiederanders, M., Day, D. M., Nelson, C., \& Van Ommeren, A. (2005). Effects of a relapse prevention program on sexual recidivism: Final results from California's Sex Offender Treatment and Evaluation Project (SOTEP). Sexual Abuse: A Journal of Research and Treatment, 17(1), 79-107.

McDonald, R. P. (1978). Generalizability in factorable domains: "Domain validity and generalizability.” Educational and Psychological Measurement, 38, 75-79. 
Pereda, N., Guilera, G., Forns, M., \&amp; Gómez-Benito, J. (2009). The prevalence of child sexual abuse in community and student samples: A meta-analysis. Clinical psychology review, 29(4), 328-338.

Pratt, T.C. (2008). Rational choice theory, crime control policy, and criminological relevance. Criminology \& Public Policy, 7(1), 43-52

Rebocho, M. F., \& Gonçalves, R. A. (2012). Sexual predators and prey: A comparative study of the hunting behavior of rapists and child molesters. Journal of interpersonal violence, 27(14), 2770-2789.

Reynald, D. M., \& Elffers, H. (2009). The future of newman's defensible space theory linking defensible space and the routine activities of place. European Journal of Criminology, 6(1), 25-46.

Schreck, C. J., \& Fisher, B. S. (2004). Specifying the influence of family and peers on violent victimization extending routine activities and lifestyles theories. Journal of interpersonal violence, 19(9), 1021-1041.

Shakeshaft, C. (2004). Educator sexual misconduct: A synthesis of existing literature. PPSS 2004-09. US Department of Education.

Smallbone, S., \& Wortley, R. K. (2000). Child sexual abuse in Queensland: Offender characteristics and modus operandi. Brisbane: Queensland Crime Commission and Queensland Police Service.

Steiger, J. H., \& Lind, J. C. (1980). Statistically based tests for the number of common factors. In annual meeting of the Psychometric Society, Iowa City, IA (Vol. 758, pp. 424-453). 
PREVENTION AND PERCEPTIONS

Sullivan, J. Beech. AR, Craig, LE, \& Gannon, TA (2010). Comparing intra-familial and extra-familial child sexual abusers with professionals who have sexually abused children with whom they work. International Journal of Offender Therapy and Comparative Criminology.

Tabachnick, B. G., Fidell, L. S., \& Osterlind, S. J. (2001). Using multivariate statistics.

Thorndike, R. M., Cunningham, G. K., Thorndike, R. L., \& Hagan, E. P. (1991). Measurement and evaluation in psychology and education (5th ed.). New York: Macmillan.

Tofte, S., \& Fellner, J. (2007). No Easy Answers: Sex Offender Laws in the US (Vol. 19, No. 4). Human Rights Watch.

Uliando, A., \& Mellor, D. (2012). Maltreatment of children in out-of-home care: A review of associated factors and outcomes. Children and youth services review, 34(12), 2280-2286.

Van Gijn, E. L., \& Lamb, M. E. (2013). Alleged sex abuse victims' accounts of their abusers' modus operandi. Journal of Forensic Social Work, 3(2), 133-149.

Van Prooijen, J. W., \& Van Der Kloot, W. A. (2001). Confirmatory analysis of exploratively obtained factor structures. Educational and Psychological Measurement, 61(5), 777-792.

Veneziano, C., Veneziano, L., \& LeGrand, S. (2000). The relationship between adolescent sex offender behaviors and victim characteristics with prior victimization. Journal of Interpersonal Violence, 15(4), 363-374.

Wijkman, M., Bijleveld, C., \& Hendriks, J. (2014). Juvenile female sex offenders: 
Offender and offence characteristics. European journal of criminology, 11(1), 2338.

Wolfe, D. A., Francis, K. J., \& Straatman, A. L. (2006). Child abuse in religiouslyaffiliated institutions: Long-term impact on men's mental health. Child Abuse \& Neglect, 30(2), 205-212.

Wolfe, D. A., Jaffe, P. G., Jetté, J. L., \& Poisson, S. E. (2003). The impact of child abuse in community institutions and organizations: Advancing professional and scientific understanding. Clinical Psychology: Science and Practice, 10(2), 179191.

Wortley, R. (2001). A classification of techniques for controlling situational precipitators of crime. Security Journal, 14(4), 63-82.

Wyatt, G. E., \& Peters, S. D. (1986). Issues in the definition of child sexual abuse in prevalence research. Child abuse \& neglect, 10(2), 231-240.

Yar, M. (2005). The novelty of 'cybercrime': An assessment in light of routine activity theory. European Journal of Criminology, 2(4), 407-427.

Zinbarg, R. E., Revelle, W., Yovel, I., \& Li, W. (2005). Cronbach's $\alpha$, Revelle's $\beta$, and McDonald's $\omega \mathrm{H}$ : Their relations with each other and two alternative conceptualizations of reliability. psychometrika, 70(1), 123-133. 
PREVENTION AND PERCEPTIONS

Chapter III. The relationship between policy, media, and perceptions of sexual offenders between 2007 and 2017: A review of the literature

Note. Previously published at the following citation.

Zatkin, J., Sitney, M., \& Kaufman, K. The relationship between policy, media, and perceptions of sexual offenders between 2007 and 2017: A review of the literature. Trauma, Violence, \& Abuse.

\begin{abstract}
Sexual violence is a prominent social problem that harms many victims every year. Perpetrators of these crimes tend to exist in a binary. Some are convicted by the criminal justice system, where they face sanctions such as jail time and registration and are demonized by society. Others never face any sanctions for harm caused and are exonerated for their actions. This review examines public perceptions of sexual offenders in the United States through the institutional level constructs of federal policy, media, and institutional myths. A review of the literature on this topic from 2007-2017 produced 37 relevant articles, which were placed into three categories using thematic analysis: 1. Perceptions about sexual offenders and perceiver differences; 2. Media about sexual offending and effects of media consumption on perceptions of offenders, and; 3 . Support for offender policies and effects of policy on perceptions of offenders. A review of these topics reveals that there are prominent institutional myths about sexual offending. A cyclical relationship is formed, where media perpetuates institutional myths, myths drive policy, and policy leads to media reporting.
\end{abstract}




\section{Introduction}

Sexual violence is a significant societal problem that adversely impacts many of its victims. In the United States, approximately $18 \%$ of adult women survived an attempted or completed rape (Black et al., 2011). The statistics are similar when considering child sexual abuse (CSA; Butchart et al., 2006). Globally, one meta-analysis reveals that between eight and $31 \%$ of girls and three to $17 \%$ of boys are sexually abused prior to turning 18 (Barth et al., 2013). According to statistics cited by the Rape, Abuse, and Incest National Network (RAINN), those who perpetrate sexual abuse are commonly men, with $85 \%$ over the age of 18 at the time of their offense (DOJ, 2013). Most perpetrators know their victims, with only $28 \%$ of rapes perpetrated by a stranger, and only 7\% of CSA cases committed by a stranger (DOJ, 2015). While sexual assault and rape are inherently violent crimes, only $11 \%$ of perpetrators use a weapon to facilitate their offense (DOJ, 2013). Though some convicted for a sexual offense go on to recidivate sexually, many do not. Harris and Hanson (2004) demonstrate that only about $24 \%$ of sexual offenders recidivate over the 15 -year period following their initial offense by committing another sexual crime. While recidivism rates are higher for offenders who are deemed to be higher risk post-treatment (Hanson \& Morton-Bourgon, 2005), treatment can be an immense help, and many offenders do desist (Willis et al., 2010).

At the same time, however, only 310 out of every 1,000 rapes are reported to the criminal justice system, with only 57 reports leading to an arrest (DOJ, 2015). For the majority of offenders, this contradiction leads to two realities. First, that those sexual offenders who face the criminal justice system must deal with extreme sanctions that can 
make living a normal life after conviction impossible. Second, that most sexual offenders never face any sanctions. This creates a binary, in which sexual offenders either completely avoid detection or are caught, tried, and demonized, with very little in between. This article will explore perceptions of sexual offenders and offending through the lens of institutional myths, policies, and media coverage. It will examine the role of these factors in leading to these binary outcomes of sexual offenders as either demonized or escaping sanctions all together. One such factor is the current laws and policies regarding sexual offending in the United States.

United States Sex Offender Policies. In the 1990's, the United States began to pass both state and federal policies that were tough on sexual crime and sexual offenders. New laws included innovative sanctions, which included chemical castration, electronic tracking and monitoring of convicted offenders, and updated registration requirements (Sample \& Kadleck, 2008). Of note, three of the most famous and punitive of the sex offender laws established during this time were inspired by a brutal and violent sexual murder of Jacob Wetterling, an 11-year-old child from Minnesota. The Jacob Wetterling Act passed in 1994 and was in response to Jacob's 1989 abduction, rape, and murder. This federal law established the sex offender registration system that currently exists in the United States and requires compliance by all states (Jacob Wetterling Act, 1994). While the Jacob Wetterling Act did not require states to make their registries public, an amendment called Megan's Law, which passed in 1996, did so. Megan's Law was named for Megan Kanka, a seven-year old girl in New Jersey who was raped and murdered in 1994 by a neighbor with two previous sex offense convictions. At the 
federal level, Megan's law requires the registration records kept by state law enforcement to be made public, and easily accessible to the community. Finally, the Adam Walsh Act was passed in response to the abduction and murder of a six-year-old Florida child. This act mandated that serious sex offenders aged 14 and older be required to register for life and update the government as to their location four times per year. The Adam Walsh Act also made failure to register as a sexual offender a felony, which can lead to further sanctions (Adam Walsh Act, 2006).

While sex crime legislation in the U.S. is clearly more complex than these three particular laws, they do comprise the foundation for the community-based supervision of sex offenders in the U.S. Other types of sanctions, such as residency and employment restrictions, also present significant challenges to sex offenders' ability to reintegrate into the community following incarceration. Further, since these laws can sometimes trigger community notification, they can also lead to vigilantism, and harsh community environments for sexual offenders (Schiavone \& Jeglic, 2009). While legislation differs internationally, countries such as Australia, New Zealand, and the United Kingdom have similarly restrictive laws for convicted sexual offenders (Harper \& Hogue, 2014; Thakker, 2012; Willis et al., 2013). The goal of these laws is to prevent sexual crime, which is an important and admirable aim. However, there has not been evidence to demonstrate that these laws are in any way effective in preventing sex crimes (Levenson et al., 2007; Koon-Magnin, 2015). In fact, quite the contrary, there is evidence to demonstrate that the consequence of these laws has been to increase offenders' rates of recidivism, due to the harsh restrictions in place (Willis, Levenson. \& Ward, 2010). 
PREVENTION AND PERCEPTIONS

Mass Media. Another historical factor significant to the public's perceptions of sex offenders is the mass media, which has covered landmark sexual crime cases. Two of the most prominent examples of cases that have impacted public perceptions of sexual violence in the United States include the large number of cases involving the Catholic Church, as well as the Jerry Sandusky and Penn State University case (Cheit et al., 2009). The extent of child sexual abuse linked to the Catholic Church was first uncovered by the Boston Globe in 2002 in a series of investigative articles. The paper reported that the Church was systematically covering-up the sexual abuse of more than 1,000 child victims by more than 300 priests over three decades. This scandal received widespread national media coverage and was the subject of a more recent Oscar winning Best Picture, "Spotlight." The second case focused on long-standing child sexual abuse perpetrated by Jerry Sandusky. Jerry Sandusky was a former Penn State Football coach who had been using his power, resources, and charity work to sexually abuse young boys for decades, often on Penn State property (Freeh, 2012). The case was reported in 2011, and evidence indicated that Penn State staff and administrators knew about the abuse and covered it up to protect the University (Freeh, 2012). While these cases are most notable and garnered international as well as U.S. publicity, many other cases internationally helped define how individuals who sexually offend are perceived and discussed in public discourse (e.g., Sir Jimmy Savile [UK], Dr. Miles Bradbury, Brother Kostka Chute [UK]; Erooga et al., 2019).

\section{Review Scope and Goals}


It is evident that sexual violence is a widespread societal problem that can lead to adverse consequences for survivors and their communities. It is therefore important that policies exist to prevent victimization. The policies that do exist to punish those who sexually offend and to prevent recidivism are widely supported by the public. However, these policies are not effective in stopping sexual crimes from happening and may in fact promote recidivism (Levenson et al., 2007; Koon-Magnin, 2015).

Existing policies are largely ineffective, as they were created in response to extreme, horrific sexual violence cases that are not representative of the norm. These policies are rooted in a number of institutionalized myths that do not reflect the reality of sexual offending in the United States. To further examine the reality of sexual violence perpetration, this literature review will aim to answer the following research questions:

1. What is the relationship between media, public policy, and public perceptions of sexual offenders and offending?

2. What are the most prevalent and impactful institutional myths about sexual offenders and offending that influence perceptions of sexual offenders?

\section{Methods}

A systematic search was conducted using Google Scholar and the PsychInfo database. The following combinations of search terms were utilized to guide the review of the literature and included: (1) perceptions + sex offender, (2) public attitudes + sex offender, (3) public policy + sex offender + perception, and (4) media + sex offender + perception. Each search was first done on PsychInfo, followed by a Google Scholar search. In all, a total of eight searches. 
To best define the area of interest, literature for this paper was bounded by a number of inclusion criteria. First, all articles had to meet the standards of empirical peerreview. Second, only literature published after 2006 was included in the review, as this was the year that defined a new period of sex offender legislation in the United States (i.e., the year that the Adam Walsh Act was implemented). Third, literature published after 2017 was excluded, as the \#MeToo movement ushered in a new layer of conversation around sexual violence. Fourth, articles were included if their central focus pertained to public perceptions, policies, or media surrounding sexual offenses.

Articles in the "public perceptions" category included a focus on institutional myths, demographic differences in perceiver opinions, and community attitudes toward sexual offenders. Articles included in the "public policy" category relate to how individuals support policies such as registration, notification, residency restrictions, and other sex offender sanctions or punishments. Finally, articles included in the "media" category examined how sexual offenders and offenses are described in the media, or how media influences perceptions of offenders.

A number of exclusion criteria also helped focus the scope of this review. Articles were excluded if they: (1) only related to a specific type of offender or perceiver (e.g. juvenile offenders; homicidal offender); (2) only related to perceptions by specific groups (e.g. clinicians, prison guards); or (3) only tangentially concerned institutional level perceptions of sexual offenders (e.g. negative mental health ramifications of sex offender policy on sexual offenders). 
The initial eight searches identified 241 potential articles. Once duplicates were removed, 182 articles remained. The abstracts for each of these articles were reviewed to determine their eligibility for inclusion. This step eliminated 144 out-of-scope articles, yielding 38 articles. Upon closer examination, it was noted that two of the 38 articles used the same data and methodology, so one of the two was removed. This resulted in a total of 37 articles to be included in the review. Each of the articles was then read in depth and placed into one of three main categories based on its primary main purpose, thesis, or research question: General Sex Offender Perceptions, Public Policy, or Media. As overlap existed between the three focus areas, a qualitative coding scheme was created to place main findings from each of the 37 articles into a sub-category within the three main areas.

The 37 included articles were read in depth, and a summary paragraph was written by the first author. Summary paragraphs included the methodology of the article, and key results. These summary paragraphs were then qualitatively analyzed using a grounded-theory approach (Charmaz, 2006) by the first author, and a set of codes was created to help further define the three main areas of interest (Table 1). Using these codes, articles were placed into one of three main categories based on the main purpose, thesis, or research question of the article: General Perceptions, Public Policy, or Media. Overlap existed between the three main areas, for example, an article about general perceptions about offenders may also look at perceptions of registration, a policy. When overlap existed, the first author used the article's main finding or theme to determine fit. 


\section{Results}

This section will cover main themes that were found throughout the literature review. Tables 2-4 show the sample, country of origin, key points, and analytical method for all reviewed articles. A summary of responses to the main research questions can be found on Table 5 .

\section{Perceptions of Sexual Offenders}

Twelve of the articles pertained primarily to general perceptions of sexual offenders and offending. These articles reflect information regarding institutional myths about offenders, as well as details on differences in perceptions of those who offend based on perceiver demographics.

Institutional Myths. Institutional myths are defined as incorrect widespread beliefs that dictate the way in which the public perceives offenders. Four institutional myths were identified by the twelve articles in this section of the paper.

The first myth, the stranger danger, myth reflects the idea that most perpetrators

of sexual violence do not know their victims, and instead target random strangers (Craun $\&$ Theriot, 2009). This myth appears to be more prevalent with child sexual abuse, with $43 \%$ of one sample believing that those who abuse children find their victims at public locations, such as parks or school playgrounds (Katz-Schiavone et al., 2008). However, these studies also show that a portion of the population is aware that stranger danger is a myth. In one study, $56.7 \%$ of participants were equally concerned about strangers, acquaintances, and well-known individuals committing child sexual abuse (Craun \& Theriot, 2009). This result was replicated in other studies, which demonstrated that the 
majority of individuals were aware that most survivors of sexual assault, including child survivors, were victimized by someone that they knew.

(Katz-Schiavone et al., 2008; Levenson et al., 2007).

The second myth identified, crime on the rise, suggests that sex crimes are becoming more common and that men who commit sex crimes are more dangerous than other types of offenders. Supporting belief in this myth, one study reported that $77 \%$ of their sample perceives sexual offending as on the rise and $68 \%$ believed that sexual offenders recidivate at a higher rate than other types of criminals (Levenson et al., 2007). This study was replicated in 2015 with similar results, demonstrating that this myth has remained consistent over time (Koon-Magnin, 2015). Further, a belief that sex crimes have increased over the last 20 years is positively and significantly correlated with the perception of risk related to registered sexual offenders (Socia \& Harris, 2016). As children are often considered to be especially vulnerable, this myth is particularly relevant for perceptions of child sexual abuse. In fact, one study examined the relationship between three salient types of beliefs about sexual offenders (i.e., sexual offenders generally target women, sexual offenders target children, sexual offenders target strangers), and used these beliefs to predict other perceptions of sex offenders (Mancini \& Pickett, 2016). Study findings indicated that the belief that offenders often target children predicts the perception that offenders cannot reform and that victims cannot recover. In contrast, the other two offender types (female victims and stranger victims) did not predict other offender perceptions. These findings suggest that those who believe most sexual abuse victims are children have more extreme and negative 
views about sexual offenders (Mancini \& Pickett, 2016). In fact, while people show a significant level of fear toward all sexual offenders, the greatest fears are toward pedophiles and individuals who commit incest (Kernsmith et al., 2009).

The third myth, offender homogeneity, suggests that all sexual offenders make up a homogenous group of "specialist" criminals (Galeste et al., 2012). A factor analysis conducted on a measure of fear of those who sexually offend produced a one-factor solution, demonstrating that fear exists at high levels for offenders despite their crime type (Kernsmith et al., 2009). Another prominent aspect of the homogeneity myth is that all offenders have histories of being sexually victimized or are mentally ill, which predisposes them to sexually abusing others (Levenson et al., 2007; Mancini \& Pickett, 2016). One study examined the effects of using the term "sexual offender" or "juvenile sexual offender" in comparison to more neutral terms, such as "person who has committed a sexual crime" (Harris \& Socia, 2016). The rationale for this finding suggests that the term "sexual offender" may conjure images of the most dangerous and violent sex offenders independent of the facts of any particular case, which may skew perceptions of all such offenders. Further, results indicate that those who saw the term "sex offender" were more supportive of internet registries, residency restrictions, and social media bans for offenders. The authors point out that those in the experimental condition, who saw the term "sex offender" were more likely to select "strongly agree," indicating that the term "sex offender" adds strength and certainty to support of restrictive offender policies. 
Finally, the unreformable myth suggests that sexual offenders always recidivate at high rates, and that treatment is useless and ineffective (Galeste et al., 2012). In reality, only about $24 \%$ of all sexual offenders recidivate by committing another sexual crime (Katz-Schiavone et al., 2008). Further, treatment has been shown to lower recidivism rates (Willis et al., 2010). One study demonstrated that $98 \%$ of their sample believed that most sexual offenders reoffend and two-thirds of the sample believed that treatment was ineffective (Katz-Schiavone et al., 2008). These results were replicated with other samples, revealing that individuals believe that $74 \%$ of rapists and $76 \%$ of child sexual abusers recidivate, with half of participants believing that treatment is ineffective in preventing recidivism (Levenson et al., 2007; Koon-Magnin, 2015). When asked directly about treatment, studies indicated that many believe it is too costly, a waste of time and money, and that treatment could only be successful if offenders truly wanted to change (Katz-Schiavone et al., 2008; Thakker, 2012). This myth is especially important since it is so pervasive and because those who believe that offenders are unreformable are especially punitive toward offenders (Pickett et al., 2013).

Perceiver Demographic Differences. Attitudes toward sexual offenders are generally quite negative (Klein, 2015; Willis et al., 2013), however, there are some demographic differences that consistently affect how perceivers feel about offenders. The largest difference in the literature is by gender, with more negative beliefs about offenders held by females than males (Bergstrom et al., 2017; Willis et al., 2013). Specifically, females show significantly higher levels of fear toward offenders than do males (Kernsmith et al., 2009; Koon-Magnin, 2015). Women also estimate offender 
recidivism rates significantly more highly than men (Brown, Deakin \& Spencer, 2008), assign higher levels of risk to registered offenders (Socia \& Harris, 2016), and are more punitive toward offenders (King \& Roberts, 2015).

Parental status can also have an effect on offender attitudes, with parents being more likely to believe offenders cannot change and that they are dangerous (Klein, 2015). Many studies show that less formal education is also positively correlated with negative attitudes about offenders (King \& Roberts, 2015; Shackley et al., 2014; Socia \& Harris, 2016; Willis et al., 2013), although with one study found that individuals with higher levels of education responded more negatively to offenders (Bergstrom et al., 2017). Another study looked at how the Big Five Personality Characteristics (McCrae \& Costa, 1999) predicted attitudes toward offenders and found that those high in Openness to Experience or Agreeableness were significantly more likely to believe in rehabilitation, with those high in Extraversion having more negative attitudes about offenders (Olver \& Barlow, 2010). Finally, and importantly, a study measuring belief in prominent sex offender myths found no significant demographic-based differences (Katz-Schiavone et al., 2008). This indicates that while there are some demographic differences related to how negatively individuals perceive offenders, the majority of society has highly negative perceptions, and buys into many institutional myths about offenders.

\section{Media and Perceptions of Sexual Offenders}

Media coverage of sexual crimes is an important factor that shapes how society perceives sexual offenders and their crimes. The news media has been criticized for perpetuating an atypical, violent view of sex crimes, which can lead to a public call for 
restrictive and ineffective offender policies. However, it is unclear whether the media perpetuates panic about offenders or responds to existing public panic about offenders. This section includes nine articles that address how sexual crimes and sexual offenders are portrayed in the news media, as well as the literature about the effects that news media exposure has on perceptions of sexual offenders.

Sexual Crime News Coverage. Three articles included in the review relied on a content analysis methodology to provide a broad picture of how sexual violence is portrayed in the United States media. The first of these examined how magazines covered child sexual abuse from 1992-2004. Analyses indicate that most years had little coverage of CSA, with spikes in 1993 and 2002. The spike in 2002 was due to the sexual abuse scandal in the Catholic Church, and this topic dominated the news $(n=45)$. Closely following were articles about celebrities $(\mathrm{n}=31)$. All but four of the articles contained at least one of the coded "newsworthiness" factors, with 45 articles identified as containing factors that deemed the story worthy of reporting to the public. This study suggests that magazine coverage of child sexual abuse is dominated by sensational cases and reporting (Cheit et al., 2009).

The next media content analysis examined institutional sexual offender myths present in print media, and in what context those myths are presented. Results indicate that media tends to report more on child victims than older victims and focus more on violent crimes, such as rape or assault. Registration was the most commonly discussed policy ( $45.1 \%$ of articles) and effectiveness of policy was only discussed in $15.5 \%$ of the articles. About one-third of the articles included at least one sex offender myth, with 
offender homogeneity being most common. Within articles that presented the recidivism myth, $82.6 \%$ were about child sexual abuse. Of articles where the homogeneity myth was present, about two-thirds also discussed sex crime policy. Lawmakers were likely to perpetuate the recidivism myth that sex offenders cannot be cured. This study reveals that the homogeneity and recidivism myths are both present in media discussion of abuse and are related to child sexual abuse and policy discussion (Galeste et al., 2012).

The third content analysis also centered on how child sexual abuse is portrayed in the media, with a focus on moving past national stories about prominent offenders to smaller, local stories in a time period where institutional cases did not take precedence. Results illustrate that most of the coverage ( $80 \%)$ was episodic, giving information about one specific crime as opposed to thematic, or about a variety of similar crimes. Common subjects included criminal justice (33\%), school setting (12\%), solutions (8\%) and incest (7\%). Articles were generally written in regard to a current criminal justice investigation (73\%). Of the stories that described a specific CSA incident, 74\% identified the victimoffender relationship. Here, $70 \%$ described a case where the victim knew the accuser, and in $29 \%$ was an authority figure. Only $4 \%$ of the reports focused on stranger assault. Most of the sample used vague language such as abuse or molestation, with $40 \%$ describing a hands-on sexual offense, and another $40 \%$ could not be described due to missing information from victims or perpetrators. Most victims (56\%) were female and about $33 \%$ were under the age of ten. Eighty-nine percent (89\%) of the offenders were male and $64 \%$ were adults. Articles generally described a "notable" feature of the CSA, such as multiple victims, violence, or an authority figure perpetrating the offense. This 
study shows that even non-sensationalized news stories typically include sensationalized aspects (Meija et al., 2012).

Case Specific Coverage. Some of the literature reviewed examines media coverage in relation to specific events. One study looks at how public interest in sex offenders and sex crimes shifted after the Adam Walsh Act was passed in 2006. This study demonstrated visually that a spike in utilization of the "sex offender" search term could be seen around the time of the passage of the Adam Walsh Act, but this trend did not reach statistical significance. However, the trend analysis was paired with a content analysis of USA Today articles, which did indicate that many more stories about sexual offenders were written around the time that the Adam Walsh Act was passed (Burchfield et al., 2014).

In the United Kingdom, the Jimmy Savile scandal has served as a major conversational point about sexual violence. Sir Jimmy Savile is known as the UK's most prolific sex offender, perpetrating against a large number of males and females across the age continuum (See Erooga, 2018 for more details). Harper and Hogue (2016) examined press coverage before and after the Savile scandal hit the news in 2012, finding that there was a significant increase in sex crime news coverage following the disclosure of Savile's crimes, overrepresented by 10 in a 2012 sample of news articles and by 22.5 in a 2013 sample. Interestingly, it was also found that post-Savile news articles were qualitatively less angry and negative in tone (Harper \& Hogue, 2016). Another study examined how high-profile cases of sexual offending guide British public discourse about sex crimes. A sample of 148 articles from Britain's ten most popular newspapers were 
PREVENTION AND PERCEPTIONS

collected for this study and a quantitative content analysis was performed. Only 62 separate cases were represented in these articles, with six cases being discussed in more than five articles. So, six cases made up 44 or $67 \%$ of the articles. Three of the offenders in these articles were immigrants, one was a female teacher, and two were celebrities (Savile and Stuart Hall). Three of the perpetrators abused child victims.

Media Coverage and Prevention. There has been minimal discussion about prevention in media coverage discussed in the literature, all of which is focused on child sexual abuse prevention. The content analysis conducted by Meija and colleagues (2012) also analyzed articles to determine if they included prevention solutions, finding that $30 \%$ of the articles discussed prevention in some capacity. Eighty two percent $(82 \%)$ of the articles provided suggestions for intervention, and $18 \%$ for prevention. Environmental interventions called for more criminal justice presence, and many of the proposed interventions were aimed at addressing individual perpetrators. The prevention solutions mostly included education (9\%), while only seven articles suggested policy intervention (Meija et al., 2012). A content analysis conducted by Weatherred (2017) focused on how the news media attributed responsibility for CSA and how prevention solutions were discussed. This study found that over time there has been a shift in responsibility attribution from the individual to the institutional level, meaning that the news has been putting less blame on individual perpetrators and more blame on institutions. However, when solutions were posed, individual-level solutions that are rooted in sex offender myths are still most frequently cited as best practices (Weatherred, 2017). 
PREVENTION AND PERCEPTIONS

Effects of Media on Sex Offender Perceptions. A few studies included in this review focused on how news media consumption interacts with attitudes and perceptions of sexual offenders. In one British study, half of the sample assumed that media underreported or accurately reported sex crime stories. A majority of this same sample assumed that the media either exaggerates or accurately reports personal risk of victimization. This finding provides support for the crime on the rise myth, where people believe crime in general is higher than it is but underestimate their own risk. This study also found that public attitudes mirror those in the media (Brown et al., 2008). Another study with a New Zealand-based sample demonstrated that focus group participants identified the media as their most important resource for information about sexual offenders. However, this sample also expressed skepticism about the way media portrays sex crimes, wondering if news coverage was always accurate (Thakker, 2012).

Other studies have explored the effects of different types of media coverage on perceptions of offenders. In one case, a study demonstrated that tabloids use more sensational and offensive descriptors for offenders than newspapers. In response to this finding, a follow-up study was conducted to examine how readers of broadsheets (formal newspapers) and readers of tabloids respond differently to sexual offenders. Results indicated that tabloid readers both trust offenders significantly less and want more social distance from offenders than broadsheet readers. Additionally, tabloid readers have significantly more negative perceptions of sexual offenders in regard to sentencing and management, stereotype endorsement, and risk perception than broadsheet readers (Harper \& Hogue, 2016). 
A similar study was conducted in New Zealand investigating whether the framing of a news story has an effect on community attitudes toward sexual offenders. Participants were given either a "typical" fear-inducing report about sexual offenders, an informative media report, or no media report. Results show that participants in the informative report condition felt the least negatively toward sexual offenders and felt that they were less likely to recidivate compared to participants in either the fear or the control conditions. This finding reveals that overall, an informative media approach could have a positive effect on changing explicit attitudes (Malinen et al., 2014).

There may also be some identity-based protective factors related to media consumption about sexual offenders. Mancini and Shields (2014) conducted a study which examined perceptions of media coverage of the Catholic Church child sexual abuse scandal and how watching affected both Catholics and non-Catholics. Descriptive statistics showed that Catholics both watched more media coverage about the sexual abuse scandal and had greater confidence in the Catholic Church's ability to prevent future abuse. Logistic regression models reveal that consumption of news coverage significantly and positively impacts the way that Catholics view the church but has no effect for non-Catholics. This implies that group membership of an organization that is facing negative media coverage may experience a protective factor sometimes called a "boomerang effect," where negative messaging may cause group members to be more dismissive of problems, such as sexual abuse (Mancini \& Shields, 2014).

\section{Perceptions of Sexual Offending Policies}


All 50 states have passed strict state legislation regarding sexual offenders. Yet, these laws have produced little evidence demonstrating their effectiveness in preventing sex crime, but, just the same, they are widely supported by the public (Burchfield et al., 2014; Katz-Schiavone et al., 2008). In fact, a landmark study conducted by Levenson and her colleagues (2007) found that $49 \%$ of their study's sample stated that it was "completely true" that they would support current policies, such as registration and community notification, even if there was not any scientific evidence to support these policies. This study was replicated in 2015 with an experimental condition added, which included a handout that explicitly stated on every page that there is no scientific evidence to show that current sex offender policies are effective. The control group did not receive this disclaimer. Still, there was strong support for all "prevention" strategies, including chemical castration, community notification, and residency restrictions, with no significant differences between the control and experimental conditions. Further, there was a strong belief among study participants in both conditions that these strategies are effective, with more than half of the total sample stating that they would support these policies without any scientific evidence of their efficacy (Koon-Magnin, 2015). In this section, 16 studies explored public perceptions of specific sex offender policies, as well as how support for specific policies relates to other variables.

Lawmakers' Perceptions. Three articles investigated lawmakers' perceptions of sex offender polices and sex offenders themselves, which provided some insight into the motivation behind sex offender policy creation. The first study sought to understand lawmaker perceptions of sexual offenders and the sex crime laws that they sponsored or 
authored (Meloy et al., 2013). Through a thematic analysis, this study found that the majority of the legislators (55\%) believed that their laws were functioning well, but could not cite empirical studies to support their assertion. Most legislators noted that their laws were based on influential cases involving young, female children. Half of the participants reported that they do not believe that treatment is effective for sexual offenders. However, many did note potential negative consequences of their laws, with the majority of the sample (89\%) providing at least one serious negative consequence for offenders. This study supports the notion that lawmakers buy into some prevalent offender myths regarding recidivism, but do not necessarily believe that the laws they've created are without flaws. A second study conducted by the same authors also included the perspectives of 25 practicing lawyers finding that practitioners acknowledged the role that prominent and violent victimizations have in the creation of offender related legislation. This study also noted that practicing lawyers are more hopeful about the efficacy of sex offender treatment than their lawmaker counterparts (Meloy et al., 2012).

Sample and Kadleck (2008) reported on a study examining thoughts, opinions, and beliefs of Illinois legislators with regard to the "sex offender problem." Many of the respondents stated that they believe sexual offending is a huge and growing problem, and when asked to define sexual offenders, tended to focus on the stereotype of an adult male with severe mental health issues. Some participants (23\%) viewed offending as part of a biological defect, such as brain chemistry, and two-thirds believed that all offenders are psychologically abnormal, with some believing that these abnormalities come from experiencing child sexual abuse themselves. The vast majority of participants (78\%) 
believed that all offenders recidivate and need to be incarcerated to prevent further harm to society. When thinking about the crimes that most offenders commit, study participants often thought of child pornography and child sexual abuse. Most discussed raping children specifically, and many also linked rape with murder. When considering victims, about half mentioned women, and all of the participants included children. Further, $77 \%$ of the study respondents mentioned protecting children when they talked about legislation. As far as legislation efficacy, $62 \%$ of participants reported that laws need to go farther to be effective. Some "prevention techniques" suggested by respondents included stamping the phrase "sex offender" on driver's licenses, as well as castration, and execution. Finally, many legislators in this study stated that their primary source of information on sexual offenders was the media

Punishment and Sanctions. Eight studies included in this review examined public perceptions about how sex offenders should be punished after they are found guilty of committing a sexual crime. This policy category included perceptions of jail time, monetary fines, castration, and the death penalty. The average recommendation for a sex offender prison sentence ranges from 15.5 years to 38.8 years (King \& Roberts, 2015; Levenson et al., 2007). The modal number of years for a prison sentence recommendation in one study was 99 years (Levenson et al., 2007). Further, evidence suggests that the public believes that sex offenders should be punished more severely than other types of criminals (Rogers \& Ferguson, 2011).

One study reviewed examined motivations underlying punishment for sexual offenders (Bergstrom et al., 2017). Motivations include deterrence (i.e., stopping 
recidivism), incapacitation (i.e., incarceration to prevent recidivism), and retribution (i.e., punishment in kind, "an eye for an eye"). Over half of the sample (52.2\%) supported incapacitation-based punishment, or imprisonment to stop reoffending. Consistent with this, $25.1 \%$ supported retribution-based punishment, while $22.4 \%$ were in favor of deterrence-based punishment. In a separate study, the authors examined support for the death penalty in relation to sexual offender. The only significant demographic variable that correlates with death penalty support is less education. Belief in recidivism and belief that the criminal justice system does not prevent sexual offending also significantly predicted support for capital punishment for adult sex offenders. While being a victim of a sex crime does not predict support, knowing a victim does. (Mancini \& Mears, 2010). In general, however, public perception shies away from very severe punishments in relation to sexual offenders such as surgical castration, listing names in a newspaper, and life in prison (Comartin et al., 2009; Olver \& Barlow, 2010). Support for severe sanctions is positively correlated with fear of sexual offenders and being the parent of a young child (Comartin et al., 2009).

Registration, Notification, and Monitoring. Perhaps the most studied and supported policies pertaining to sexual offenders are registration, notification, and monitoring. These policies impact both offenders released from prison as well as those who remain in the community. The average recommendation for time spent on a sex offender registry ranges from 20.5 to 41.9 years (King \& Roberts, 2015; Levenson et al., 2007). One study determined that the majority of their public sample believed that all types of sexual offenders should have to register, with $65.1 \%$ of the sample reporting a 
belief that statutory rapists should have to register. Support for registration was also predicted by fear of sexual offenders (Kernsmith et al., 2009).

In general, there is wide public support for community notification policies. A UK qualitative study indicated that British members of the public both wanted information about previous sex crimes of any offender living near them and felt that notification is a good way to monitor offenders in the community (Brown et al., 2008). Koon-Magnin (2015) reported that $65 \%$ of their sample believed that community notification was an effective approach to preventing sexual crimes, even when participants were told that there was no scientific evidence to support this approach. Study participants also believed that the public should have access to the name, photo, home address, vehicle description, license plate, HIV status, and victim age of all offenders on the registry. Only $3 \%$ of respondents believed that no information should be made public (Levenson et al., 2007). Support for community notification laws do vary by offenders' level of risk, with $89 \%$ supporting it for high risk offenders, $51 \%$ for moderate risk offenders, and $20 \%$ for low risk offenders. Only $17 \%$ of respondents believed that notification laws make recovery more difficult for offenders (Schiavone \& Jeglic, 2010). Even though support for community notification is ubiquitous, some members of the public are skeptical of its success in preventing sex crimes. A focus group study of community notification support in Wales demonstrates that even among those who support community notification, some are skeptical about the government's ability to effectively conduct the notification process or are unhappy with how it is structured (McCartan, 2013). Further, although many in the U.S. support notification 
laws, $57 \%$ of the public sample in one study was unsure if the law effectively prevents sex offender recidivism (Schiavone \& Jeglic, 2010).

Budd and Mancini (2017) examined support for electronic monitoring of offenders in relation to prominent sex offender myths and parental status. About $79 \%$ of this public sample perceives GPS monitoring as "very" or "somewhat effective" in preventing recidivism. Variables that predicted support for monitoring are belief in the "stranger danger" myth, or belief that most victims of sexual violence are children. Of those who participated in this study, parents and those who believe in the recidivism myth were unsure of how well GPS monitoring would work to prevent recidivism. This study suggests mixed support for this prevention method (Budd \& Mancini, 2017). Although support for sex offender registration and notification are high, some studies have demonstrated that support for these policies is motivated by a fear of offenders and perpetuates this fear, as well. In an investigation of individuals who knew of a sex offender in their neighborhood, $48 \%$ of respondents reported being primarily concerned about "stranger danger" perpetration, which served as the strongest predictor of misperception about offenders in this particular study (Craun \& Theriot, 2009). Those who believed the registry to be effective, also perceived significantly higher levels of sex offender risk (Socia \& Harris, 2016). This effect was also present in the public's support of community notification, with those supporting this policy indicating more negative attitudes toward sexual offenders (Shackley et al., 2014). It's important to note that this effect may be exaggerated with offenders of child sexual abuse (Brown et al., 2008). 
Overall, these findings imply that registration and notification can lead to the perpetuation of myths and misunderstandings about the nature of sexual violence.

Residency Restrictions. Individuals with a history of sex offending are also significantly impacted by laws imposing residency restrictions. Anderson and colleagues (2015) examined public perceptions of housing restrictions impacting sex offenders. As part of this research they assessed perceptions of acceptable distances that sex offenders should maintain from schools and daycare settings and asked if 500 feet was sufficient. The majority of the respondents $(60 \%)$ indicated that this was not enough of a restriction. Of this group, $56.3 \%$ believed the appropriate distance should be more than 500 feet, but less than one mile away. Logistic regression analyses showed that being young, married, or having young children increased the odds of respondents supporting more restrictive zones. In contrast, living in an urban area and having more education were negatively related to supporting such restrictions. This reveals that the public overall, are supportive of residency restrictions, but do not think the restrictions need be much more extreme than they already are. Of note, only $0.2 \%$ of study participants thought restrictions should be crime dependent, supporting belief in the myth of offender homogeneity (Anderson, et al. , 2015). This study's results are supported by another study's finding that $79 \%$ of the public believes it is fair that offenders cannot return home due to residency restrictions, the majority also do not believe that housing restrictions reduce sexual recidivism (Schiavone \& Jeglic, 2010). 


\section{Discussion}

This final section will discuss responses to the two research questions posited in the methods section of this paper. Then, the literature will be discussed as a whole, followed by limitations of this review, and future directions for research.

Perceptions, Policy, and the Media. The first research question asks how media, public policy, and perceptions of sexual offenders relate to one another. Findings from the review of the literature indicate that there is a clear cyclical relationship between media, institutional myths about offenders, and policy that forms an institutional narrative which contributes significantly to defining how offenders are perceived. Media coverage of sexual crimes perpetuates institutional myths about offenders and policies directed toward sex offenders are written to appease the public. In turn, the existence and perceptions of public support for harsh polices regarding sexual offenders allows the media to continue reporting on sexual crime with a slant that focuses on the most heinous crimes, and justifies severe, long-term punishments for offenders.

In the relationship between media and institutional myths, it is telling that the majority of the content analyses reviewed focus specifically on child sexual abuse (Cheit et al., 2009, Meija et al., 2012). This more singular focus perpetuates part of the homogeneity myth and the vulnerable victims myth, where sex offenders are thought first to be child predators. Further, studies on the effects of media consumption show that those who consume more media tend to believe that there is more risk for sexual crime, adding to the "crime on the rise" myth (Brown et al., 2008). While the type of media does make a difference in explicit attitudes about offenders, with those who read more 
informative, as opposed to sensationalized, media having more positive opinions (Harper \& Hogue, 2016; Malinen et al., 2014), media type does not have a significant effect on implicit attitudes about offenders. This means that initial reactions toward offenders are primed to be quite negative (Malinen et al., 2014).

It is also clear that public perceptions and institutional myths regarding sexual offending are a primary driving force in policy creation and implementation for sexual offenders, explaining the relationship between institutional myths and policy. The idea of the prototypical offender being one who rapes and murders children is supported by all of the major federal sex offender laws being developed in response to the violent rape and murder of a child (Meloy et al., 2013; Sample \& Kadleck, 2008). Policy makers are subject to the same culture that perpetuates institutional myths, and the same media coverage, as the rest of society. It is evident that they make laws based on both their own principles and what they see as the desires of their constituents.

Legislators often believe, rightly so, that their constituents want laws that are harshly punitive toward those who sexually offend. The public harbors an excessive amount of fear for all types of sexual offenders (Kernsmith et al., 2009) and this fear is a key predictor of negative attitudes toward sex offenders, belief in institutional myths, and support for restrictive sex offender policies. The perpetuation of the myth of sex offenders as a homogenous group (Pickett et al., 2013) is fueled by relentless selective news coverage focused on violent sexual offenders victimizing children, which reifies the publics' belief that all sex offenders present a high safety risk. This encourages public demands for political action to stop victimization and increase community safety (Meloy 
et al., 2013). This leads to an assumption that support for sex offender policy is based on fear and emotion, not on logic. This assumption is supported by the number of people who are willing to support registration and notification policies even without any scientific evidence to support the effectiveness of these strategies in preventing recidivism (Levenson et al., 2007, Koon-Magnin, 2015). Adding to this is the belief that offenders need to be kept away from society to prevent them from committing more sexual crimes (Levenson et al., 2007). It seems that the existence of restrictive offender policies also prompts stereotypical perceptions of sexual offenders, as many are aware that polices may not prevent recidivism but want these policies in place regardless (Koon-Magin, 2015).

Prevalence of Institutional Myths. This study's second research question pertained to the most prevalent institutional myths related to sexual offenders and offending. The four primary myths addressed included: "stranger danger;" crime on the rise; homogeneity of offenders; and recidivism. While all four have a place in impacting policies, perceptions, and the media, perhaps the two most prevalent and damaging myths appear to be the offender homogeneity and the sex offender recidivism myths.

The homogeneity myth suggests that all sex offenders are basically the same; violent adult males who are calculating, intelligent, and prey primarily on vulnerable victims, who tend to be children. Offenders are also seen as having significant biological and psychological deficiencies that are causal factors in his sexual offending and was likely caused by their own experience of child sexual abuse. This myth suggests that these offenders have assaulted multiple victims and will continue assaulting even if 
involved in treatment (Pickett et al., 2013). While this characterization does fit for a small percentage of sexual offenders, in reality, perpetrators are quite heterogeneous (Willis et al., 2010). The homogeneity myth is perpetuated by media coverage, with news stories tending to focus on the same type of violent serial offender (Cheit et al., 2009; Galeste et al., 2012). This myth is also perpetuated by policies that are written with violent child sexual abusers in mind, but are applied to all types of sexual offenders, independent of risk (Sample \& Kadleck, 2008). The perpetuation of the homogeneity myth fosters public fear of all types of offenders, and encourages an overestimate of the risk that many offenders pose to society (Comartin et al., 2009; Kernsmith et al., 2009). Members of the public may be aware that there are different types of offenders who pose different degrees of risk, but the institutional homogeneity narrative tends to "erase" many of these important individual differences.

Evidence suggests that the recidivism myth is perhaps the most impactful of the four. Staggering numbers of people believe that all offenders recidivate, and that treatment for sexual offenders is ineffective (Payne et al., 2010). The media perpetuates this myth by reporting on perpetrators that have many victims, as well as by casting doubt about the efficacy of treatment (Galeste et al., 2012). The impact of this myth is that there is very little support for treatment of sexual offenders, and a persistent belief that offender policies such as registration and community notification should exist even if they do not affect recidivism rates. In truth, recidivism is more likely to happen with offenders who do not have social support and accountability (Willis et al., 2010), and current sex offender policies can make it difficult for offenders to find social support, 
jobs, or even a place to live (Schiavone \& Jeglic, 2010). This demonstrates that this myth is both pervasive and damaging to sexual violence prevention efforts.

Strengths of Studies In This Area. The literature reviewed has many strengths. First, the methodologies used to examine this topic were varied, which allows for a more complete picture of the construct of offender perceptions. Many of the studies included in this review utilized well-conceived qualitative and quantitative methodologies. Moreover, the methods chosen by the authors were well-matched to the research questions posed by the studies. Further, a breadth of topics related to this issue was address by the existing studies in this area and many conceptual connections existed among the articles. Articles often varied in their focus, with some only focusing on child sexual abuse, and others examining sexual violence more generally. While three general categories were used to group articles (i.e., media, policy, and general perceptions), many studies could have fit into all three categories. Each article added a new perspective to the overall construct of offender perceptions, clarifying the relationship between media, policy, and institutional myths. In particular, the institutional myths reviewed were present in many of the articles reviewed, even if not presented as an explicit construct or variable of interest.

Finally, the literature in general focuses on a difficult topic. Although some offenders receive a bit too much demonization for their crimes, they still committed an act that harmed another person. A fine line must be walked in discussing this literature, to ensure that the conversation about how offenders are perceived and treated does not seem like rape apology or an attempt to excuse offending behavior. This is where most of the articles excelled. They consistently pointed out that offenders should be held 
culpable for their actions, but that the way in which the system punished offenders is not effective. There was also a call for a more nuanced view, acknowledging that an offender who kidnaps, rapes, and murders a child is quite different from a curious teenager who inappropriately touches a young family member, or even an adult who commits a single act of sexual violence and then desists (Levenson et al., 2007; Willis et al., 2010). The literature does hold the second two examples of offenders accountable for their actions, but suggests that they are given a chance to rehabilitate, change their behavior, and become upstanding members of society (Schiavone \& Jeglic, 2010). This is often done with great concern for victims of sexual violence, and with reference to sexual violence prevention. The thought here is that changing the institutional narrative about sexual offenders will lead to less sexual violence, fostering a safer community and resulting in fewer people dealing with the negative consequences of victimization.

Literature Critique. Although there are many strengths to this literature, there are also some weaknesses that warrant mention. While the varied methodology is a strength, there are some areas where future research could still improve upon study methodologically. Many of the frequently cited studies in this review are primarily descriptive in nature (Levenson et al., 2007; Katz-Schiavone et al., 2008). Furthermore, many of these studies focus on phone interview data within one state, or other examples based on convenience samples. The literature could benefit from more qualitative work exploring how perceptions are formed and maintained, as well as more research at both state/county levels and federal levels to better understand why geographic location might 
impact how the institutional narrative of sexual offending impacts different communities. Articles may also have been missed due to the limited nature of the search terms.

Another limitation is one that was pointed out by Harper and Hogue (2017), that there is not a clear distinction between the concept of "attitudes" and the concept of "perceptions" in this literature. While this review focused on identifying articles that emphasize perceptions, many used the word "attitude" to describe their construct of interest, which serves as a limitation of the review. A major finding of this review is that individual attitudes about offenders can differ from the institutional narrative.

Researchers in this area could be more mindful about utilizing an ecological approach to parse out the difference and relationship between individual attitudes and societal perceptions. This clarification would allow for clearer answers to the question of how the institutional narrative reflects upon individual attitudes. This confusion between attitudes and perceptions in the literature also points to a methodological limitation, in that the first author's views on the categorization of articles in this review may not be shared by all researchers. There is work to be done in this area in the realm of operationalizing key terms so that better understanding of this topic can be formed.

A third limitation involves representation and diversity within the articles in the review. As a whole, this area of literature surrounding perceptions of those who sexually offend can do more to deepen based on perceiver diversity, particularly in terms of race. While women, parents, and people with less education have more negative perceptions of offenders, research on these differences is limited, and leaves out many groups (Bergstrom et al., 2017; King \& Roberts, 2015; Klein, 2015; Willis et al., 2013). More 
work should be done to understand how different racial groups perceive offenders and offending, particularly in their own communities. Willingness to report sexual crime may be dependent upon trust of law enforcement, a group which has shown significant bias toward people of color. This is supported by Klein (2015), who does present some preliminary findings surrounding racial differences in offender perceptions.

Finally, there was more information regarding perceptions of child sexual abusers in this literature, seen particularly in the content analyses (Cheit et al., 2009; Meija et al., 2012) and policy articles (Sample \& Kadleck, 2008). The authors of these articles are not necessarily responsible for this skew, as CSA is represented more in both media and policy than sexual violence against adults. However, this review may be biased toward perceptions of those who commit CSA, as opposed to those who offend against adults.

Research Implications and Future Directions. The results and limitations of this review bring about many ideas for future research. A summary of these implications can be found on Table Two. First, more work could be done to see how perceptions of accused and convicted perpetrators of sexual violence differ, with an aim to see if accused perpetrators face the same level of scorn as their convicted counterparts. More work could also be done to understand what makes a sexual offender "worthy" of a conviction, as well as an examination of protective factors for offenders such as victim age, offender race, or offender socioeconomic status. In a society where all sexual offenders can receive sanctions that are designed for violent perpetrators of child sexual abuse, it follows that there may be some offenders who are given a pass, or incredibly light sanctions. 
Finally, it should be noted that even with the 2007-2017 cutoff criteria for articles included in this review, it is likely that the institutional narrative surrounding sexual offenders has shifted since the publication of many included articles. Since the cutoff period, the \#MeToo movement, and a social media response to Hollywood producer Harvey Weinstein sexually harassing and abusing numerous women, has propelled the conversation about sexual harassment and assault into the mainstream (Barnett, 2017). On top of this, a doctor for Olympic Gymnastics, Larry Nassar, has been convicted of molesting hundreds of young girls under the guise of medical treatment (Dyer, 2018). If the model proposed in this study holds, this will lead to further perpetuation of institutional myths, and new policies passed to prevent sexual abuse based on these myths. Therefore, it will become important to monitor how conversation and perception of sexual crime and sexual offenders' changes over this new era of conversation surrounding sexual offenders and offenses.

Intervention Implications. Finally, potential interventions to prevent sexual violence are highlighted through the results of these findings, and in Tale 6. Given that the most damaging institutional myth is that sexual offenders cannot be treated, the institutional culture around treatment and recidivism must be shifted. Researchers in this field cite the importance of communication between those who work with offenders and the media (McCartan et al., 2015; Willis et al., 2010). This is a great place to begin. Shifting the way that recidivism, in particular, is talked about in the media, and discussing treatment with a more positive outlook, could be the first step in shifting institutional culture by adding more nuance to the recidivism conversation. 
Next, the idea that current federal polices (e.g., Megan's Law, Adam Walsh Act) prevent sexual violence by stopping recidivism must be challenged. Despite positive perceptions of these laws by some legislators and members of the public, these policies do not represent effective approaches to sexual violence prevention. Greater transparency about what these polices actually accomplish could be another institutional level intervention that may lead to more policy research on what kinds of federal policies effectively function to prevent sexual violence and recidivism.

\section{Conclusion}

This review has revealed that though sexual violence is a societal problem with serious impacts for victims and society, perceptions of sexual offenders are based on a narrative that is perpetuated by media, policy, and institutional myths. Media perpetuates the idea that offenders are a homogenous group of monstrous "others" that attack vulnerable victims and cannot be treated. This myth is the basis for sex offender policies in the United States. The existence of these policies allows for the media to continue perpetuating the institutional narrative, meanwhile, the policies perpetuated by this narrative are not effective in preventing sexual violence. With more research on this topic, as well as institutional level policy and media interventions, the conversation around sexual offenders and offending may begin to change. A changed conversation could lead to more nuance, where offenders are seen as a heterogeneous group, and no longer subjected to a binary where they are either demonized or exonerated. This paradigm shift could open up new opportunities for more effective prevention of sexual violence. 
PREVENTION AND PERCEPTIONS

\section{Tables and Figures}

\section{Table 1. Coding Scheme for Findings}

\begin{tabular}{lll} 
Perception Codes & Media Codes & Policy Codes \\
\hline General Myths & General Media & General \\
& Policy \\
Stranger Danger & Sex Crime News Coverage & Lawmaker \\
& & Perceptions \\
Vulnerable Victims & Case Specific Coverage & Punishment \\
Crime on the Rise & Media and Prevention & Registration \\
Homogeneity & Effects of Media on Perception & Notification \\
Recidivism & & Monitoring \\
Perceiver Differences & & Residency \\
& & Restrictions \\
& & Rehabilitation \\
\hline
\end{tabular}

Table 2. Offender Perceptions Articles

\begin{tabular}{|c|c|c|c|c|}
\hline Citation & Sample & Country of Origin & Key Finding & $\begin{array}{l}\text { Analytical } \\
\text { Approach }\end{array}$ \\
\hline $\begin{array}{l}\text { Brown, } \\
\text { Deakin, } \\
\& \\
\text { Spencer } \\
(2008)\end{array}$ & 979 British Participants & United Kingdom & $\begin{array}{l}\text { Participants expressed } \\
\text { concern over community } \\
\text { management strategies, } \\
\text { including reintegration, } \\
\text { regarding sexual offenders. }\end{array}$ & Mixed Method \\
\hline $\begin{array}{l}\text { Craun } \\
\& \\
\text { Theriot } \\
(2009)\end{array}$ & $\begin{array}{l}565 \text { participants randomly } \\
\text { sampled from a large } \\
\text { southeastern county }\end{array}$ & United States & $\begin{array}{l}\text { Presence of a registered } \\
\text { sexual offender in a } \\
\text { neighborhood significantly } \\
\text { increases support of } \\
\text { "stranger danger" myth. }\end{array}$ & Quantitative \\
\hline & & & Use of the term "sex & \\
\hline Harris & 1,000 randomly selected & & offender" increases support & \\
\hline $\begin{array}{l}\text { \& Socia } \\
(2016)\end{array}$ & $\begin{array}{l}\text { participants, propensity } \\
\text { matched for condition }\end{array}$ & United States & $\begin{array}{l}\text { for common punitive } \\
\text { policies surrounding sexual }\end{array}$ & Quantitative \\
\hline
\end{tabular}




\section{Katz- \\ Levens \\ on, \& \\ Ackerm \\ an \\ (2008)}

Schiavo 127 participants recruited from

ne, Craigslist

Klein $\quad 877$ participants recruited through Mturk

Mancin

i \& $\quad 537$ individuals from all states

Pickett except South Dakota

Olver
$\&$
Barlow 78 undergraduate students
$(2010)$
Pickett, $\quad$ A web-based sample of 537
Mancin $\quad$ Americans
i, \& $\quad$

United States

$$
\text { Country of Origin Key Finding }
$$

Participants were more

United States

likely to endorse myths

surrounding homogeneity

and recidivism, and least

likely to endorse "stranger

danger" myths.

Those who endorse myths

about sexual offenders are

more likely to have negative

attitudes about sexual

offenders.

Publics perceptions of

offenders are more negative

when the homogeneity

United States

Canada

United States

myth, particularly

surrounding child victims, is

endorsed .

Personality factors such as

openness and agreeableness

may predict more positive

attitudes about offender

rehabilitation.

Concern for victims and

belief in offender

stereotypes best predict

crime laws.
Analytical Approach

Quantitative

Quantitative

Quantitative

Quantitative 


\begin{tabular}{l} 
Citation Sample \\
\hline Mears \\
(2013) \\
Shackle \\
y, \\
Weiner, 552 Australians recruited \\
Day, \& through social media \\
Willis \\
(2014)
\end{tabular}

Socia \&

Harris

(2016)

A nationally representative sample of 1,000 US adults

Thakke 5 focus groups with a total of r (2012) 22 individual participants

\section{Willis,}

\section{Malinin}

, \&

A web-based sample of 401

Johnsto

New Zealanders
Country of Origin Key Finding

Analytical

Approach
Australia

Australia

$\left(\frac{10}{2}\right.$

United States

New Zealand

New Zealand
Higher education levels are

correlated with less negative

offender attitudes, and

support of community

notification is negatively

Quantitative

correlated with attitudes

toward offenders

Myth-based beliefs,

particularly those

surrounding registration and

the "crime on the rise" myth Quantitative

leads to further myth-based

beliefs about offending.

Perceptions in New Zealand

are primarily based off of

media, and are a mix of

Qualitative

myth-based and factual.

Though everyone has

negative attitudes toward

offenders, attitudes are more Quantitative

negative for females and

those with less education 
PREVENTION AND PERCEPTIONS

Table 3. Media Articles

\begin{tabular}{|c|c|c|c|c|}
\hline Citation & Sample & $\begin{array}{l}\text { Country of } \\
\text { Origin }\end{array}$ & Key Finding & $\begin{array}{l}\text { Analytical } \\
\text { Approach }\end{array}$ \\
\hline $\begin{array}{l}\text { Burchfield, } \\
\text { Sample, \& Lytle } \\
\text { (2014) }\end{array}$ & $\begin{array}{l}460 \text { time } \\
\text { points } \\
\text { between } 2005 \\
\text { and } 2012 \\
\text { collected via } \\
\text { google trends }\end{array}$ & United States & $\begin{array}{l}\text { Media and public in sexual } \\
\text { offenders is stable over } \\
\text { time, showing that media } \\
\text { may not be perpetuating } \\
\text { moral panic. }\end{array}$ & $\begin{array}{l}\text { Mixed } \\
\text { Methods }\end{array}$ \\
\hline $\begin{array}{l}\text { Cheit, Shavit, \& } \\
\text { Reiss-Davis } \\
\text { (2009) }\end{array}$ & $\begin{array}{l}172 \text { articles in } \\
\text { prominent } \\
\text { news } \\
\text { magazines } \\
\text { that examine } \\
\text { child sexual } \\
\text { abuse }\end{array}$ & United States & $\begin{array}{l}\text { Established that } \\
\text { "newsworthiness" is a } \\
\text { leading factor as to why } \\
\text { CSA stories are published, } \\
\text { and that media interest } \\
\text { waned from 2000-2010. }\end{array}$ & Qualitative \\
\hline $\begin{array}{l}\text { Galeste, Fradella, } \\
\text { \& Vogel (2012) }\end{array}$ & $\begin{array}{l}334 \text { print } \\
\text { media articles } \\
\text { published in } \\
\text { the year } 2009\end{array}$ & United States & $\begin{array}{l}\text { Sex offender myths are } \\
\text { present in media and news } \\
\text { articles, particularly those } \\
\text { that cover offender policies. }\end{array}$ & Quantitative \\
\hline $\begin{array}{l}\text { Harper \& Hogue } \\
(2014)\end{array}$ & $\begin{array}{l}148 \text { articles } \\
\text { from Britain's } \\
\text { most popular } \\
\text { newspapers }\end{array}$ & $\begin{array}{l}\text { United } \\
\text { Kingdom }\end{array}$ & $\begin{array}{l}\text { News articles about sexual } \\
\text { crimes were angrier than } \\
\text { other types of news articles. }\end{array}$ & Quantitative \\
\hline $\begin{array}{l}\text { Harper \& Hogue } \\
\text { (2016) }\end{array}$ & $\begin{array}{l}528 \text { snowball } \\
\text { sampled } \\
\text { community } \\
\text { members }\end{array}$ & $\begin{array}{l}\text { United } \\
\text { Kingdom }\end{array}$ & $\begin{array}{l}\text { Shows that tabloids are } \\
\text { more likely than broadsheet } \\
\text { newspapers to perpetuate } \\
\text { myths, and posits that } \\
\text { media promotes heuristic- }\end{array}$ & $\begin{array}{l}\text { Mixed } \\
\text { Methods }\end{array}$ \\
\hline
\end{tabular}


PREVENTION AND PERCEPTIONS

\begin{tabular}{|c|c|c|c|c|}
\hline Citation & Sample & $\begin{array}{l}\text { Country of } \\
\text { Origin }\end{array}$ & Key Finding & $\begin{array}{l}\text { Analytical } \\
\text { Approach }\end{array}$ \\
\hline $\begin{array}{l}\text { Malinen, Willis, \& } \\
\text { Johnston (2014) }\end{array}$ & $\begin{array}{l}87 \text { students at } \\
\text { a university in } \\
\text { New Zealand }\end{array}$ & New Zealand & $\begin{array}{l}\text { based thinking surrounding } \\
\text { sexual offenders. } \\
\text { Media can influence } \\
\text { cognition and behavior, but } \\
\text { not affect or implicit } \\
\text { attitudes, surrounding } \\
\text { sexual offenders. }\end{array}$ & Quantitative \\
\hline $\begin{array}{l}\text { Mancini \& Shields } \\
\text { (2014) }\end{array}$ & $\begin{array}{l}1,045 \\
\text { participants } \\
\text { who } \\
\text { responded to a } \\
\text { New York } \\
\text { Times poll }\end{array}$ & United States & $\begin{array}{l}\text { The perception of fairness } \\
\text { surrounding news coverage } \\
\text { about sexual abuse in the } \\
\text { Catholic Church caused } \\
\text { Catholics with perceived } \\
\text { bias to be more optimistic } \\
\text { about the church. }\end{array}$ & 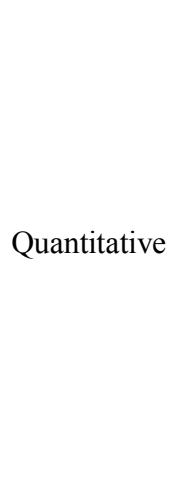 \\
\hline & $\begin{array}{l}260 \text { news } \\
\text { articles from } \\
\text { local }\end{array}$ & & News coverage surrounding & \\
\hline $\begin{array}{l}\text { Meija, Cheyne, \& } \\
\text { Dorfman (2012) }\end{array}$ & $\begin{array}{l}\text { newspapers } \\
\text { picked from } \\
42 \text { random } \\
\text { days in a two- } \\
\text { year period }\end{array}$ & United States & $\begin{array}{l}\text { child sexual abuse rarely } \\
\text { focuses on context or } \\
\text { prevention. }\end{array}$ & Qualitative \\
\hline Weatherred (2017) & $\begin{array}{l}503 \text { articles } \\
\text { from the } \\
\text { Lexis/Nexis } \\
\text { Academic } \\
\text { Database }\end{array}$ & United States & $\begin{array}{l}\text { While media has shifted } \\
\text { blame from an individual to } \\
\text { a societal level, solutions } \\
\text { posed are still at the } \\
\text { individual level. }\end{array}$ & Quantitative \\
\hline
\end{tabular}


PREVENTION AND PERCEPTIONS

Table 4. Policy Articles

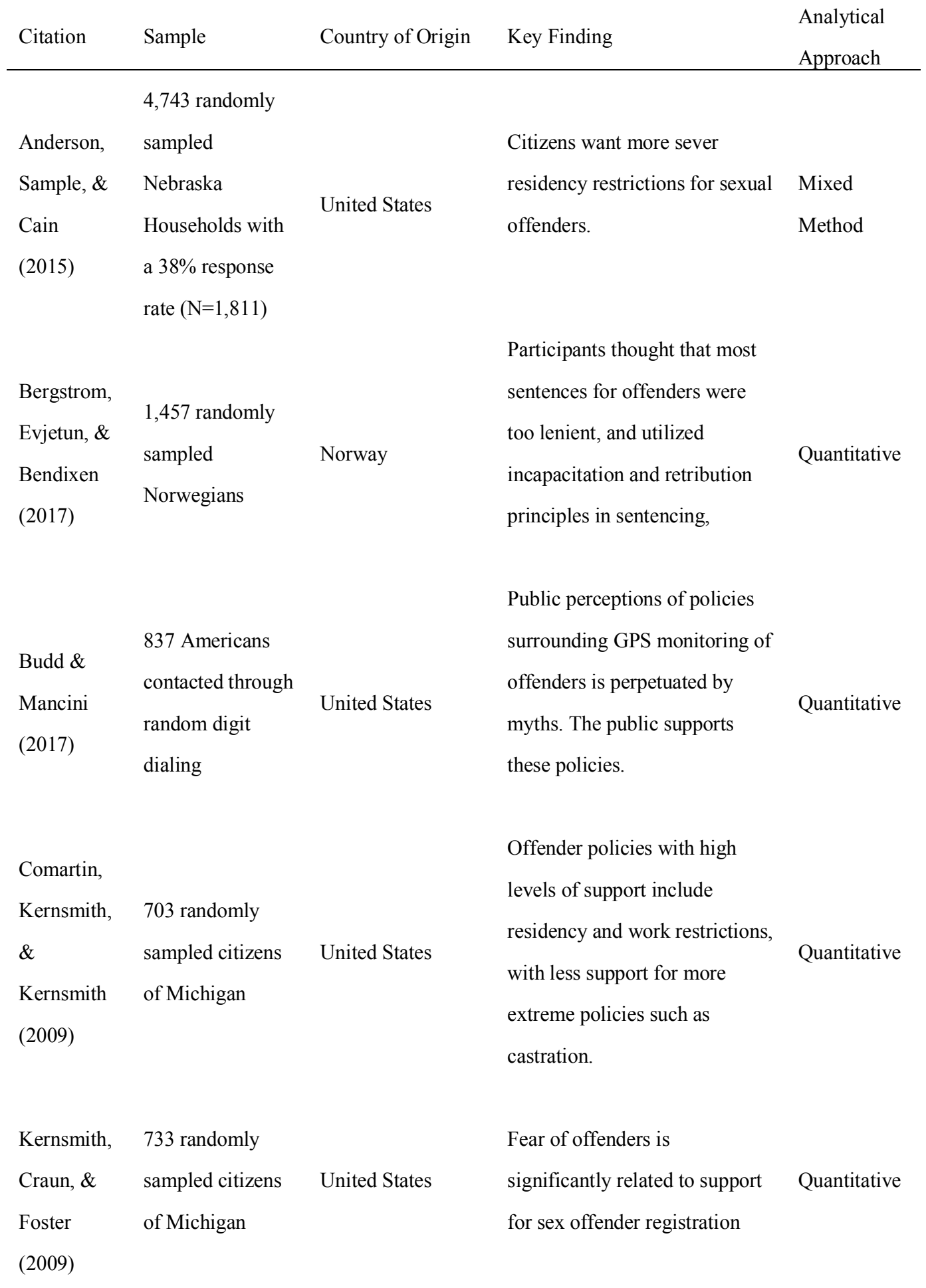


PREVENTION AND PERCEPTIONS

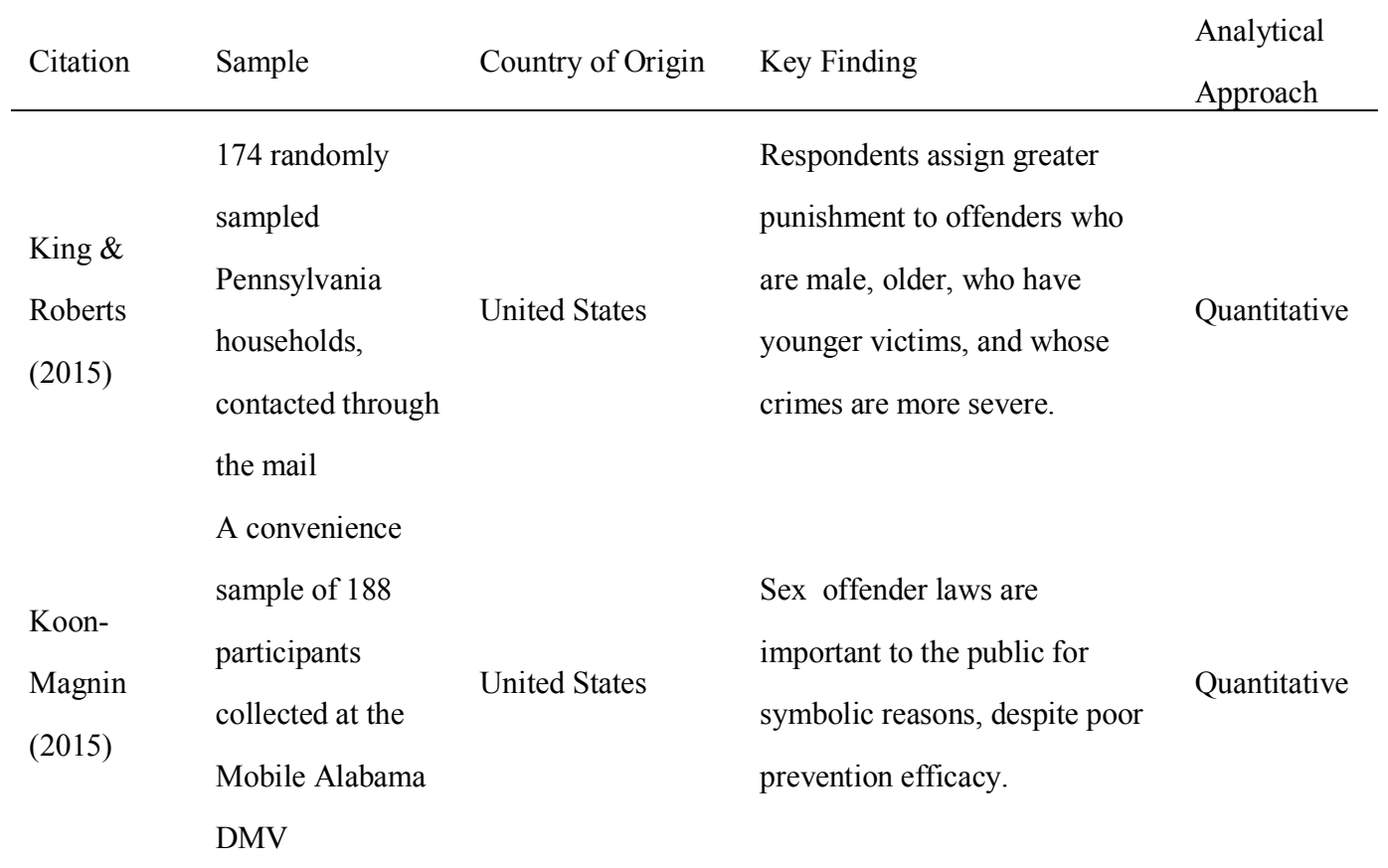

A convenience

Levenson, sample of 193

Brannon, participants

Fortney, \& collected at the

United States

People are very supportive of registration polices due to a

Baker Melbourne

(2007) Florida DMV

1,101 participants who responded to

Mancini \& a national

Mears telephone poll

United States conducted by the Minneapolis Star Tribune in 1991

myth-based understanding of sexual offenders, including

Quantitative myths about homogeneity and recidivism.

Support for capital punishment for sexual offenders increases when the victim is a child, and that there is more support for Quantitative$$
\text { Tribune in } 1991
$$

$\begin{array}{ll}\text { McCartan } & 35 \text { focus group } \\ \text { (2013) } & \text { participants from }\end{array}$

Focus group participants

believe that communities

should be more involved in
Qualitative 
PREVENTION AND PERCEPTIONS

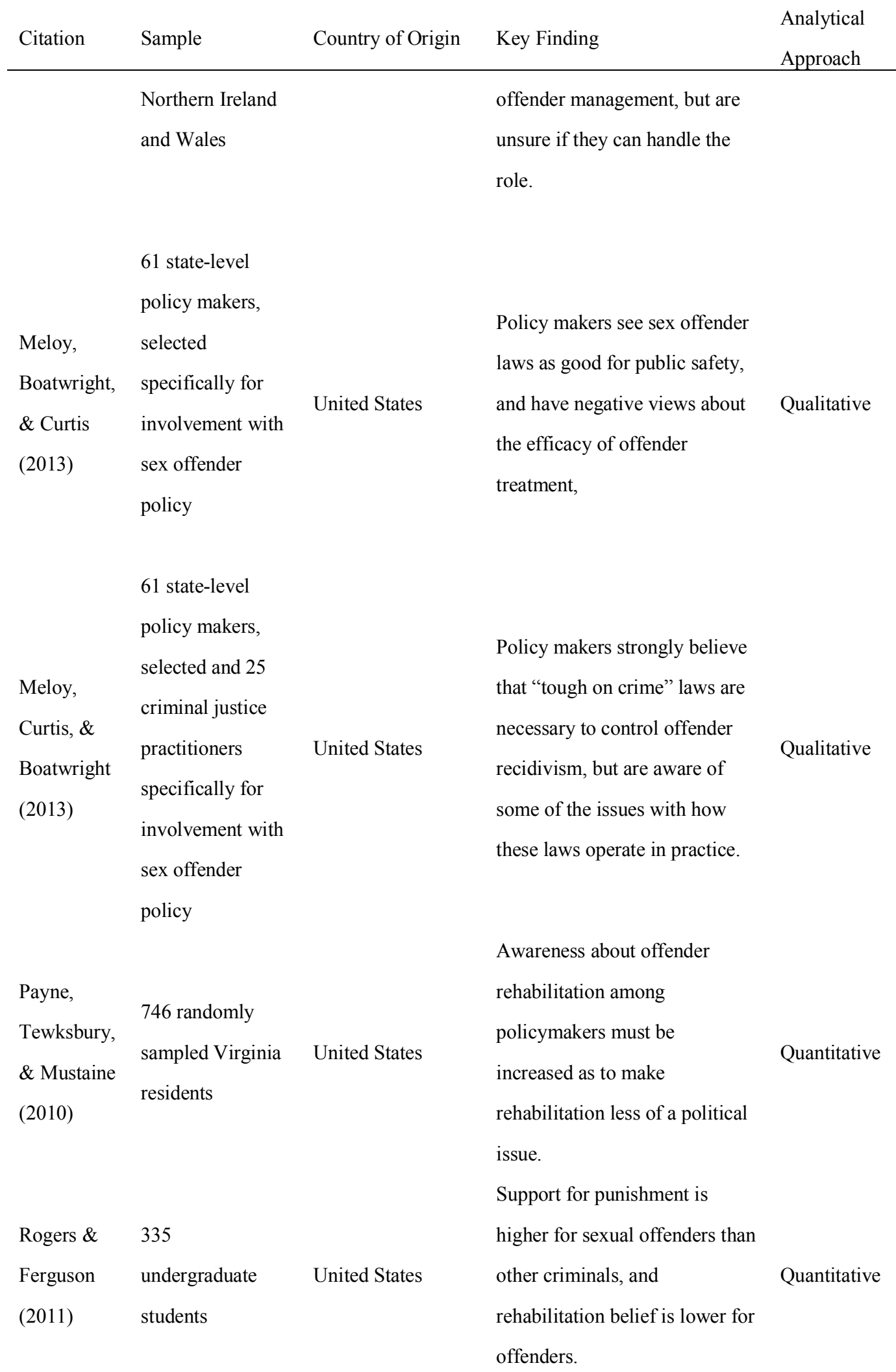


PREVENTION AND PERCEPTIONS

\begin{tabular}{|c|c|c|c|c|}
\hline Citation & Sample & Country of Origin & Key Finding & $\begin{array}{l}\text { Analytical } \\
\text { Approach }\end{array}$ \\
\hline $\begin{array}{l}\text { Sample \& } \\
\text { Kadleck } \\
(2008)\end{array}$ & $\begin{array}{l}\text { A random sample } \\
\text { of } 25 \text { Illinois } \\
\text { State Legislators }\end{array}$ & United States & $\begin{array}{l}\text { The personal beliefs and } \\
\text { perceptions of legislators } \\
\text { surrounding sexual offenders } \\
\text { influences the laws that they } \\
\text { pass. }\end{array}$ & Qualitative \\
\hline $\begin{array}{l}\text { Schiavone } \\
\text { \& Jeglic } \\
(2010)\end{array}$ & $\begin{array}{l}\text { A sample of } 115 \\
\text { participants } \\
\text { recruited from a } \\
\text { nationwide online } \\
\text { community } \\
\text { message board }\end{array}$ & United States & $\begin{array}{l}\text { Participants have high levels of } \\
\text { support for Megan's Law, but } \\
\text { do not believe that the law } \\
\text { hinders recidivism. }\end{array}$ & Quantitative \\
\hline
\end{tabular}

\section{Table 5. Main Findings}

Research Question

1. What is the relationship between media, public policy, and public perceptions of sexual offenders and offending?

2. What are the most prevalent and impactful institutional myths about sexual offenders and offending that influence perceptions of sexual offenders?
Findings

1. The relationship is cyclical

2. Perpetuates mythical beliefs

3. Focuses mostly on child sexual abuse

1. Most perpetrators do not know their victims (stranger danger)

2. Sexual abuse is the most pervasive and dangerous crime (crime on the rise)

3. All offenders are the same (homogeneity)

4. Offenders cannot be rehabilitated (unreformable) 
Table 6. Implications and Next Steps

Policy and Intervention

Research

1. More communication needed between media and those who work with offenders

2. Greater transparency about what offender policies accomplish

3. More policy-based work to understand what actually prevents offender recidivism

1. Studies that examine who is "worthy" of the sex offender label are needed

2. Studies applying Institutional Myths to specific settings, to see if they differ

3. Studies examining how communication and rhetoric changes in the post \#MeToo decade (2018-2028). 
PREVENTION AND PERCEPTIONS

\section{References}

Adam Walsh Child Protection and Safety Act, Pub. L. 109-248, 120 Stat. 587, codified as amended 42 U.S.C. $\S 16901$ et seq. (2006).

Ali, R. (2011). Dear colleague letter from assistant secretary for civil rights Russlynn Ali. Washington, DC: Department of Education, Office of Civil Rights.

Anderson, A. L., Sample, L. L., \& Cain, C. M. (2015). Residency restrictions for sex offenders: Public opinion on appropriate distances. Criminal Justice Policy Review, 26(3), 262-277.

Banyard, V. L., Plante, E. G., \& Moynihan, M. M. (2004). Bystander education: Bringing a broader community perspective to sexual violence prevention. Journal of Community Psychology, 32(1), 61-79.

Barth, J., Bermetz, L., Heim, E., Trelle, S., \& Tonia, T. (2013). The current prevalence of child sexual abuse worldwide: a systematic review and metaanalysis. International journal of public health, 58(3), 469-483.

Bennet, J. (2017). The \#metoo moment: No longer complicit. New York Times.

Bergstrøm, H., Evjetun, P., \& Bendixen, M. (2017). Punishment justifications in rape cases: a community study. Journal of Scandinavian Studies in Criminology and Crime Prevention, 18(2), 123-140.

Black, M., Basile, K., Breiding, M., Smith, S., Walters, M., Merrick, M., ... \& Stevens, M. (2011). National intimate partner and sexual violence survey: 2010 summary report.

Breckler, S. J. (1984). Empirical validation of affect, behavior, and cognition as distinct 
PREVENTION AND PERCEPTIONS

components of attitude. Journal of Personality and Social Psychology, 47(6), 1191.

Bronfenbrenner, U. (1977). Toward an experimental ecology of human development. American Psychologist, 32(7), 513-531.

Brown, S., Deakin, J., \& Spencer, J. (2008). What people think about the management of sex offenders in the community. The Howard Journal of Crime and Justice, 47(3), 259-274.

Budd, K. M., \& Mancini, C. (2017). Public perceptions of GPS monitoring for convicted sex offenders: opinions on effectiveness of electronic monitoring to reduce sexual recidivism. International Journal of Offender Therapy and Comparative Criminology, 61(12), 1335-1353.

Burchfield, K., Sample, L. L., \& Lytle, R. (2014). Public interest in sex offenders: A perpetual panic. Criminology, Criminal Justice, Law \& Society, 15 (96).

Butchart, A., Phinney Harvey, A., Mian, M., Furniss, T., Kahane, T., \& World Health Organization. (2006). Preventing child maltreatment: a guide to taking action and generating evidence.

Carr, A., Dooley, B., Fitzpatrick, M., Flanagan, E., Flanagan-Howard, R., \& Tierney, K. (2010). Adult adjustment of survivors of institutional child abuse in Ireland. Child Abuse \& Neglect, 34(7), 477-489

Centers for Disease Control and Prevention (2004). Sexual violence prevention: beginning the dialogue. Atlanta, GA: Centers for Disease Control and Prevention; 2004 
Charmaz, K. (2006). Constructing grounded theory: A practical guide through qualitative analysis. Sage.

Cheit, R. E., Shavit, Y., \& Reiss-Davis, Z. (2010). Magazine coverage of child sexual abuse, 1992-2004. Journal of Child Sexual Abuse, 19(1), 99-117.

Church, W.T., Wakeman, E.E., Miller, S.L., Clements, C.B. and Sun, F. (2008). The community attitudes toward sex offenders scale: the development of a psychometric assessment instrument. Research on Social Work Practice 18 (3), 251-259

Comartin, E. B., Kernsmith, P. D., \& Kernsmith, R. M. (2009). Sanctions for sex offenders: Fear and public policy. Journal of Offender Rehabilitation, 48(7), 605619.

Craun, S. W., \& Theriot, M. T. (2009). Misperceptions of sex offender perpetration: Considering the impact of sex offender registration. Journal of Interpersonal Violence, 24(12), 2057-2072.

Riggs, D.S., Murdock, T., Walsh, W. (1992), A prospective examination of posttraumatic stress disorder in rape victims. Journal of Traumatic Stress, 455-475.

Department of Justice (2013). Felony defendants in large urban counties, 2009. Office of Justice Programs, Bureau of Justice Statistics.

Department of Justice (2013). Female victims of sexual violence, 1994-2010. Office of Justice Programs, Bureau of Justice Statistics.

Department of Justice (2015). National crime victimization survey, 2010-2014. Office of Justice Programs, Bureau of Justice Statistics. 
PREVENTION AND PERCEPTIONS

Department of Justice (2000). Sexual assault of young children as reported to law enforcement.

Office of Justice Programs, Bureau of Justice Statistics.

Department of Justice (2014). Socio-emotional impact of violent crime. Office of Justice Programs, Bureau of Justice Statistics.

Department of Justice (2015). National crime victimization survey, 2010-2014. Office of Justice Programs, Bureau of Justice Statistics.

Kilpatrick, D.G., Edmunds, C.N., Seymour, A.K. (1992). Rape in america: A report to the nation. Arlington, VA: National Victim Center and Medical University of South Carolina.

Duncan, S. H. (2014). The devil is in the details: Will the campus save act provide more or less protection to victims of campus assaults. $J C \& U L, 40,443$.

Dyer, O. (2018). Former USA Gymnastics team doctor sentenced for abusing hundreds of girl athletes.

Fater, K., \& Mullaney, J. A. (2000). The lived experience of adult male survivors who allege childhood sexual abuse by clergy. Issues in Mental Health Nursing, 21(3), $281-295$

Freeh, L. (2012). The Freeh Report on Pennsylvania State University.

Galeste, M. A., Fradella, H. F., \& Vogel, B. (2012). Sex offender myths in print media: Separating fact from fiction in US newspapers. Western Criminology Review, 13, 4. 
PREVENTION AND PERCEPTIONS

Glick, P., \& Fiske, S. T. (1996). The ambivalent sexism inventory: Differentiating hostile and benevolent sexism. Journal of personality and social psychology, 70(3), 491.

Hanson, R. K., \& Bussiere, M. T. (1998). Predicting relapse: a meta-analysis of sexual offender recidivism studies. Journal of consulting and clinical psychology, 66(2), 348.

Hanson, R. K., \& Morton-Bourgon, K. E. (2005). The characteristics of persistent sexual offenders: a meta-analysis of recidivism studies. Journal of consulting and clinical psychology, 73(6), 1154.

Harper, C. A., \& Hogue, T. E. (2014). A prototype-willingness model of sexual crime discourse in england and wales. The Howard Journal of Crime and Justice, 53(5), $511-524$.

Harper, C. A., \& Hogue, T. E. (2017). Press coverage as a heuristic guide for social decision-making about sexual offenders. Psychology, Crime \& Law, 23(2), 118134.

Harper, C. A., Hogue, T. E., \& Bartels, R. M. (2017). Attitudes towards sexual offenders: What do we know, and why are they important?. Aggression and violent behavior, 34, 201-213.

Harris, A. J. R., \& Hanson, R. K. (2004). Sex offender recidivism: A simple question. Ottawa, Ontario: Public Safety and Emergency Preparedness Canada, 3.

Harris, A. J., \& Socia, K. M. (2016). What's in a name? Evaluating the effects of the "sex offender" label on public opinions and beliefs. Sexual Abuse, 28(7), 660-678. 
PREVENTION AND PERCEPTIONS

Harris, A. J., Lobanov-Rostovsky, C., \& Levenson, J. S. (2010). Widening the net: The effects of transitioning to the Adam Walsh Act's federally mandated sex offender classification system. Criminal Justice and Behavior, 37(5), 503-519.

Isely, P.J., Isley, P., Freiburger, J. and McMackin, R. 2008. In their own voices: A qualitative study of men abused as children by catholic clergy. Journal of Child Sexual Abuse, 17(3-4): 201-215

Jacob Wetterling Crimes against Children Registration Act, Pub. L. 103-322, 108 Stat. 2038, codified as amended 42 U.S.C. $\S 114062,14071$ (1994).

Jussim, L. (2012). Social perception and social reality: Why accuracy dominates bias and self-fulfilling prophecy. OUP USA.

Katz-Schiavone, S., Levenson, J. S., \& Ackerman, A. R. (2008). Myths and facts about sexual violence: Public perceptions and implications for prevention. Journal of Criminal Justice and Popular Culture, 15(3), 291-311.

Kelly, J. G., Ryan, A. M., Altman, B. E., \& Stelzner, S. P. (2000). Understanding and c hanging social systems. In Handbook of Community Psychology (pp. 133-159). Springer, Boston, MA.

Kernsmith, P. D., Craun, S. W., \& Foster, J. (2009). Public attitudes toward sexual offenders and sex offender registration. Journal of Child Sexual Abuse, 18(3), 290-301.

Kilpatrick, D., Edmunds, C., \& Seymour, A. K. (1992). The national women's study. Arlington, Va: National Victim Center.

King, L. L., \& Roberts, J. J. (2017). The complexity of public attitudes toward sex 
PREVENTION AND PERCEPTIONS

crimes. Victims \& Offenders, 12(1), 71-89.

Klein, J. L. (2015). Vilifying the pedophiles and perverts: A nationwide test of the community Attitudes toward sex offenders (CATSO) scale. Criminology, Criminal Justice, Law \& Society, 16 (41).

Koon-Magnin, S. (2015). Perceptions of and support for sex offender policies: Testing Levenson, Brannon, Fortney, and Baker's findings. Journal of Criminal Justice, 43(1), 80-88.

Levenson, J. S., Brannon, Y. N., Fortney, T., \& Baker, J. (2007). Public perceptions about sex offenders and community protection policies. Analyses of Social Issues and Public Policy, 7(1), 137-161.

Luke, D.A. (2005). Getting the big picture in community science: Methods that capture context. American Journal of Community Psychology, 35(3/4), 185-200.

Malinen, S., Willis, G. M., \& Johnston, L. (2014). Might informative media reporting of sexual offending influence community members' attitudes towards sex offenders?. Psychology, Crime \& Law, 20(6), 535-552.

Man, C. D., \& Cronan, J. P. (2001). Forecasting sexual abuse in prison: The prison subculture of masculinity as a backdrop for deliberate indifference. Journal of Criminal Law \& Criminology, 92 (127).

Mancini, C., \& Mears, D. P. (2010). To execute or not to execute? Examining public support for capital punishment of sex offenders. Journal of Criminal Justice, 38(5), 959-968. 
PREVENTION AND PERCEPTIONS

Mancini, C., \& Pickett, J. T. (2016). The good, the bad, and the incomprehensible: Typifications of victims and offenders as antecedents of beliefs about sex crime. Journal of Interpersonal Violence, 31(2), 257-281.

Mancini, C., \& Shields, R. T. (2014). Notes on a (sex crime) scandal: The impact of media coverage of sexual abuse in the Catholic Church on public opinion. Journal of Criminal Justice, 42(2), 221-232.

Mancini, C., Pickett, J. T., Call, C., \& Roche, S. P. (2016). Mandatory reporting (MR) in higher education: College students' perceptions of laws designed to reduce campus sexual assault. Criminal Justice Review, 41(2), 219-235.

McCartan, K. (2013). From a lack of engagement and mistrust to partnership? Public attitudes to the disclosure of sex offender information. International Journal of Police Science \& Management, 15(3), 219-236.

McCartan, K. F., Kemshall, H., \& Tabachnick, J. (2015). The construction of community understandings of sexual violence: Rethinking public, practitioner and policy discourses. Journal of Sexual Aggression, 21(1), 100-116.

McCrae, R. R., \& Costa Jr, P. T. (1999). A five-factor theory of personality. Handbook of personality: Theory and research, 2, 139-153.

Megan's Law, Pub. L. 104-145, 110 Stat. 1345, codified as amended 42 U.S.C. § 13701 (1996).

Mejia, P., Cheyne, A., \& Dorfman, L. (2012). News coverage of child sexual abuse and prevention, 2007-2009. Journal of Child Sexual Abuse, 21(4), 470-487. 
PREVENTION AND PERCEPTIONS

Meloy, M., Boatwright, J., \& Curtis, K. (2013). Views from the top and bottom: Lawmakers and practitioners discuss sex offender laws. American Journal of Criminal Justice, 38(4), 616-638.

Meloy, M., Curtis, K., \& Boatwright, J. (2013). The sponsors of sex offender bills speak up: Policy makers' perceptions of sex offenders, sex crimes, and sex offender legislation. Criminal Justice and Behavior, 40(4), 438-452.

National Institute of Justice \& Centers for Disease Control \& Prevention, Prevalence, Incidence and Consequences of Violence Against Women Survey (1998)

Olver, M. E., \& Barlow, A. A. (2010). Public attitudes toward sex offenders and their relationship to personality traits and demographic characteristics. Behavioral Sciences \& the Law, 28(6), 832-849.

Payne, B. K., Tewksbury, R., \& Mustaine, E. E. (2010). Attitudes about rehabilitating sex offenders: Demographic, victimization, and community-level influences. Journal of Criminal Justice, 38(4), 580-588.

Pereda, N., Guilera, G., Forns, M., \& Gómez-Benito, J. (2009). The prevalence of child sexualabuse in community and student samples: A meta-analysis. Clinical Psychology Review, 29(4), 328-338.

Pickett, J. T., Mancini, C., \& Mears, D. P. (2013). Vulnerable victims, monstrous offenders, and unmanageable risk: Explaining public opinion on the social control of sex crime. Criminology, 51(3), 729-759. 
Rogers, D. L., \& Ferguson, C. J. (2011). Punishment and rehabilitation attitudes toward sex offenders versus nonsexual offenders. Journal of Aggression, Maltreatment \& Trauma, 20(4), 395-414.

Rothbaum, B. O., Foa, E. B., Riggs, D. S., Murdock, T., \& Walsh, W. (1992). A prospective examination of post-traumatic stress disorder in rape victims. Journal of Traumatic Stress, 5(3), 455-475.

Sample, L. L., \& Kadleck, C. (2008). Sex offender laws: Legislators' accounts of the need for policy. Criminal Justice Policy Review, 19(1), 40-62.

Saul, S., \& Taylor, K. (2017). Betsy DeVos reverses Obama-era policy on campus sexual assault Investigations. New York Times, 22.

Schiavone, S. K., \& Jeglic, E. L. (2009). Public perception of sex offender social policies and the impact on sex offenders. International Journal of Offender Therapy and Comparative Criminology, 53(6), 679-695.

Shackley, M., Weiner, C., Day, A., \& Willis, G. M. (2014). Assessment of public attitudes towards sex offenders in an Australian population. Psychology, Crime \& Law, 20(6), 553-572.

Shakeshaft, C. (2004). Educator sexual misconduct: A synthesis of existing literature. PPSS 2004-09. US Department of Education

Socia, K. M., \& Harris, A. J. (2016). Evaluating public perceptions of the risk presented by registered sex offenders: Evidence of crime control theater?. Psychology, Public Policy, and Law, 22(4), 375. 
Stack, L. (2016). Light sentence for Brock Turner in Stanford rape case draws outrage. The New York Times, 6 .

Thakker, J. (2012). Public attitudes to sex offenders in New Zealand. Journal of Sexual Aggression, 18(2), 149-163.

Weatherred, J. L. (2017). Framing child sexual abuse: A longitudinal content analysis of newspaper and television coverage, 2002-2012. Journal of Child Sexual Abuse, 26(1), 3-22.

Willis, G. M., Levenson, J. S., \& Ward, T. (2010). Desistance and attitudes towards sex offenders: Facilitation or hindrance?. Journal of Family Violence, 25(6), 545-556.

Willis, G. M., Malinen, S., \& Johnston, L. (2013). Demographic differences in public attitudes towards sex offenders. Psychiatry, Psychology and Law, 20 (2), 230-24 


\title{
Chapter IV. The impact of student status and assault type on sexual assault
}

\section{blame attributions}

\begin{abstract}
While many negative perceptions of those who perpetrate sexual violence exist, campus sexual assault is an underreported crime, where many offenders do not face serious consequences. This study will utilize a vignette based experimental design to understand whether the public sees campus offending as a similarly punishable crime to off-campus offending. To do this, two independent variables will be manipulated: Crime type (force, verbal coercion, and incapacitation) and student status (college student or non-student) for a 2X3 Factorial Design. Dependent variables include offender punishment and victim blaming. It is hypothesized that student status will serve as a protective factor for offenders, as will the commission of an assault type that is perceived to be less severe. It is also hypothesized that students who commit sexual assault while drinking will be punished less harshly, but student survivors who are assaulted while drinking will receive more blame than non-students. Findings in this study were not significant, but trends in the data support no differences in perception between students and non-students and minor differences in perception based on offense type.
\end{abstract}




\section{Introduction}

Sexual violence is a widespread societal problem that impacts numerous individuals throughout their lives. In the United States, about 17\% of adult women and three percent of adult men have survived an attempted or completed rape (NIJ, 1998). On college campuses, one out of five, or $20 \%$ women and $6 \%$ of men have experienced sexual assault, which includes but is not limited to rape (Koss et al., 1985; Krebs et al., 2007). While this study looks at perceptions of a male perpetrator and female survivor, it is noted that this is not the only configuration. All too common, experiencing an act of sexual violence can lead to both short- and long-term negative impacts for survivors (Cook \& Fox, 2012; Melssen, 2013; Sit \& Schuller, 2018).

In order to prevent acts of sexual violence and the antecedent negative consequences, attention must be paid to those individuals who perpetrate these acts. Reviews of the sexual violence perpetrator literature highlight overarching negative societal perceptions of those who commit sexual violence, particularly when the act is especially aggressive or the victim is underage (Zatkin et al., 2021). Yet, most people who perpetrate a sexually violent crime do not face any criminal sanctions. Only 310 out of every 1,000 rapes are reported to the criminal justice system and only 57 of those reports result in a conviction for the perpetrator (DOJ, 2015).

However, those offenders who are convicted of a sexual crime are treated harshly by society. In the United States, policies such as The Jacob Wetterling Act, Megan's Law, and the Adam Walsh Act impose punitive registration and community notification standards for offenders. Beyond this, it is common to see convicted sexual offenders face 
other sanctions, such as employment and residency restrictions, that make it difficult for these individuals to reintegrate into society after completing their punishment (Levenson et al., 2007).

Societal hatred of sexual offenders is due, in part, to a false narrative of sexual offending that predominates societal knowledge (Zatkin et al., 2021). Mythical beliefs frame the way sexual offenders are perceived at the institutional level, which is perpetuated by offender policy and offender media coverage. However, research has demonstrated that society views some offenders more negatively than others. Specifically, negative perceptions of offenders are positively correlated with sex crime severity and victim age, where those who commit violent sexual crimes against children are perceived most negatively (Kernsmith et al., 2009; King \& Roberts, 2015).

It is unclear whether the extreme societal distaste for those who sexually offend extends to all types of perpetrators. One sub-group that receives ample attention both in the media and in the psychological literature is perpetrators of sexual assault on college campuses. In fact, much of the public conversation surrounding sexual offending has focused on campus sexual assault. However, public perceptions of campus offenders seem to be mixed. The youth and inexperience of young college men, paired with relative societal privilege, allows some to see campus perpetrators as more deserving of redemption and rehabilitation than other types of offenders. On the other hand, social activism surrounding campus sexual violence prevention has led to extreme backlash and a call for more punitive measures (Linder \& Meyers, 2018; Mitra, 2015). 
PREVENTION AND PERCEPTIONS

Men who perpetrate sexual crimes on college campuses generally do not fit into the larger institutional narrative, but perhaps have a specific perpetration narrative of their own. Lisak and Miller (2002) introduced the idea of the "undetected rapist" through their work. This type of perpetrator utilizes drugs and alcohol to make chosen victims more vulnerable in settings such as parties, in order to facilitate sexual assault. As the literature around sexual assault has grown, this is the type of perpetrator that has been commonly discussed (Krebs et al., 2009; Mouilso et al., 2012). Media stories, such as that of the Brock Turner case, have helped to perpetuate this specific imagery for the general public as well. Though this narrative differs from the narrative of the general sexual offender, it still relies upon myths about sexual offending. What is unclear is whether the campus setting invokes the same reactions as assault off campus.

This study will aim to foster a better understanding about the campus context and the ways in which campus sexual assault may be perceived as similar to or different from other sub-types of perpetration.

\section{Theoretical Background}

\section{Victim Blaming and Attribution Theory}

Much of the literature surrounding the perception of sexual crimes relies upon attribution theory (Heider, 1958), or how individuals assign responsibility to victim and perpetrator within a crime scenario. The idea behind this is that individuals can gather information, allocate responsibility, and utilize their findings to understand the cause of or an explanation for events (Fiske \& Taylor, 1991). Unlike many other crimes, sexual assault invokes the phenomenon of victim blaming, or the inclination to assume that the 
victim of a crime is at least partially responsible for their fate (Whatley, 1996).

Numerous studies examining attribution of blame in sexual assault cases show that, more often than not, victims of sexual assault are blamed for their own assault (Grubb \& Turner, 2012).

While a victim of sexual assault should never be blamed, it is a misconception that the general public blames victims more so than perpetrators. Research supports that the manipulation of victim characteristics can impact how much blame is attributed to a sexual assault victim. For example, older victims, drunk victims, and/or victims who are dressed in a revealing manner receive higher attributions of blame than their counterparts (Abbey et al., 1998; Lambert \& Raichle, 2000; Mynatt \& Allgeier, 1990). However, victim blame and perpetrator blame are not mutually exclusive, meaning that individuals can simultaneously blame the victim and the perpetrator for a sexual assault. With this, perpetrators are generally assigned higher levels of blame than victims, even when victim blaming exists (Gerber et al., 2004; Landstrom et al., 2016). Of course, it is problematic to blame a victim for their own assault at all — victims should not receive merely "less" blame than their perpetrators.

\section{Offending Theory: Rational Choice or Miscommunication?}

Much of the perpetration literature focuses on a concept called Modus Operandi (MO), or the pattern of behavior an individual utilizes to perpetrate a crime (Kaufman et al., 1998; Kaufman et al., 2010). The term is traditionally used by law enforcement and criminologists, for the purpose of crime prevention and response. In the sexual assault literature, MO refers to the offender's pattern of behavior before, during, and after a 
sexual assault occurs (Kaufman et al., 1998; Kaufman et al., 2010). This means that the MO process is not only about how the assault occurs, but tactics used to select, groom, and isolate a victim, as well as tactics used to silence a victim after the assault (Hazelwood \& Warren, 2003).

A major theory underlying the study of MO is Rational Choice Theory (RCT; Cornish \& Clarke, 1987). This theory posits that prior to committing a crime, the perpetrator weighs the perceived benefits against the likelihood and potential consequences of getting caught. In other words, offenses are not accidents, but calculated choices made by the offender. These choices do not necessarily need to be premeditated, as the choice to offend can be made as an opportunity arises. What holds under the RCT framework is that offenders know that their actions are harmful and/or punishable, and only act if they feel that they can get away with it.

The Miscommunication Model (Tannen, 1992) has also been used to explain sexual assault. This model posits that men and women have different communication styles and that misinterpretation of verbal and nonverbal cues can lead to rape. If this model were to explain perpetration, the implication would be that offenders are unaware that they are committing sexual assault, therefore not making a true choice to offend. However, this model has not been substantiated by the research literature. Instead, studies have demonstrated that offenders use miscommunication as an excuse to justify their actions (Hansen et al., 2010). Young men have been shown to understand indirect refusals in a non-sexual context and there is no evidence that miscommunication is a cause of sexual violence (Beres, 2014; O'Byrne et al., 2006; O'Byrne et al., 2008). 
These studies confirm that offenders understand that their actions are harmful and choose to proceed with them, just the same. In the context of campus sexual assault, the application of RCT also works to dispel the common rape myth that offenders are unaware of the severity of their actions (Frese et al., 2004). Therefore, understanding typical offending patterns from an RCT perspective, as well as community reactions to those offending patterns, can lead to a better understanding of how to prevent campus sexual assault.

\section{Vignette Studies}

The methodological approach most commonly utilized in studies to evaluate attribution of blame in sexual assault scenarios is based on the use of brief case descriptions or "vignettes." This approach appears to be more reliable, valid, and realistic than other methods, such as surveys or questionnaires (Alexander \& Becker, 1978). The power of the vignette is in its ability to be easily adjusted to examine a broad range of important variables. This format allows researchers to examine factors that impact perceptions and judgments of sexual assault cases (Ward, 1995). Further, utilization of vignettes allows for manipulation of specific variables related to an assault (e.g., increasing severity), which is an indispensable tool for experimental design.

Much of the sexual assault literature utilizing vignette studies focuses on victim blaming, where different characteristics of a sexual assault victim (e.g., dress, substance intake, behavior) and their context (e.g., home, bar, party) are manipulated to compare differences in blame (Van der Bruggen \& Grubb, 2014). While less common, the vignette methodology has also been utilized to examine perpetration (Gerber et al., 2004; 
King \& Roberts, 2015; Landstrom et al., 2016). Often, vignettes used for measuring perceptions and blame attribution related to perpetration ask participants to decide how a perpetrator should be punished. The proposed study will utilize vignettes, written from an RCT perspective, to determine perceptions of and blame attribution of victims and perpetrators in campus sexual assault scenarios or vignettes.

\section{Comparing Campus and Non-Campus Perpetrators}

There has been an attempt in the literature to better understand individuals who perpetrate sexual violence, both on college campuses and in general. This has lent itself to basic demographic statistics, as well as an understanding of common stereotypes and myths about offenders. While it is not possible to utilize this demographic information to profile offenders, some commonalities do exist. This section will discuss what is known about both campus-based offenders and those in other settings, as well as the myths and stereotypes surrounding both groups. Finally, this section will review how perceptions of campus offenders are both similar to and different from perceptions of general offenders.

\section{General Perpetration Facts and Myths}

In general, those who are convicted of sexual offenses are adult men, with $85 \%$ of all offenders being men over the age of 18 (DOJ, 2013). Their victims are usually females. This is not to say that men are not sexually victimized - they are. However, most victims are female.

In terms of general offenders, the above statistics are all that can be factually generalized. Beyond basic age and gender demographics, offender characteristics are too heterogeneous to profile. There are four major myths that society believes about 
offenders (Zatkin et al., 2021). These myths include: (1) Offenders are strangers to victims; (2) Those who commit sex crimes are more dangerous than other types of offender; (3) All offenders are the same; and (4) Offenders cannot reform and will always offend.

As with any myth, there is typically a reason that they persist. In the case of sexual offense related myths, their depiction in the media, associated public fears, and its impact on victims and their families are likely factors. Sexual offending is a crime that does serious damage to individuals and communities and should be prevented. Yet, for prevention to be effective it needs to be based on accurate risk factors. In reality, most offenders know their victims — stranger rape or assault is fairly rare (Craun \& Theriot, 2009). This debunks Myth One. Myth Two - sex offenders are more dangerous than others--has some truth behind it, as vulnerability can be associated with victimization. However, anyone can be a victim of sexual assault not just those who are particularly vulnerable (Mancini \& Pickett, 2016). Myths Three (i.e., homogeneity) and Four (i.e., recidivism) are both false, though they are the most widely believed. It is difficult to profile offenders, which illustrates that not all offenders are the same (Galeste et al., 2012). And, though some adult sex offenders do reoffend, rates tend to hover around $25 \%$ (Harris \& Hanson, 2004), with sexual offenders being more likely to commit another crime that is non-sexual in nature. There is also evidence that treatment works and many who offend are capable of stopping (see Zatkin et al., 2021, for a comprehensive review). 
One more important note about these myths. Many of them are based on offenders who have committed Child Sexual Abuse. In particular, the stereotypical child sexual offender is an older man who sexually abuses a young child (usually a boy). When an offender does not fit this stereotype, such as a young man on a college campus with a "bright future," society seems to excuse his behavior. Instead of applying these myths, it is possible that campus offenders seem so different from the above characterization, which may cause the public to excuse their behavior. Next, I will explore what is known about campus perpetrators and discuss where offending myths do and do not apply.

\section{The Campus Perpetrator}

On college campuses, sexual violence is still a gendered crime, with $95 \%$ of assaults being perpetrated by men (Krebs et al., 2016). Unlike general offenders, those who perpetrate on college campuses are more likely to be younger, as undergraduate students are more likely to perpetrate than graduate students. Additionally, the highest risk group for perpetration is males in their first year of college (Campbell et al., 2017). Victims are generally female and more likely to be in their first year of college (Koss et al., 1987). Beyond this, campus perpetrators are just as heterogenous a group as noncampus perpetrators (Krebs et al., 2016).

In terms of offender myths, there has been no literature to date that examines how perceptions about campus-based offenders compare to those of other offenders. However, knowing that offending myths are pervasive among all types of offenders, it can be assumed that myths carry over to the campus setting in some fashion. Campus perpetration challenges these myths within the context of a college campus. 
On campus, perpetrators are generally known to their victims, at least casually. For example, one survey found that $53 \%$ of campus rapes were perpetrated by an acquaintance of the victim. The other $47 \%$ was not made up of strangers (though stranger assault does occasionally occur), but by perpetrators who know their victims very well (Krebs et al., 2016). Of note here is the fact that campus activism and prevention programming has done quite a bit to debunk this myth, and most college students know that perpetrators are unlikely to be strangers who jump out of the bushes (Linder \& Lacy, 2020). It is possible, however, that this myth still persists to a certain extent, where campus perpetrators are seen as a dangerous "other," or individuals who are unlike "normal" college students, and thus assumed to not be in one's social circle. Regardless of activism on campus, women still tend to be on guard for stranger offenders, even with the knowledge that they are unlikely to be assaulted by a stranger (Linder \& Lacy, 2020). In terms of Myth Two, some literature supports the idea that campus perpetrators target the most vulnerable victims, planning their assault ahead of time. Other literature supports sexual assault as more of an opportunistic crime that is fueled by alcohol, hookup culture, and peer-pressure. Some research has found that most campus offenders have perpetrated multiple sexual crimes, and suggests that these young men are planning their assaults ahead of time (Berkman \& Ehntholt, 2016). However, other research has shown that binge drinking is both common on college campuses and is related to a more opportunistic type of offending (Kingree \& Thompson, 2015). Likely, some campus offenders utilize both planned and opportunistic MO strategies, sometimes pre-selecting vulnerable victims. 
In terms of Myth Three, or homogeneity, there is no profile for campus offenders. While some characteristics such as involvement in athletics or Greek Life (Loh et al., 2005; Seabrook et al., 2018), alcohol use (Kingree \& Thompson, 2015), and antisocial behavior (Mouilso \& Calhoun, 2016) can be correlated to offending behaviors, campus offenders are not a homogenous group. Community-level risk factors for offending include peer pressure (Berkowitz, 1992) and experiences of childhood adversity (Mellins et al., 2017; Salazar et al., 2018; Zinzow \& Thompson, 2014). These factors do not predict or cause sexual violence and many who offend do not display any of these risk factors.

Finally, Myth Four, or the Recidivism Myth, is perhaps most important when considering how campus perpetrators are seen differently than other offenders. Prominent research in the area cites campus perpetrators as repeat offenders, who utilize a similar planned MO pattern repeatedly, with multiple victims (Lisak \& Miller, 2002). While this "undetected rapist" scenario does exist, the literature portrays a much more complex reality. Statistically, between $6 \%$ and $13 \%$ of college men have either attempted or completed a rape on campus (Abbey \& McAuslan, 2004; Koss et.al., 1987; Lisak \& Miller, 2002; Swartout et.al, 2015; Wheeler et.al., 2002; White \& Smith, 2004). These numbers are small, but they do begin to approach the statistic of $20 \%$ of college women sexually victimized on campus, which asserts that perhaps not all perpetrators are repeat offenders. Beyond this, the oft cited one in four victimization statistic encompasses more than rape or attempted rape (Koss, 1987). When asked about broader sexual misconduct, between 19 and 47 percent of college men admit to perpetration behaviors (Abbey \& 
McAuslan, 2004; Koss et.al., 1987; Loh et.al., 2005; Mills \& Granoff, 1992; Strang et.al., 2013; White \& Smith, 2004). These numbers do not support the same small group of men as repeat offenders. On top of this, research on the trajectory of sexual offenders determines that many offenders desist after one victim (Abbey \& McAuslan, 2004).

There is a clear consensus that like other types of offenders, campus offenders do not conform to perpetration myths. What is unclear, however, is how society sees campus offenders in relation to these myths. Does simply being a student on a college campus give offenders societal protections? To untangle this, a first step seems to be understanding whether those who perpetrate as students on college campuses are perceived differently than similar offenders who perpetrate off campus. If there is a significant difference in how these offenders are blamed, it seems that further exploration of how these myths dictate this difference is warranted.

\section{Campus Offenders and Assault Tactics}

Another factor that can impact how a perpetrator of sexual assault is perceived and punished is the modus operandi that they utilized to assault a victim. Literature suggests that perpetrators use three major types of tactics in order to commit a rape or sexual assault: (1) force; (2) incapacitation; and (3) verbal coercion. Force involves physically restraining or physically coercing an individual to engage in sexual behavior against their will (Fedina et al., 2018). This type of assault is rooted in power, and is often what first comes to mind when thinking about sexual assault (Cleveland et al., 1999). Force is also correlated with less victim blaming than other tactics (Russell et al., 2011). However, force is least common in the context of campus sexual assault. 
More common on campus is assault by incapacitation, or the utilization of drugs and alcohol to commit sexual assault. This tactic is used to both "bolden" perpetrators and weaken victims. On campus, drugs such as roofies are not often used $(<1 \%$ of cases, Krebs et al., 2007), and the most frequent substance used for incapacitation is alcohol (Krebs et al., 2007). Some perpetrators will purposely incapacitate their victims and others take advantage of victims who have been drinking on their own (Krebs et al., 2007). Victims who have been drinking tend to be blamed more for their own assault than those who have not been drinking (Grubb \& Turner, 2012).

Perhaps the most utilized perpetration tactic on campuses is verbal coercion, which is also hardest to define. Most agree that coercion is a power-based but nonphysical, verbal effort to bully a victim who would not otherwise comply into sexual behavior (Pugh \& Becker, 2018). Tactics used here are intimidation, lies, or other types of pressure that make a victim feel that she has no choice to comply, because she will be in physical or psychological danger otherwise (Fedina et al., 2018). This is a very common tactic used by campus offenders. Additionally, victim blaming tends to be highest under these circumstances (Pugh \& Becker, 2018; Weiss, 2009).

\section{Punishment of Sexual Assault}

A common way to measure attribution of blame for sexual offenders has been to examine how participants feel they should be punished for their actions (King \& Roberts, 2015). In comparison to other crimes, research suggests that the public believes that offenders should be punished more severely than other types of criminals (Rogers \& Ferguson, 2011). On college campuses, however, sexual offenders are sometimes not 
sanctioned through the justice system, but through campus mechanisms (DeMatteo et al., 2015; McMahon, 2008). This section will discuss common punishments for offenders both on and off campus.

\section{Criminal Justice System}

In the criminal justice system, sexual offenders who are convicted of a sexual crime are mandated to some combination of prison, sex offender registration, and required treatment. For elaboration on what these punishments consist of, see the review by Zatkin and colleagues (2021). Some literature shows that prison sentences seems to be the most highly supported punishment for offenders (Bergstrom et al., 2017). The average recommendation for a prison sentence ranges from 15.5 to 38.8 years (King \& Roberts, 2015; Levenson et al., 2007). Another highly supported punishment for sexual crimes is public registration, with many believing that all sexual offenders should have to register (Kernsmith et al., 2009). Generally, individuals believe that convicted sexual offenders should be on a registry between 20.5 and 41.9 years (King \& Roberts, 2015; Levenson et al., 2007).

An alternative to prison and registration that has become common for juvenile offenders is mandatory counseling (Nelson et al., 2002; Zimring, 2002). This can take place both in the community and in residential treatment centers. There is no data on public support for this type of sanction, however, it most aligns with what is seen on college campuses. This may be because campus offenders look more like juveniles than adults in the public's eyes.

\section{Punishment on Campus}


It is not clear whether sanctioning campus offenders is the responsibility of Colleges and Universities or the responsibility of the criminal justice system (DeMatteo, et al., 2015; McMahon, 2008). Campus punishment seems to be less enduring than common sanctions through the criminal justice system, with the most commonly employed sanctions being expulsion (84.3\%), suspension (77.3\%), probation (63.1\%), censure (56.3\%), restitution (47.8\%), and loss of privileges (35.7\%) (Karjane et al., 2002). However, the White House Task Force to Protect Students from Sexual Assault (2014) recommends that campus offenders face both campus sanctions and the criminal justice system. In practice, however, most campuses do not have policies that require coordinated sanctions with the police (McCaskill, 2014).

As many campus offenders do not face the criminal justice system, it is unclear how campus offenses are judged relative to criminal justice sanctions. This uncertainty adds to the main question underlying this study: does the public see campus offending as a similarly punishable crime to off-campus offending?

\section{Research Questions and Hypotheses}

Based on the literature reviewed, above, we are lacking a clear understanding of how the campus setting impacts the way in which sexual offenders are perceived and punished. This study is intended to provide initial insights to foster a better understanding of the relationships between blame attribution and both sexual assault location and severity. In particular, this research aims to understand if and how perceptions of campus sexual assault differ from assault off campus. Below is a list of four research questions and their corresponding hypotheses. 
PREVENTION AND PERCEPTIONS

Research Question One. Does "college student status" impact the way an

offender is punished? This question seeks to uncover whether being enrolled as a college student is protective factor for young people who commit acts of sexual violence. The relative perceived youth of college students, as well as the different system of adjudication for sexual crimes on campus (McKaskill, 2014), it is hypothesized that offenders will be punished less harshly within a college environment than outside (H1).

\section{Research Question Two. Does sexual crime type impact the punishment} severity individuals see as fair? This question aims to examine the perceived severity of a crime, and how that impacts the way an offender is punished. Two hypotheses come from this question, which look to examine the relationship between severity and student status. The first is that participants will see sexual assault using physical force as most deserving of severe punishment regardless of whether a student or non-student is the offender (H2a). On a similar note, the next hypothesis is that participants will see verbal coercion as least punishable, regardless of offender student status $(\mathrm{H} 2 \mathrm{~b})$. The literature supports this trend, where physical force is seen as most severe and verbal coercion as least severe, across contexts and offender identities (Brown et al., 2009; Testa et al., 2004). There is no evidence in the literature to show that this pattern will differ for student offenders.

\section{Research Question Three. Is utilizing alcohol as a tool for sexual assault} perpetration perceived differently if the offender is a student? Here, this study will examine whether the utilization of alcohol to commit a sexual assault will be perceived differently based on offender student status. It is hypothesized that students will be 
punished less harshly for assault by incapacitation than non-students (H3). This is due to the normalization of drinking culture on college campuses (Borsari \& Carey, 2001). It is plausible that because drinking and alcohol are seen as "what college students do," perpetrators who are college students will be looked upon less harshly for utilizing alcohol to commit sexual assault.

\section{Research Question Four. How do student status and severity impact victim-}

blaming? This question looks at how survivors are perceived, as opposed to perpetrators. While it is known that people blame perpetrators more than survivors, it has also been shown that survivors are often blamed to some extent for their own assaults (Hayes et al., 2013). One factor that has been supported in the literature is that more "gray assaults" (i.e., assaults that are not based on physical force) lead to higher rates of victim blaming. Therefore, this study hypothesizes that victim blaming will be highest in the coercion condition, and lowest in the force condition (H4a). This gets a bit trickier when the role of alcohol is considered, where college student survivors who were assaulted while drinking may be perceived differently than non-students. Along with $\mathrm{H} 3$ (i.e., less harsh punishment for students using incapacitation to assault), it is hypothesized that victim blaming would rise in cases of assault by incapacitation for student survivors (H4b).

\section{Methods}

This section describes the study's methodology. The methods section includes a description of proposed participants, variables, procedures, and the data analysis plan.

\section{Participants.}


PREVENTION AND PERCEPTIONS

Recruitment. Participants were recruited using Amazon's Mechanical Turk

(MTurk) software. MTurk is an online labor market utilized by researchers to employ "workers" for short-term tasks, such as filling out surveys (Dworkin et al., 2016). This recruitment method has been used in psychological studies and has been shown to be as effective as other online survey recruitment methods (Franiuk et al., 2020). An alternative that was explored involved the utilization of a sample of college students. However, because campus location is a variable of interest in the study, a sample that is not specific to a college campus will provide a broader, more useful perspective on how the study population (United States Citizens) responds to this study.

Sample Size. A power analysis utilizing G*Power software for MANOVA via Pillai's Trace with six response groups and two response variables, indicates that a sample size of $N=129$ will be necessary to achieve significant power at the .05 alpha level with a medium effect size of .15 (as suggested in Steyn \& Ellis, 2009). Similar, recently published, vignette style studies have sample sizes ranging from $N=163$ to $N=826$ (Dyar et al., 2019; Stuart et al., 2019). As MTurk-collected samples for vignette-based studies can come with high attrition rates (Franiuk et al., 2019), a starting sample of 400 was collected for this study. As expected, about 75 participants were eliminated from analyses. Of these 75 participants, 20 did not finish any of the survey items, and 55 gave a "nonsense" response to an open-ended question (e.g., a response of "TEENIC" for a sport played in college) or finished the survey in an unreasonably short amount of time (i.e., 30 seconds). This resulted in a final sample size of 325 . 


\section{Study Design.}

This study is a $2 \times 3$ Factorial Design, where independent variables include the location of the sexual assault (on a college campus or off of a college campus) and the type of sexual assault (physical force, incapacitation, and verbal coercion). After consenting to participate in the study, respondents were randomly assigned to one of six conditions (details are provided below). The core vignette describes a young woman named Liz, who attends a party with a friend. After losing track of her friend, she runs into an acquaintance named Josh, and the two spend the remainder of the party dancing and flirting. Josh offers to walk Liz home, where they watch a movie. During this movie, Josh sexually assaults Liz. This vignette style is adapted from a similar vignette utilized by Abbey and colleagues (2003) for their study of potential date rape and was modified to fit the goals of this study.

The first independent variable, student status, is manipulated in this study by changing key phrases in the vignette that show that Liz and Josh know one another from either work or a college class (See Supplemental Material).

The second independent variable, sexual assault type (i.e., physical force, incapacitation, verbal coercion) is manipulated by altering the end of the vignette to depict a specific type of sexual assault (i.e., physical force, verbal coercion, and incapacitation; See Supplemental Material). The "force" condition depicts a scenario that clearly meets all legal criteria for rape (Yndo \& Zawacki, 2017). The incapacitation scenario is modeled after similar vignettes in the literature, as is the coercion scenario (Yndo \& Zawacki, 2017). 
PREVENTION AND PERCEPTIONS

Random assignment allowed each participant to see one vignette, with a random combination of two of the independent variables.

\section{Dependent Variables.}

After reading the vignette assigned by condition, participants were told that Liz decided to press charges against Josh for his actions and were asked to answer a series of questions as though they are a jury member at the trial. These questions addressed Victim Blaming and Punishment.

Victim Blaming. Victim blaming was measured using a 5-item scale (van Prooijen \& van den Bos, 2009). Each item was measured on a 7-point Likert-type scale, with anchors being "Strongly Disgree (1)" and "Strongly Agree (7)." All items ask about who is at fault for the interaction between Liz and Josh and are provided in Supplemental Material.

Punishment. Punishment was measured with three items, each asking about a distinct type of punishment: Jail, Sex Offender Registration, and Mandatory Counseling. Jail means that the offender will spend time in prison, Sex Offender Registration means that they will be on a public registration list, and Mandatory Counseling means that the offender will have to see a therapist to prevent recidivism. Modeled after a study by King \& Roberts (2015), participants were asked to assign a sentence for each punishment type ranging from 0-99 years. The implication of 0 years is that the punishment is not deserved, and the implication of 99 years is a life sentence. Each punishment type serves as a single dependent variable. Wording for each punishment variable can be found in the Supplemental Material. 
PREVENTION AND PERCEPTIONS

Sex Offender Status. As the literature supports that labeling a person as a sexual offender is positively related to punitive measures (Socia \& Harris, 2016), respondents were asked to state whether they believe Josh is a sexual offender through a single yes/no question. Exact wording can be seen in the Supplemental Material.

Covariates. To account for demographic differences that may impact the way that participants view the vignette, three participant variables (i.e., gender, parental status, education level), were included in this study as covariates. These variables were collected from a demographics questionnaire that all participants will see after the vignette-based questions (Supplemental Material). According to a literature review conducted by Zatkin and her colleagues (2021), gender, parental status, and education level are three variables that can have an impact upon how sexual offenders are perceived. Namely, females, parents, and individuals with fewer years of education view offenders more negatively than others (King \& Roberts, 2015; Shackley et al., 2014; Socia \& Harris, 2016; Willis et al., 2013). However, these differences are sometimes negligible, as overall perceptions of sexual offenders are negative (Katz-Schiavone et al., 2008).

\section{Results}

This section will cover the results from this study. First, it will describe the demographics of the sample, followed by a description of how the hypotheses were analyzed. Finally, covariates of the study and an exploratory analysis are discussed.

Sample Demographics. The final sample includes 325 participants. The sample is predominately white $(80.6 \%)$, but more evenly divided across gender ( $45 \%$ men, $54.5 \%$ 
women, $.5 \%$ non-binary). The range in age is from 20 to 83 years $(M=42.65, S D=$ 13.3). Almost two-thirds (61.5\%) of the sample are parents. For the $91.6 \%$ of the sample that attended at least some college, $21.8 \%$ were involved in Greek Life, $29.2 \%$ played a sport, and $25.8 \%$ were involved in a campus religious organization. See Table 1 for demographic information.

Descriptive Statistics for Punishment Variables. Across conditions, mean punishment for the offender in the vignette was harsh. On average, participants suggested 19 years of jail $(S D=23.8), 32.5$ years on the offender registry $(S D=33.7)$, and 23.8 years of mandatory counseling $(S D=29.6)$ for Josh. Interestingly, the modal suggestion for both jail and registration was zero years, while it was 10 years for mandatory counseling.

Preliminary Analyses. Prior to hypothesis testing, all variables were analyzed to determine if assumptions for MANOVA were met. There were significant correlations between three of the four dependent variables, but none reached the .9 threshold for multicollinearity (Table 2). No univariate or multivariate outliers were detected. Box's M test was not significant at the .001 level $(p=.02)$, indicating homogeneity of covariance. Levene's test was also not significant, indicating homogeneity of variance.

Hypothesis Driven Analyses. For all hypotheses, a two-way multivariate analysis of variance (MANOVA) was conducted. The dependent variables for this analysis were the three punishment variables and the mean score for the victim blaming scale, with the independent variables being the standardized versions of student status and assault type. The only significant finding was for Victim Blaming in terms of assault type $(F(2$, 
$325)=3.56, p=.03, \eta^{2}=.022$ ). Plots showing marginal means for all four dependent variables can be seen in Figures 1-4.

Post-Hoc Analyses. To test for differences within assault type, Tukey's HSD posthoc test was included with the initial MANOVA model. This analysis examines Victim Blaming in terms of Assault type $(p=.03)$. Here, we see that participants have engaged in victim blaming significantly less when presented with assault by force than with either assault by alcohol $(p=.04)$ or assault by coercion ( $p=.09$; a trend toward significance). There was no difference in victim blaming between alcohol and coercion $(p=.93)$.

Covariates. To see if demographic factors might impact the significance of the model, parental status, gender and education level were added as covariates. None of these variables impacted the significance of the model, so the original MANOVA model was retained.

Sex Offender Status. Two chi-square analyses were conducted to see if student status or assault type impacted whether participants viewed Josh as a sexual offender. Neither produced significant results ( $p=.46$ for student status, and $p=.98$ for assault type). Across conditions, $81 \%$ of the sample endorsed Josh as a sexual offender by responding "yes" to this item.

\section{Discussion}

This section will discuss the results in terms of each research question, and then provide implications, limitations, and future directions for this study. This is the first study to examine differences in perceptions between student and non-student offenders and provides important insights into the offender perceptions literature. 
PREVENTION AND PERCEPTIONS

Research Question One. This question aimed to answer whether college students were punished differently as compared to non-students for the perpetration of sexual assault. The results of the study indicate that there are no significant differences in the perception of appropriate punishment within this sample, and that there is no statistical support for H1. In other words, there is no evidence in this study that appropriate punishments for college student sexual offenders are perceived differently than offcampus offenders. This aligns with the offender homogeneity myth (Zatkin et al., 2021). According to this data, participants may have difficulty differentiating between types of offenders.

Research Question Two. This question explores main effects for the second variable of interest, assault type. While the proposed hypotheses ( $\mathrm{H} 2 \mathrm{a}$ and $\mathrm{H} 2 \mathrm{~b}$ ) were not supported by the results of this study, one finding trends toward significance. Offenders who commit sexual assault using force were "given" more years on the offender registry by respondents than those who commit sexual assault through coercion. This finding is supported by the literature, which reflects repeated instances where the use of force in sexual assault is judged most harshly (Brown et al., 2009; Testa et al., 2004). It is unclear, however, why this pattern only holds for registration, and not for jail or counseling time. These findings also align with the recidivism myth (Zatkin et al., 2021). Offenders who use force are most "typical" of the offender schema, and therefore are seen as most likely to continue offending (Linder \& Lacy, 2020). The lack of significant differences in the mandatory counseling variable are also consistent with the recidivism 
myth, as it supports the notion that offenders are unlikely to respond to treatment (Willis et al., 2013).

Given the Rational Choice Theory (RCT, Cornish \& Clarke, 1986) perspective, it can be argued that this study did not uncover differences in perception based on offense type since the outcome was stated as Liz accusing Josh of sexual assault. Specifically, RCT suggests that offenders will change their perpetration pattern to best fit the context in which they are offending. Since participants only saw one ending and were told that Josh was on trial for committing sexual assault, they may have seen the assault type as a means to his end goal. This is further supported by the majority of the sample labeling Josh as a sexual offender. It could be that if Josh's actions and label were left more ambiguous, assault by force may have been punished more harshly.

Research Question Three. This question and the accompanying hypothesis examined whether alcohol as a tool for assault impacts perceptions of student offenders differently than non-student offenders. While findings were not statistically significant, descriptive results do show a curious pattern regarding college student status. For jail time, mean years assigned for non-students who perpetrated through use of force is 20.3 years, and incapacitation 20.4 years. For students, the mean years assigned is 21.5 for force, and 18.9 for incapacitation (Figure 1). This pattern holds for registration time and mandatory counseling (See Figures 2 and 3). For now, H3 cannot be supported.

Research Question Four. This final question evaluates the role of victim blaming. Here, findings indicate that victim blaming is lowest when force is used, and higher in cases of incapacitation and coercion. The difference between force and incapacitation is 
statistically significant, while the difference between force and coercion may be considered trending toward significance. In all cases, victim blaming is lowest in cases of force. This leads to partial support for H4a, which states that victim blaming will be lowest in the force condition, and highest in the coercion condition. H4b, which looked into the interaction between student status and victim blaming when alcohol is involved, cannot be supported at this time. This does not align with past research on campus culture regarding the involvement of alcohol in sexual assault and may be worth more investigation.

\section{Implications}

The one significant finding in this study, indicated that we victim blame more in cases of coercion and incapacitation than in cases of force. This is consistent with the literature, and consistent with the idea that "forcible" rape is the only real crime (Russell et al., 2011). Victim blaming is also significantly and negatively correlated with two of the three punishment variables: jail and counseling. These correlations are on the lower side, providing some support for the notion that we tend to victim blame more, while punishing offenders more, at the same time. This supports past findings in the literature which state that victim and perpetrator blame are not mutually exclusive (Gerber et al., 2004; Landstrom et al., 2016). In fact, results of this study reveal that victim blaming may be impacted by context, while perpetrator blame typically is not.

The majority of this study's hypothesized group differences were not supported. However, study findings do contribute to our understanding of how the public perceives sexual offenders, in general. Namely, this study strengthens the idea that society judges' 
offenders negatively regardless of the circumstances of their assault (Sample \& Kadleck, 2008). Eighty-one-percent (81\%) of study participants described Josh as a sex offender, and suggested an average of 19 years of jail, 32.5 years on the offender registry, and 23.8 years of mandatory counseling across conditions. It is notable that in contrast, the average jail sentence for rape is 6.2 years, and 15 years for murder (DOJ, 2010). This means that participants assigned double the average sentence for rape, and four more years than the typical murder sentence for the "offender" in the vignette. These are long term and lingering punishments that are not impacted by the offender being in college.

Another interesting finding is that descriptively, this sample suggested that Josh should be registered ( $M=32.5$ years) for longer than he received counseling ( $M=23.8$ years). Average time spent on the registry varies by state and crime type, but the most punitive measures are around 20 years (Bouffard \& Askew, 2019). There is no known average duration for mandated counseling. Again, average punishments are much higher in the experiment than what is seen in the real world. This supports the pervasiveness of the recidivism myth. Past research has shown that fear of offenders leads to harsher punishments (Sample \& Kadleck, 2008), and that perceptions of appropriate punishment do not align with actual punishments (Bailey \& Klein, 2018).

This is further complicated by ample evidence that the registry is ineffective, and harmful for juveniles (Letourneau et al., 2018). Registered juveniles are more likely to have mental health issues, suicidal ideation, and be victims of sexual violence (Letourneau et al., 2018). The campus case is noteworthy, because college students are somewhere between juvenile and adult offenders. Moreover, evidence suggests that the 
brain does not finish developing until the age of 25 , which means that college students may have more in common cognitively with juvenile offenders than adult offenders (Voith et al., 2020). Supporting this assertion is a finding that campus offenders often desist without intervention, or only have one victim (Abbey et al., 2012). College campus sexual violence protocols can serve as a buffer for young people who can benefit from redirection and become non-offenders. Knowing that the public may not see a difference between campus offenders and non-campus offenders, means that campus administrators are in a no-win situation. It's likely that any course of action on their part will upset someone. At the same time, however, they are in a position where they can create policies that are both survivor-centered and allow fair and equitable punishment for perpetrators. Restorative justice approaches, for example, are an avenue which allow for the survivor to gain justice, and for the perpetrator to be held accountable while being allowed to grow, change, work to move beyond their offending behavior (Harper et al., 2017; Koss et al., 2014).

It is also important to consider that the modal suggestion in this study for both jail and registration across conditions is zero years ( $16.6 \%$ of the sample), and for mandatory counseling is 10 years $(12.6 \%$ of the sample). While the average punishments were high, the vignettes make it clear that Josh DID rape Liz in all three study scenarios. No punishment in this case is just as problematic as punishment that is too harsh. This brings to mind the larger research question asked by this study_ why do we demonize some offenders, and exonerate others? Perhaps the better question is why some individuals veer toward being too punitive, and others are not punitive enough. To the extent that 
findings from vignette studies reflect not only public opinions, but those of school administrators, this question may have important implications for how schools determine their balance between more restorative justice and more punitive approaches to addressing campus sexual assault.

\section{Limitations}

One significant limitation to this study is the integrity of the sample. The first author noticed some inconsistencies with open-ended items provided by M-Turk participants. Primarily, a number of open-ended items were responded to in all capital letters, severely misspelled, and did not answer the question posed. For example, COLOFORNIA was a common response $(N=5)$ for the question, "state which sport you played in college." While these respondents were eliminated from final analyses, there is concern that the sample still contains illegitimate responses. There is a growing concern that Bots, or computer programs designed to complete MTurk tasks, are a strong presence in data produced in this platform (Chimielewski \& Kucker, 2020). Another concern is that there are individuals who use data farms designed to bypass collection restrictions and may not be located in the United States as their IP Addresses suggest (Chimielewski \& Kucker, 2020). The consensus in the literature is that these concerns can be dealt with by screening the data through the use of response validity indicators (Chimielewski \& Kucker, 2020). Though the first author did carefully screen the data as detailed in the methods section, the study could have included a more robust attention check to ascertain if the data analyzed was strictly from legitimate participants. 
Another limitation is a concern that the vignette used in this study too subtly differentiated between the student and non-student conditions. Both vignettes describe an event that could be perceived as a college party, even though the non-college condition pair clearly met at work. Therefore, it is possible that from a participant perspective, both conditions were seen as measuring individuals in the same context (i.e., rather than the college, non-college distinction intended). Such a case could explain why there were virtually no differences between respondents in these two conditions, on any of the outcomes.

Similarly, the lack of a college student comparison group in this study also represents a limitation. With an average respondent age of 42 years old, the participants in this study likely have a different perspective on college and campus sexual assault than current college/university-age students. While the study sample did include individuals reflecting a wide range of demographics (i.e., with the exception of race), targeting a college-specific sample may lead to a clearer picture about how current college students perceive campus sexual assault.

Finally, it must be noted that the study sample was almost exclusively white, suggesting that these findings are unlikely to generalize to individuals from different racial groups. Moreover, it is unknown how the participants perceived the race of the survivor and perpetrator in the study vignette. Very little research has been conducted in this area, but there are strong findings in the literature about race and bias with regard to the criminal justice system. For example, black men are more likely to face harsh 
punishment for crimes than their white counterparts (Eberhardt et al., 2006). Both of these issues would be important to address in future studies.

\section{Future Research Directions}

The process of conducting this investigation, as well as, its findings suggest a number of directions for future studies. First, it would be worthwhile to replicate this study with a college sample and a matched community control group. College student data would not have the same issues with validity that are present with the MTurk sample and would offer insights into how college students perceive themselves relative to the general population. Moreover, inclusion of a community comparison group of similar age and socio-economic status would help further address sampling concerns associated with the current study.

Though participants were asked if they were parents, it would be useful to ask questions about the gender and age of children in future studies. It has been shown that parents of young children are harsher on sexual offenders, and have more fear toward offenders (Kernsmith et al., 2009). Similarly, it might be that parents of college-aged women would punish Josh more harshly in this vignette. Further investigation into the impact of parenting on perceptions is warranted.

Future studies should also examine participants' perceptions of the vignette perpetrator's age and more carefully manipulate this variable. Study conditions could systematically look at different combinations of perpetrator - survivor age (e.g., Both in their early 20s, both older, younger survivor (20's) and older perpetrator (30's). Findings from such a study, if significant, could provide insights into important age 
differences and address what may have been too subtle of a manipulation in this study. On a similar note, a line of script could be added to the non-student vignette indicating that the two (i.e., perpetrator and survivor) are not in college, and a manipulation check could be included as well, to ensure that this manipulation had the intended impact.

In the long-run, if it turns out that college student status does not impact how offenders are perceived, it may be most useful to begin a more systematic examination of the effects of other demographic variables on perceptions of and myths about campus sexual offenders. Examining different racial combinations of the perpetrator and survivor may be particularly productive. Studies examining other perpetrator and survivor demographic variables (such as race), can help identify in what ways perpetration myths may differ, or if they are stable, across target participants. Finally, there may also be value in looking at how different segments of the public (e.g., older vs. younger, lower vs. higher SES, different racial groups) may impact findings.

\section{Conclusions}

This study examined differences in perceptions of victim blaming and offender punishment for college students and non-students, as well as based on assault type. While there are differences in victim blaming based on assault type, there were no other differences detected in this study. This supports the idea that we have stable views toward sexual offenders across contexts, but more research is warranted to better understand these perceptions. This is an important addition to the literature surrounding perceptions of sexual offenders and can lead into new avenues of research uncovering whether our perceptions of offenders are stable across context. 
PREVENTION AND PERCEPTIONS

Table 1. Sample Demographics

\begin{tabular}{lcc}
\hline \multicolumn{1}{r}{ Characteristic } & N & $\%$ \\
\hline Gender & 146 & 45 \\
Man & 177 & 54.5 \\
Woman & 1 & 0.5 \\
Non-Binary & & \\
Race & 262 & 80.6 \\
White & 72 & 19.4 \\
Non-White & & \\
Parental Status & 200 & 61.5 \\
Parent & 124 & 38.2 \\
Non-Parent & & \\
Education Level & 294 & 91.6 \\
College & 27 & \\
No College & & \\
\hline
\end{tabular}

Table 2. Correlations between Dependent Variables

\begin{tabular}{lrrrr}
\multicolumn{5}{l}{ DV Correlations } \\
\hline \multicolumn{1}{c}{1} & \multicolumn{2}{l}{ 2 } & 3 & 4 \\
\hline 1 & - & & & \\
2 & $.635^{* *}$ & - & & \\
3 & $.800^{* *}$ & $.718^{* *}$ & - & \\
4 & $.295^{* *}$ & -.87 & $.156^{* *}$ & - \\
\hline
\end{tabular}

**. Correlation is sig. at the .01 level

Note. 1: Jail, 2: Registration, 3: Counseling, 4: Victim

Blaming 
Figure 1. Estimated Marginal Means for Jail Variable

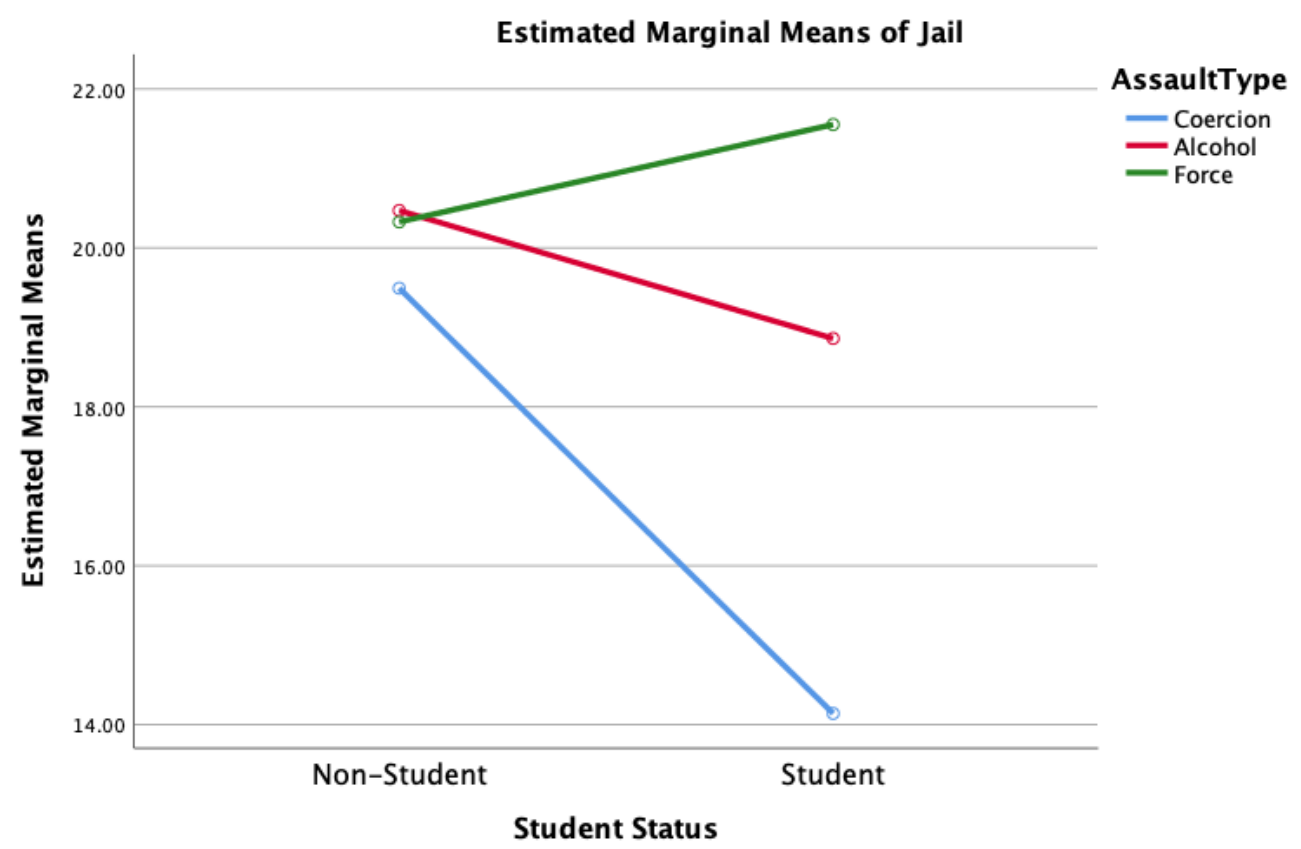


Figure 2. Estimated Marginal Means for Registration Variable

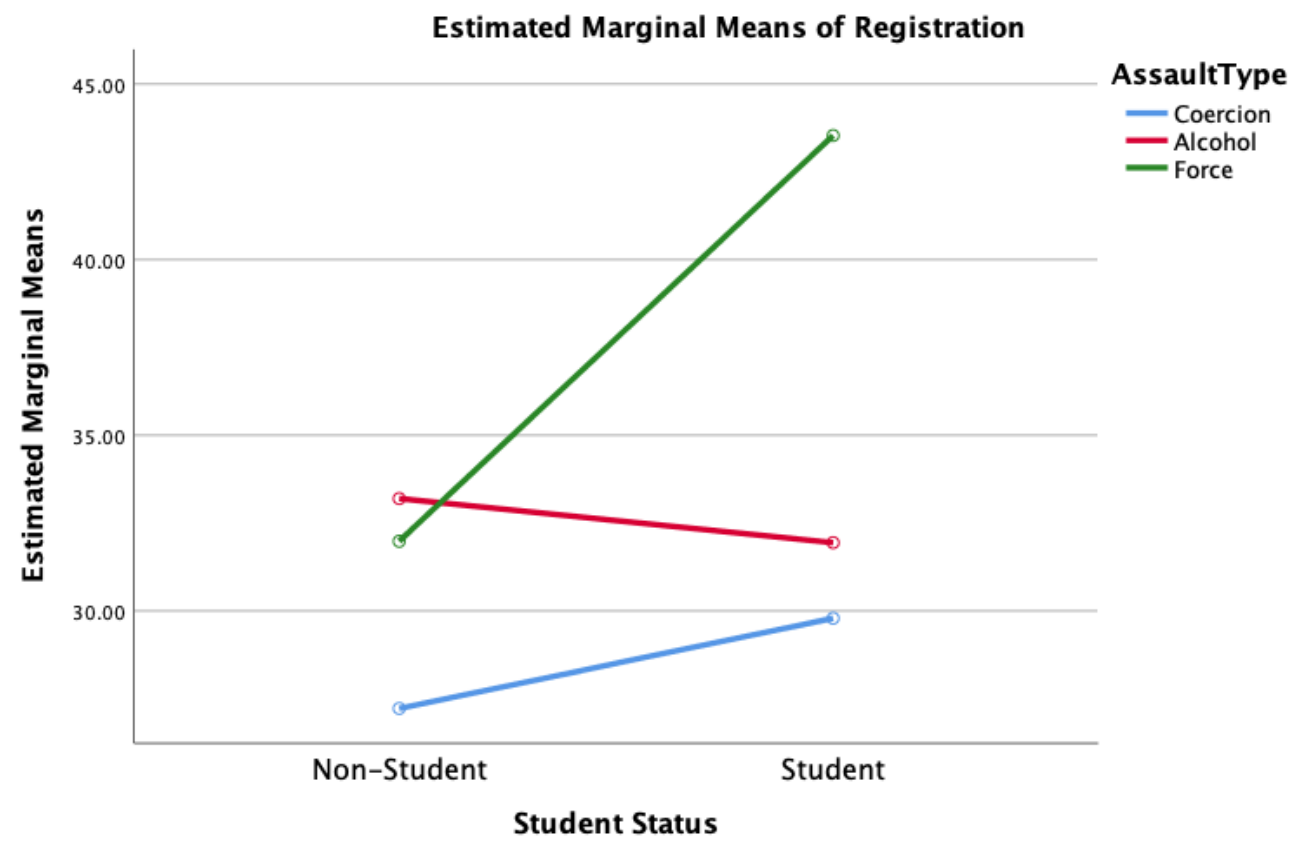

Figure 3. Estimated Marginal Means for Counseling Variable

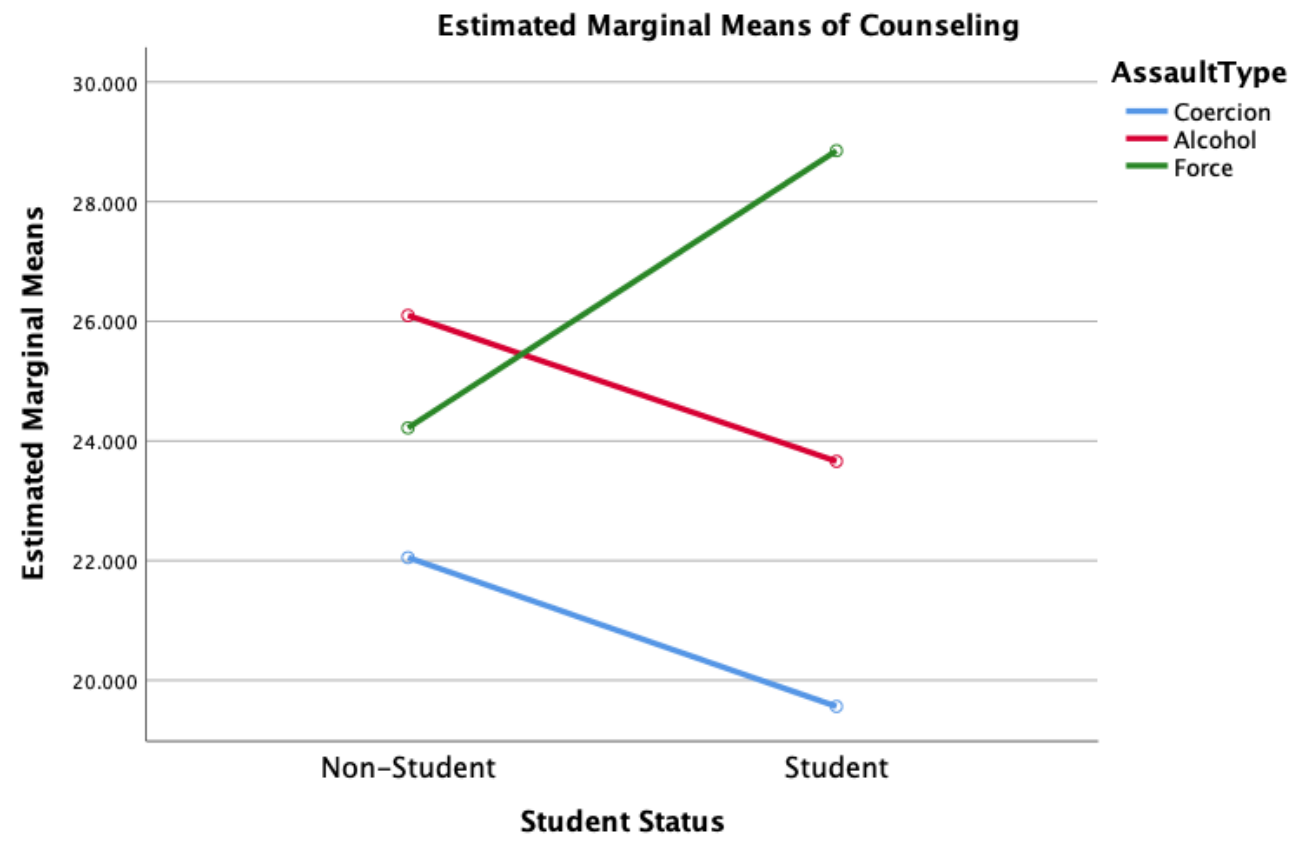


Figure 4. Estimated Marginal Means for Victim Blaming variable

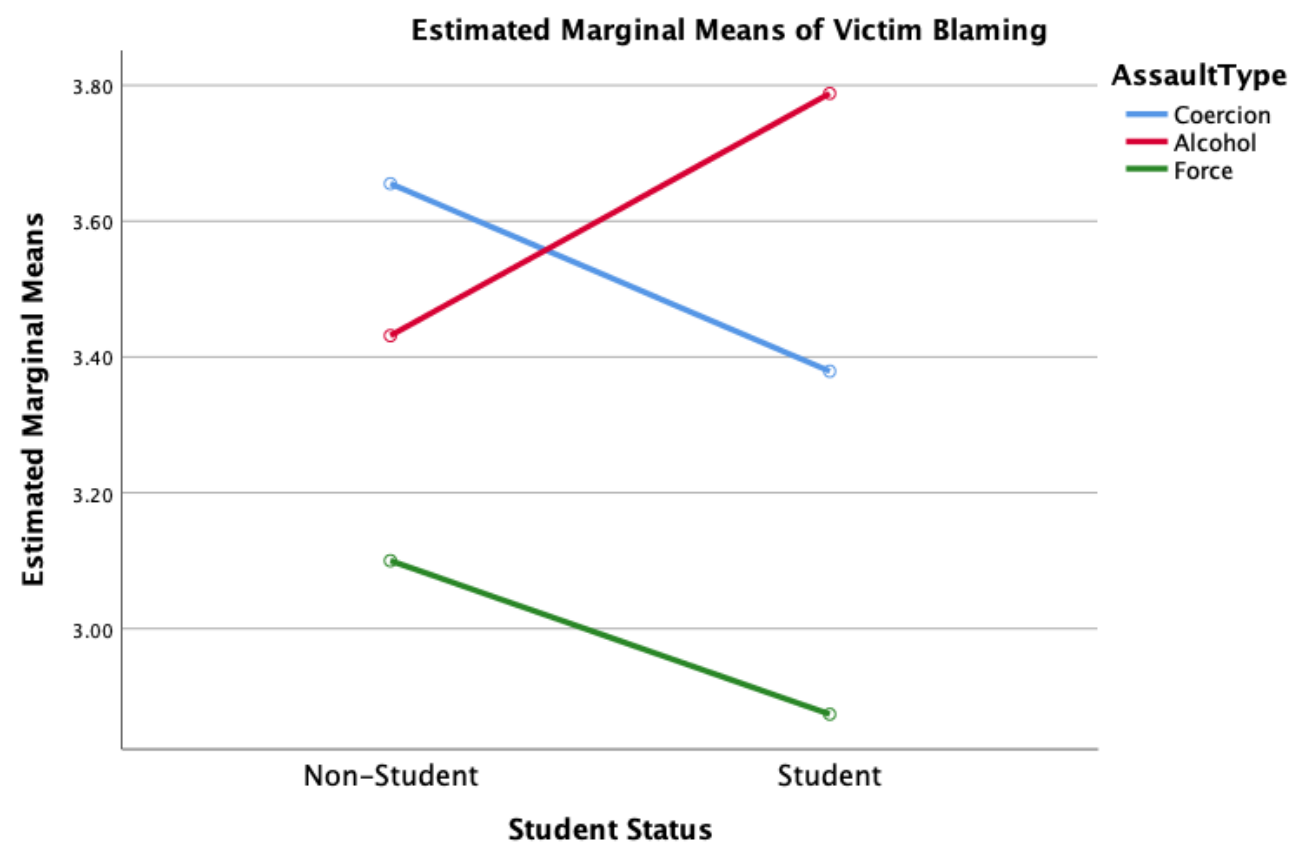


PREVENTION AND PERCEPTIONS

\section{Supplemental Material}

Liz (20 years old) is excited to spend her Friday evening at the 21 st birthday party of a close friend, Sam (ON CAMPUS OR IN HER NEIGHBORHOOD). She spends time getting ready for the party with her friend and roommate, Jen. Upon arriving at Sam's house, Liz and Jen notice that there are quite a few people at the party, dancing, laughing, and having a good time. After about an hour at the party, Liz takes a bathroom break, and afterward, cannot find Jen. She spends about 10 minutes looking for her friend, but the party is very crowded, and she does not have any luck spotting her. As Liz is looking around, she sees Josh (21 years old), who she has seen around (CAMPUS OR THE OFFICE). Josh (IS IN LIZ'S CHEMISTRY 101 CLASS OR WORKS IN A DIFFERENT DEPARTMENT AT LIZ'S OFFICE), and Liz had always thought that he was cute. Josh recognizes Liz, and the two begin a conversation about (THEIR CHEMISTRY HOMEWORK OR A BORING STAFF MEETING). Josh asks Liz if she wants to dance, and the two have a fun time dancing, flirting, and laughing together. A few hours pass, and the party starts to wind down. Liz still cannot find Jen, so Josh offers to walk her back to her (DORM OR APARTMENT). Once they arrive, Josh asks Liz if he can come in, and she says yes. The two decide to watch a movie on the couch, and wait for Jen to get home. Fifteen minutes into the movie, Josh leans over, puts his hand on Liz's thigh under her skirt, and kisses her. Liz pushes Josh away, and tells him that even though she likes him, she does not want to get intimate with him tonight. (ADD ONE OF THE THREE ENDINGS HERE)

(1) FORCE ENDING: Josh then shoves Liz down onto the couch with one hand, unbuttoning his pants with the other. Liz continues to tell Josh no, but he has sex with her anyway. 
PREVENTION AND PERCEPTIONS

(2) INCAPACITATION ENDING: Josh tells Liz that he respects her decision, and offers to make her another drink. Liz accepts, she and Josh continue drinking throughout the night. When Liz wakes up the next morning, she sees a used condom in the trash can, feels pain in her vaginal area, and realizes Josh had sex with her.

(3) COERCION ENDING: Josh moves away, but seems upset. The two continue watching the movie, and in another 10 minutes, Josh places his hand on Liz's chest, and tries to kiss her. Liz again tells Josh that she wants to move slowly, and he moves away, looking more upset. Ten minutes later, Josh tells Liz that if she liked him, she would make out with him. Liz feels unsure of what to do, but tells Josh that they can keep kissing. After kissing for a while, Josh begins to remove Liz's clothes, as well as his own. Liz freezes up, and lies still while Josh has sex with her.

Liz feels that Josh sexually assaulted her, and decides to press charges. Imagine that you are part of the jury as you respond to the following questions.

\section{Victim Blaming}

(van Prooijen, \& van den Bos, 2009)

a. I believe that what happened to Liz was caused by her own behavior.

1. Strongly Disagree

2. Disagree

3. Somewhat Disagree

4. Neither Agree nor Disagree

5. Somewhat Agree 
6. Agree

7. Strongly Agree

b. I believe that Liz is responsible for what happened to her.

1. Strongly Disagree

2. Disagree

3. Somewhat Disagree

4. Neither Agree nor Disagree

5. Somewhat Agree

6. Agree

7. Strongly Agree

c. I think Liz deserved what happened to her.

1. Strongly Disagree

2. Disagree

3. Somewhat Disagree

4. Neither Agree nor Disagree

5. Somewhat Agree

6. Agree

7. Strongly Agree

d. I think Liz has been very careless.

1. Strongly Disagree

2. Disagree

3. Somewhat Disagree

4. Neither Agree nor Disagree

5. Somewhat Agree

6. Agree 
7. Strongly Agree

e. Liz recovered soon after this incident.

1. Strongly Disagree

2. Disagree

3. Somewhat Disagree

4. Neither Agree nor Disagree

5. Somewhat Agree

6. Agree

i. Strongly Agree

\section{Sex Offender Label}

Do you think that Josh is a sex offender?

1. Yes

2. No

\section{Punishment Variables}

Jail (King \& Roberts, 2015)

a. For how many years should Josh go to jail for what he did? If you do not think Josh should go to jail, please enter " 0 " in the box below

ii. Enter a number between 0 and 99

Registration (King \& Roberts, 2015)

a. For how many years would you require Josh to have his name, address, and photo with the police so the public can see this information? If you do not think Josh should have to register, please enter "0" in the box below.

i. Enter a number between 0 and 99 
Mandatory Counseling

a. For how many years should Josh be mandated to attend a counseling program for sexual offenders? If you do not think that Josh should have to attend a counseling program, please enter " 0 " in the box below.

i. Enter a number between 0 and 99

\section{Demographics Questions}

What is your gender?
○ Man
○ Woman
○ Nonbinary

What race/ethnicity(s) do you identify with? Check all that apply

$\circ$ White

○ Black

- Hispanic/Latin(x)

- Asian

- Pacific Islander

- Native American

- Indian/South Asian

- Arab/Middle Eastern

o Other:

How old are you?

Insert number here

What is your highest level of education?

- Some high school

- High school graduate

○ Some college

○ Bachelor's Degree

- Master's Degree or Higher

What part of the United States do you live in?

○ Northwest 

○ Southwest
○ Midwest
○ Northeast
○ South
○ Southeast

How much money do you make each year?
○ Less than 20,000
○ $20,000-40,000$
○ $40,000-60,000$
○ $60,000-80,000$
○ More than 80,000

Are you a parent?
○ Yes
○ No

What is your education level? Please note the highest degree earned.

- Some high school

- High school or GED

- Some college

- Bachelor's degree

- Vocational degree

- Master's degree

- $\mathrm{PhD} / \mathrm{MD}$ or other professional degree

\section{IF RESPONDENT SELECTS “SOME COLLEGE” OR HIGHER}

Have you been involved in a Pan-hellenic organization? (Sorority or Fraternity)

$$
\text { ○ Yes }
$$


$\circ$ No

Did you play on a college sports team?
$\circ$ Yes
○ No

IF YES, please state which sport

Were you or are you involved in any campus religious organizations?
$\circ$ Yes
$\circ$ No

IF YES, please state the religious organization 


\section{References}

Abbey, A., Buck, P. O., Zawacki, T., \& Saenz, C. (2003). Alcohol's effects on perceptions of a potential date rape. Journal of studies on alcohol, 64(5), 669-677.

Abbey, A., \& McAuslan, P. (2004). A longitudinal examination of male college students' perpetration of sexual assault. Journal of consulting and clinical psychology, 72(5), 747.

Abbey, A., McAuslan, P., \& Ross, L. T. (1998). Sexual assault perpetration by college men: The role of alcohol, misperception of sexual intent, and sexual beliefs and experiences. Journal of Social and Clinical Psychology, 17(2), 167-195.

Abbey, A., Wegner, R., Pierce, J., \& Jacques-Tiura, A. J. (2012). Patterns of sexual aggression in a community sample of young men: Risk factors associated with persistence, desistance, and initiation over a 1-year interval. Psychology of violence, 2(1), 1.

Alexander, C. S., \& Becker, H. J. (1978). The use of vignettes in survey research. Public opinion quarterly, 42(1), 93-104.

Bailey, D. J., \& Klein, J. L. (2018). Ashamed and alone: Comparing offender and family member experiences with the sex offender registry. Criminal Justice Review, 43(4), 440- 457

Beres, M. A. (2014). Rethinking the concept of consent for anti-sexual violence activism and education. Feminism \& Psychology, 24(3), 373-389. 
Bergstrøm, H., Evjetun, P., \& Bendixen, M. (2017). Punishment justifications in rape cases: a community study. Journal of Scandinavian Studies in Criminology and Crime Prevention, 18(2), 123-140.

Berkowitz, A. (1992). College men as perpetrators of acquaintance rape and sexual assault: A review of recent research. Journal of American College Health, 40(4), 175-181.

Borsari, B., \& Carey, K. B. (2001). Peer influences on college drinking: A review of the research. Journal of substance abuse, 13(4), 391-424.

Brown, A. L., Testa, M., \& Messman-Moore, T. L. (2009). Psychological consequences of sexual victimization resulting from force, incapacitation, or verbal coercion. Violence Against Women, 15(8), 898-919.

Bouffard, J. A., \& Askew, L. N. (2019). Time-series analyses of the impact of sex offender registration and notification law implementation and subsequent modifications on rates of sexual offenses. Crime \& Delinquency, 65(11), 14831512.

Campbell, J. C., Sabri, B., Budhathoki, C., Kaufman, M. R., Alhusen, J., \& Decker, M. R. (2017). Unwanted sexual acts among university students: Correlates of victimization and perpetration. Journal of interpersonal violence.

Cleveland, H. H., Koss, M. P., \& Lyons, J. (1999). Rape tactics from the survivors' perspective: Contextual dependence and within-event independence. Journal of Interpersonal Violence, 14(5), 532-547. 
Cook, C. L., \& Fox, K. A. (2012). Testing the relative importance of contemporaneous offenses: The impacts of fear of sexual assault versus fear of physical harm among men and women. Journal of Criminal Justice, 40(2), 142-151.

Cornish, D. B., \& Clarke, R. V. (1987). Understanding crime displacement: An application of rational choice theory. Criminology, 25(4), 933-948.

DeMatteo, D., Galloway, M., Arnold, S., \& Patel, U. (2015). Sexual assault on college campuses: A 50-state survey of criminal sexual assault statutes and their relevance to campus sexual assault. Psychology, Public Policy, and Law, 2l(3), 227.

Department of Justice (2013). Felony defendants in large urban counties, 2009. Office of Justice Programs, Bureau of Justice Statistics.

Department of Justice (2013). Female victims of sexual violence, 1994-2010. Office of Justice Programs, Bureau of Justice Statistics.

Department of Justice (2015). National crime victimization survey, 2010-2014. Office of Justice Programs, Bureau of Justice Statistics.

Department of Justice (2000). Sexual assault of young children as reported to law enforcement.

Office of Justice Programs, Bureau of Justice Statistics.

Department of Justice (2014). Socio-emotional impact of violent crime. Office of Justice Programs, Bureau of Justice Statistics.

Department of Justice (2015). National crime victimization survey, 2010-2014. Office of Justice Programs, Bureau of Justice Statistics. 
Dworkin, J., Hessel, H., Gliske, K., \& Rudi, J. H. (2016). A comparison of three online recruitment strategies for engaging parents. Family Relations, 65(4), 550-561.

Dyar, C., Feinstein, B. A., \& Anderson, R. E. (2019). An experimental investigation of victim blaming in sexual assault: The roles of victim sexual orientation, coercion type, and stereotypes about bisexual women. Journal of Interpersonal Violence.

Eberhardt, J. L., Davies, P. G., Purdie-Vaughns, V. J., \& Johnson, S. L. (2006). Looking deathworthy: Perceived stereotypicality of Black defendants predicts capitalsentencing outcomes. Psychological science, 17(5), 383-386.

Fedina, L., Holmes, J. L., \& Backes, B. L. (2018). Campus sexual assault: A systematic review of prevalence research from 2000 to 2015. Trauma, violence, \& abuse, 19(1), 76-93.

Fiske, S. T., \& Taylor, S. E. (1991). Social cognition. Mcgraw-Hill Book Company.

Franiuk, R., Luca, A., \& Robinson, S. (2020). The effects of victim and perpetrator characteristics on ratings of guilt in a sexual assault case. Violence against women, 26(6- 7), 614-635.

Frese, B., Moya, M., \& Megías, J. L. (2004). Social perception of rape: How rape myth acceptance modulates the influence of situational factors. Journal of interpersonal violence, 19(2), 143-161.

Gerber, G. L., Cronin, J. M., \& Steigman, H. J. (2004). Attributions of blame in sexual assault to perpetrators and victims of both genders. Journal of Applied Social Psychology, 34(10), 2149-2165. 
PREVENTION AND PERCEPTIONS

Grubb, A., \& Turner, E. (2012). Attribution of blame in rape cases: A review of the impact of rape myth acceptance, gender role conformity and substance use on victim blaming. Aggression and Violent Behavior, 17(5), 443-452.

Harper, S., Maskaly, J., Kirkner, A., \& Lorenz, K. (2017). Enhancing title IX due process standards in campus sexual assault adjudication: Considering the roles of distributive, procedural, and restorative justice. Journal of school violence, 16(3), 302-316.

Hansen, S., O’Byrne, R., \& Rapley, M. (2010). Young heterosexual men's use of the miscommunication model in explaining acquaintance rape. Sexuality Research and Social Policy, 7(1), 45-49.

Hayes, R. M., Lorenz, K., \& Bell, K. A. (2013). Victim blaming others: Rape myth acceptance and the just world belief. Feminist Criminology, 8(3), 202-220.

Hazelwood, R. R., \& Warren, J. I. (2003). Linkage analysis: Modus operandi, ritual, and signature in serial sexual crime. Aggression and violent behavior, 8(6), 587-598.

Heider, F. (1958). The psychology of interpersonal relations Wiley. New York.

Karjane, H. K., Fisher, B. S., \& Cullen, F. T. (1999). Campus sexual assault: How A merica's institutions of higher education respond. Final Report, NIJ Grant.

Katz-Schiavone, S., Levenson, J. S., \& Ackerman, A. R. (2008). Myths and facts about sexual violence: Public perceptions and implications for prevention. Journal of Criminal Justice and Popular Culture, 15(3), 291-311.

Kaufman, K. L., Holmberg, J. K., Orts, K. A., McCrady, F. E., Rotzien, A. L., Daleiden, E. L., \& Hilliker, D. R. (1998). Factors influencing sexual offenders' modus 
PREVENTION AND PERCEPTIONS

operandi: An examination of victim-offender relatedness and age. Child Maltreatment, 3(4), 349-361.

Kernsmith, P. D., Craun, S. W., \& Foster, J. (2009). Public attitudes toward sexual offenders and sex offender registration. Journal of child sexual abuse, 18(3), 290301.

King, L. L., \& Roberts, J. J. (2017). The complexity of public attitudes toward sex crimes. Victims \& Offenders, 12(1), 71-89.

Kingree, J. B., \& Thompson, M. (2015). A comparison of risk factors for alcoholinvolved and alcohol-uninvolved sexual aggression perpetration. Journal of interpersonal violence, 30(9), 1478-1492.

Koss, M. P., \& Gidycz, C. A. (1985). Sexual experiences survey: reliability and validity. Journal of consulting and clinical psychology, 53(3), 422.

Koss, M. P., Gidycz, C. A., \& Wisniewski, N. (1987). The scope of rape: Incidence and prevalence of sexual aggression and victimization in a national sample of higher education students. Journal of consulting and clinical psychology, 55(2), 162.

Koss, M. P., Wilgus, J. K., \& Williamsen, K. M. (2014). Campus sexual misconduct: Restorative justice approaches to enhance compliance with Title IX guidance. Trauma, Violence, \& Abuse, 15(3), 242-257.

Krebs, C. P., Lindquist, C. H., Warner, T. D., Fisher, B. S., \& Martin, S. L. (2007). The campus sexual assault (CSA) study. Washington, DC: National Institute of Justice, US Department of Justice. 
Krebs, C. P., Lindquist, C. H., Warner, T. D., Fisher, B. S., \& Martin, S. L. (2009). College women's experiences with physically forced, alcohol-or other drugenabled, and drug-facilitated sexual assault before and since entering college. Journal of American College Health, 57(6), 639-649.

Krebs, C., Lindquist, C., Berzofsky, M., Shook-Sa, B., Peterson, K., Planty, M., \& Stroop, J. (2016). Campus climate survey validation study: Final technical report. Washington, DC: BJS, Office of Justice Programs

Lambert, A. J., \& Raichle, K. (2000). The role of political ideology in mediating judgments of blame in rape victims and their assailants: A test of the just world, personal responsibility, and legitimization hypotheses. Personality and Social Psychology Bulletin, 26(7), 853-863.

Landström, S., Strömwall, L. A., \& Alfredsson, H. (2016). Blame attributions in sexual crimes: Effects of belief in a just world and victim behavior. Nordic Psychology, 68(1), 2-11.

Letourneau, E. J., Harris, A. J., Shields, R. T., Walfield, S. M., Ruzicka, A. E., Buckman, C., ... \& Nair, R. (2018). Effects of juvenile sex offender registration on adolescent well-being: An empirical examination. Psychology, Public Policy, and Law, 24(1), 105.

Levenson, J. S., D'Amora, D. A., \& Hern, A. L. (2007). Megan's law and its impact on community re-entry for sex offenders. Behavioral Sciences \& the Law, 25(4), $587-602$. 
PREVENTION AND PERCEPTIONS

Levenson, J. S., Brannon, Y. N., Fortney, T., \& Baker, J. (2007). Public perceptions about sex offenders and community protection policies. Analyses of Social Issues and Public Policy, 7(1), 137-161.

Linder, C., \& Lacy, M. (2020). Blue lights and pepper spray: Cisgender college women's perceptions of campus safety and implications of the "stranger danger" myth. The Journal of Higher Education, 91(3), 433-454.

Linder, C., \& Myers, J. S. (2018). Institutional betrayal as a motivator for campus sexual assault activism. NASPA Journal About Women in Higher Education, 11(1), 1-16.

Lisak, D., \& Miller, P. M. (2002). Repeat rape and multiple offending among undetected rapists. Violence and victims, 17(1), 73-84.

Loh, C., Gidycz, C. A., Lobo, T. R., \& Luthra, R. (2005). A prospective analysis of sexual assault perpetration: Risk factors related to perpetrator characteristics. Journal of Interpersonal Violence, 20(10), 1325-1348.

Mason, W., \& Suri, S. (2012). Conducting behavioral research on Amazon's Mechanical Turk. Behavior research methods, 44(1), 1-23.

McCaskill, C. (2014). Bipartisan bill takes aim at sexual assault on college and university campuses [Press release].

McMahon, P. P. (2008). Sexual violence on the college campus: A template for compliance with federal policy. Journal of American College Health, 57(3), 361366. 
Mellins, C. A., Walsh, K., Sarvet, A. L., Wall, M., Gilbert, L., Santelli, J. S., ... \& Bah, K. (2017). Sexual assault incidents among college undergraduates: Prevalence and factors associated with risk. PLoS one, 12(11), e0186471.

Melssen, M. C. (2013). Sources: Sexual Violence and Abuse: An Encyclopedia of Prevention, Impacts, and Recovery. Reference \& User Services Quarterly, 52(4), 354-354.

Mills, C. S., \& Granoff, B. J. (1992). Date and acquaintance rape among a sample of college students. Social Work, 37(6), 504-509.

Mitra, S. (2015). 'It takes six people to make a mattress feel light...': Materializing pain in carry that weight and sexual assault activism. Contemporary Theatre Review, 25(3), 386-400.

Mouilso, E. R., Fischer, S., \& Calhoun, K. S. (2012). A prospective study of sexual assault and alcohol use among first-year college women. Violence and victims, 27(1), 78-94.

Mynatt, C. R., \& Allgeier, E. R. (1990). Risk factors, self-attributions, and adjustment problems among victims of sexual coercion. Journal of Applied Social Psychology, 20(2), 130-153.

Nelson, M., Herlihy, B., \& Oescher, J. (2002). A survey of counselor attitudes towards sex offenders. Journal of Mental Health Counseling, 24(1).

O'byrne, R., Rapley, M., \& Hansen, S. (2006). 'You couldn't say “no”, could you?': young men's understandings of sexual refusal. Feminism \& Psychology, 16(2), 1 $33-154$. 
O'Byrne, R., Hansen, S., \& Rapley, M. (2008). If a girl doesn't say 'no'...”: young men, rape and claims of 'insufficient knowledge. Journal of Community \& Applied Social Psychology, 18(3), 168-193.

Pugh, B., \& Becker, P. (2018). Exploring definitions and prevalence of verbal sexual coercion and its relationship to consent to unwanted sex: Implications for affirmative consent standards on college campuses. Behavioral sciences, 8(8), 69.

Rogers, D. L., \& Ferguson, C. J. (2011). Punishment and rehabilitation attitudes toward sex offenders versus nonsexual offenders. Journal of Aggression, Maltreatment \& Trauma, 20(4), 395-414.

Russell, B. L., Oswald, D. L., \& Kraus, S. W. (2011). Evaluations of sexual assault: Perceptions of guilt and legal elements for male and female aggressors using various coercive strategies. Violence and Victims, 26(6), 799-815.

Salazar, L. F., Swartout, K. M., Swahn, M. H., Bellis, A. L., Carney, J., Vagi, K. J., \& Lokey, C. (2018). Precollege sexual violence perpetration and associated risk and protective factors among male college freshmen in Georgia. Journal of Adolescent Health, 62(3), S51-S57.

Seabrook, R. C., Ward, L. M., \& Giaccardi, S. (2018). Why is fraternity membership associated with sexual assault? Exploring the roles of conformity to masculine norms, pressure to uphold masculinity, and objectification of women. Psychology of Men \& Masculinity, 19(1), 3. 
Shackley, M., Weiner, C., Day, A., \& Willis, G. M. (2014). Assessment of public attitudes towards sex offenders in an Australian population. Psychology, Crime \& Law, 20(6), 553-572.

Sit, V., \& Schuller, R. A. (2018). Understanding support providers' views of "helpful" responses to sexual assault disclosures: The impacts of self-blame and physical resistance. Journal of interpersonal violence, 33(8), 1236-1259.

Socia, K. M., \& Harris, A. J. (2016). Evaluating public perceptions of the risk presented by registered sex offenders: Evidence of crime control theater?. Psychology, Public Policy, and Law, 22(4), 375.

Steyn Jr, H. S., \& Ellis, S. M. (2009). Estimating an effect size in one-way multivariate analysis of variance (MANOVA). Multivariate Behavioral Research, 44(1), 106129.

Strang, H., Sherman, L. W., Mayo-Wilson, E., Woods, D., \& Ariel, B. (2013). Restorative justice conferencing (RJC) using face-to-face meetings of offenders and victims: Effects on offender recidivism and victim satisfaction. A systematic review. Campbell Systematic Reviews, 9(1), 1-59.

Stuart, S. M., McKimmie, B. M., \& Masser, B. M. (2019). Rape perpetrators on trial: The effect of sexual assault-Related schemas on attributions of blame. Journal of interpersonal violence, 34(2), 310-336.

Swartout, K. M., Koss, M. P., White, J. W., Thompson, M. P., Abbey, A., \& Bellis, A. L. (2015). Trajectory analysis of the campus serial rapist assumption. JAMA pediatrics, 169(12), 1148-1154. 
Sykes, G. M., \& Matza, D. (1957). Techniques of neutralization: A theory of delinquency. American sociological review, 22(6), 664-670.

Tannen, D. (1992). That's not what I meant!: how conversational style makes or breaks your relations with others. Virago.

Testa, M., VanZile-Tamsen, C., Livingston, J. A., \& Koss, M. P. (2004). Assessing women's experiences of sexual aggression using the sexual experiences survey: Evidence for validity and implications for research. Psychology of Women Quarterly, 28(3), 256-265.

Van der Bruggen, M., \& Grubb, A. (2014). A review of the literature relating to rape victim blaming: An analysis of the impact of observer and victim characteristics on attribution of blame in rape cases. Aggression and violent behavior, 19(5), $523-531$.

Van Prooijen, J. W., \& van den Bos, K. (2009). We blame innocent victims more than I d o: Self-construal level moderates responses to just-world threats. Personality and Social Psychology Bulletin, 35(11), 1528-1539.

Voith, L. A., Anderson, R. E., \& Cahill, S. P. (2020). Extending the ACEs framework: Examining the relations between childhood abuse and later victimization and perpetrationwith college men. Journal of interpersonal violence, 35(17-18), 34873512.

Ward, C. A. (1995). Attitudes toward rape: Feminist and social psychological perspectives (Vol. 8). Sage. 
Weiss, K. G. (2009). "Boys will be boys" and other gendered accounts: An exploration of victims' excuses and justifications for unwanted sexual contact and coercion. Violence Against Women, 15(7), 810-834.

Whatley, M. A. (1996). Victim characteristics influencing attributions of responsibility to rape victims: A meta-analysis. Aggression and Violent Behavior, 1(2), 81-95

Wheeler, Jennifer G., William H. George, and Barbara J. Dahl. "Sexually aggressive college males: Empathy as a moderator in the "Confluence Model" of sexual aggression." Personality and Individual Differences 33.5 (2002): 759-775.

White, J. W., \& Smith, P. H. (2004). A longitudinal perspective on physical and sexual intimate partner violence against women. Violence Against Women and Family Violence: Developments in Research, Practice, and Policy.

Willis, G. M., Malinen, S., \& Johnston, L. (2013). Demographic differences in public attitudes towards sex offenders. Psychiatry, Psychology and Law, 20(2), 230-247.

Yndo, M. C., \& Zawacki, T. (2020). Factors influencing labeling nonconsensual sex as sexual assault. Journal of interpersonal violence, 35(7-8), 1803-1827.

Zatkin, J., Sitney, M., \& Kaufman, K. The relationship between policy, media, and perceptions of sexual offenders between 2007 and 2017: A review of the literature. Trauma, Violence, \& Abuse.

Zimring, F. E. (2002). The common thread: Diversion in the jurisprudence of juvenile courts. A century of juvenile justice, 142, 144-45. 
Zinzow, H. M., \& Thompson, M. (2015). A longitudinal study of risk factors for repeated sexual coercion and assault in US college men. Archives of sexual behavior, 44(1), 213-222. 
PREVENTION AND PERCEPTIONS

\section{Chapter 5. Conclusions}

In this chapter, the contribution of each of the three dissertation studies will be discussed, followed by the overall contribution of this dissertation to the sexual violence prevention literature. Practical implications of these findings are discussed, followed by a future direction for a line of research.

\section{Dissertation Contribution}

Each study in this dissertation examines a unique aspect of a central research question: How can we challenge common perceptions of sexual offenders and offending? Beginning with Study One, it is apparent that many of the violent perpetration tools commonly associated with sexual violence, such as blatant force, are not often utilized by those who commit child sexual abuse. Instead, the psychometric analysis of the MOQ supports a grooming process, wherein those who commit child sexual abuse use subtle, seemingly non-violent tactics to offend over time. This finding challenges a perception that those who commit child sexual abuse are murderous psychopaths. While some offenders may fit this stereotype, it is much more likely that an offender will know their victim well, or even abuse those related to them. These findings challenge the "stranger danger" myth, or the idea that those who commit sexual violence are a dangerous unknown.

Study Two further examines the relationship between public perceptions of offenders, media, and policy. A main finding here is that there are four persistent myths about sexual offenders that permeate public discourse: 1. Stranger Danger; 2. Crime on the Rise; 3. Homogeneity, and 4. Recidivism. This review highlights how alarmist media 
substantiates the Crime on the Rise myth, and state and federal policies perpetuate the recidivism myth by being overly punitive, and not focused on desistence. Study Two does leave the question of how far these myths reach, however. Most of the literature in this arena focuses upon those who abuse children, and most policies are built from cases of child sexual abuse. It is unclear from this review if the myths uncovered have limitations.

In response to Study Two, Study Three examines sexual violence within a campus context. Specifically, student offenders are compared to non-student offenders, with perceptions operationalized through punishment. A main finding here is that the general public does not punish student offenders differently than non-student offenders. Assault type (force, coercion, or incapacitation) also does not impact how offenders are punished. This is paired with significant differences for Victim Blaming, implying that views of sexual violence survivors are impacted by context, while views of offenders are not. Average punishment for offenders is high, while a large portion of the sample chose not to punish the offender in question at all. This means that there may not be a difference in how college students are perceived in comparison to non-student offenders, and similar myths may frame these perceptions. Further, the study asserts that the public seems to either demonize offenders with overly harsh punishment or exonerate them by assigning no punishment at all.

Taken together, these three studies support the stability of perceptions of sexual offenders across contexts. In other words, a myth-based understanding of sexual 
PREVENTION AND PERCEPTIONS

offenders is pervasive. The next section will discuss the practical implications of this key finding.

\section{Practical Implications}

This section will provide three practical implications that come from this dissertation. These implications regard policies about sexual offending, media coverage, and communication between researchers and the public.

This first implication of this dissertation is that policies surrounding those who perpetrate sexual violence should be revised. Though there is evidence that all offenders are perceived as similarly dangerous, in reality, offenders are a large and heterogeneous group (Galeste et al., 2012). Yet, punitive policies for sexual offenders at both the federal and state levels are more aligned with perceptions of danger and homogeneity than how offenders operate in reality (Burchfield et al., 2014; Katz-Schiavone et al., 2008). The public's fear and want for punishment is heard by politicians, who respond by supporting laws that require draconian penalties that do not actually help offenders rehabilitate (Sample \& Kadleck, 2008). At the state and federal levels, it is suggested that lawmakers evaluate their policies, and use evidence-based practices to create new policies that will lower rates of sexual violence by helping offenders rehabilitate while holding them accountable for their actions.

These policies should also differ based on the offense type. Just because we perceive offenders as one-size-fits-all, does not mean that policies that work for one offender type also work for another. For example, though the registry is harmful in general, a large amount of research has shown that it is most harmful for juvenile 
offenders (Letourneau et al., 2018). If the registry does continue to exist, what requires registration should be re-evaluated.

On college campuses, policy makers should work to find a happy medium to both hold offenders accountable and allow them to rehabilitate. This means that no punishment, as suggested by many participants in Study Three, is not the answer. Campus offenders are in a privileged position, where they can sometimes bypass the criminal justice system when convicted of sexual assault (McKaskill, 2014). Campuses in turn should work to create policies that can be a model for the criminal justice system — policies that allow for both accountability and rehabilitation.

A second implication stemming from this dissertation is how media impacts the perpetuation of offender myths. The news almost never discusses more common occurrences of intra-familial CSA and sexual assault by a friend or acquaintance on college campuses. Coverage for CSA focuses on the small number of offenders that have a large reach, often abusing from a position of power, online, or abusing a large number of children (Weatherred, 2017). To be clear, these more powerful and sensational perpetrators do cause harm, and their crimes should be publicized (Erooga et al., 2020). While these offenders do cause harm and can be covered, the media can do a better job at not making the sensational experience seem like the most common experience (Smallbone, 2020). On campuses, much media coverage focuses on polarizing figures such as Brock Turner, can be very victim-blaming, and tends to focus only on the individuals involved (O’Boyle \& $\mathrm{Li}, 2019)$. Coverage of campus sexual assault can work to ensure that victims are not blamed and help to shift focus to institutions instead of 
individuals. Campuses could work with media to publicize the reality of sexual violence on their campuses, and new innovative policies they are testing to end it. This would show that change needs to come from an organizational level.

Finally, reforms in media and policy require more communication between those who research sexual violence, those who conduct therapy with perpetrators, and the general public. It is clear from the literature that the way experts view sexual violence is vastly different than the general public (Koon-Magnin, 2015; Levenson et al., 2008). While this difference is clear to the social scientists doing this research, the persistence of this divide means that more needs to be done by way of communication with the public. Since peer-reviewed journals are not easily accessible to most, individuals may not be able to learn about sexual offenders outside of what information the mainstream media provides. To create systems-level change, those who work with offenders need to be a more prominent voice in the media. Experts can balance sensationalized news stories with facts and statistics that give a more realistic picture of the problem of sexual violence. With time, this might lead to a public that is more accepting of evidence based polices that are based in prevention, and not motivated by fear.

This is a hard challenge, particularly in a post-Trump world where many individuals no longer trust the media or politicians (Aliapoulios et al., 2021). Since the publication of Study Two, outrageous myths about pedophiles and CSA have become mainstream through the \#SaveTheChildren campaign, and the QAnon Conspiracy Theory. These theories significantly overemphasize the presence of child sex trafficking and sexual abuse, and posit that prominent government leaders are kidnapping children, 
sexually abusing them, and harvesting a chemical called "adrenochrome" to stay young (Aliapoulios et al., 2021). Clearly, these theories are far-fetched, but the willingness that people display to accept them as reality supports the pervasiveness of hatred toward people who commit child sexual abuse. Yet, these same folks seem unwilling to look behind the scare tactics and understand that sexual violence is perpetuated by systematic inequality and power imbalances, not murderous pedophiles. The good news is that most people want to see fewer children victimized by sexual violence. As experts, it is our job to help the public understand that the best way to prevent sexual violence is to understand that the issue is nuanced and does not come with quick and easy solutions.

\section{Future Directions for Research}

To further explore these nuances, it is evident that a reliable and valid scale must be created to adequately measure prominent myths about sexual offenders. Scales of this nature do exist. The Community Attitudes toward Sexual Offender scale (CATSO; Shelton et al., 2013) is the most prominently used scale of this nature. The CATSO focuses on community level perceptions and has shown that these perceptions are quite negative (Conley et al., 2011; Klein, 2015). It does not necessarily measure endorsement of myths at the individual level and cannot be applied to different types of offenders.

A new myths scale would not measure attitudes and perceptions toward offender directly but would rather measure endorsement of offender myths in general and applied to different types of offending contexts. Similar scales exist to measure myths about rape, such as the Burt scale (1980), and the Illinois Rape Myth Acceptance scale (IRMA; Payne et al., 1999). These scales have been used copiously in the literature to examine 
how endorsement of rape myths impacts assessment and attribution in sexual violence cases (Coker et al., 2020; Garza \& Franklin, 2020; Perrson \& Dinghra, 2020). A similar scale that measures endorsement of myths about perpetration could add to this literature, to help understand how we attribute blame in cases of sexual violence. It would also be fascinating to understand whether rape myths and perpetration myths are correlated, a study which has not been conducted to date.

With the findings from this dissertation, there is evidence to support one myth scale that can be used with all offender types, as the myths seem to be pervasive across context. Of course, one application of the scale would be to cross-validate across context to further understand pervasiveness of these myths. Another use for a new myths scale would be as an aid to code media, knowing the influence on myths and policies. Understanding the prevalence of perpetration myths in television shows, movies, and news coverage will be a valuable tool in understanding public perceptions.

In short, a myths scale is needed to continue this line of research, and this dissertation provides evidence to support the creation of that scale, to continue uncovering the relationship between mythical perceptions of offenders and sexual violence prevention. 


\section{References}

Aliapoulios, M., Papasavva, A., Ballard, C., De Cristofaro, E., Stringhini, G., Zannettou, S., \& Blackburn, J. (2021). The gospel according to Q: Understanding the QAnon conspiracy from the perspective of canonical information. arXiv preprint arXiv:2101.08750.

Burchfield, K., Sample, L. L., \& Lytle, R. (2014). Public interest in sex offenders: A perpetual panic. Criminology, Criminal Justice, Law \& Society, 15 (96).

Burt, M. R. (1980). Cultural myths and supports for rape. Journal of personality and social psychology, 38(2), 217.

Coker, A. L., Bush, H. M., Clear, E. R., Brancato, C. J., \& McCauley, H. L. (2020). Bystander program effectiveness to reduce violence and violence acceptance within sexual minority male and female high school students using a cluster RCT. Prevention science, 21(3), 434-444.

Conley, T., Hill, K., Church, W. T., Stoeckel, E., \& Allen, H. (2011). Assessing probation and community corrections workers' attitudes toward sex offenders using the Community Attitudes Toward Sex Offenders (CATSO) scale in a rural state. Sexual Addiction \& Compulsivity, 18(2), 75-85.

Erooga, M., Kaufman, K., \& Zatkin, J. G. (2020). Powerful perpetrators, hidden in plain sight: an international analysis of organisational child sexual abuse cases. Journal of sexual aggression, 26(1), 62-90.

Galeste, M. A., Fradella, H. F., \& Vogel, B. (2012). Sex offender myths in print media: 
PREVENTION AND PERCEPTIONS

Separating fact from fiction in US newspapers. Western Criminology

Review, 13,4 .

Garza, A. D., \& Franklin, C. A. (2020). The effect of rape myth endorsement on police response to sexual assault survivors. Violence against women, 1077801220911460

Katz-Schiavone, S., Levenson, J. S., \& Ackerman, A. R. (2008). Myths and facts about sexual violence: Public perceptions and implications for prevention. Journal of Criminal Justice and Popular Culture, 15(3), 291-311.

Klein, J. L. (2015). Vilifying the pedophiles and perverts: A nationwide test of the community attitudes toward sex offenders (CATSO) scale. Criminology, Crim. Just. L \& Soc'y, 16, 41.

Koon-Magnin, S. (2015). Perceptions of and support for sex offender policies: Testing Levenson, Brannon, Fortney, and Baker's findings. Journal of Criminal Justice, 43(1), 80-88.

Letourneau, E. J., Harris, A. J., Shields, R. T., Walfield, S. M., Ruzicka, A. E., Buckman, C., ... \& Nair, R. (2018). Effects of juvenile sex offender registration on adolescent well-being: An empirical examination. Psychology, Public Policy, and Law, 24(1), 105.

McCaskill, C. (2014). Bipartisan bill takes aim at sexual assault on college and university campuses [Press release]. 
O’Boyle, J., \& Li, Q. J. Y. (2019). \# MeToo is different for college students: Media framing of campus sexual assault, its causes, and proposed solutions. Newspaper Research Journal, 40(4), 431-450.

Payne, D. L., Lonsway, K. A., \& Fitzgerald, L. F. (1999). Rape myth acceptance: Exploration of its structure and its measurement using thelllinois rape myth acceptance scale. Journal of Research in Personality, 33(1), 27-68.

Persson, S., \& Dhingra, K. (2020). Attributions of blame in stranger and acquaintance rape: a multilevel meta-analysis and systematic review. Trauma, Violence, \& Abuse, 1524838020977146.

Sample, L. L., \& Kadleck, C. (2008). Sex offender laws: Legislators' accounts of the need for policy. Criminal Justice Policy Review, 19(1), 40-62.

Shelton, L., Stone, J., \& Winder, B. (2013). Evaluating the factor structure and reliability of the Community Attitudes Toward Sex Offenders (CATSO) scale. Journal of Criminal Psychology.

Smallbone, S. (2020). Themed issue on sexual abuse in organisations: invited introduction and commentary.

Weatherred, J. L. (2017). Framing child sexual abuse: A longitudinal content analysis of newspaper and television coverage, 2002-2012. Journal of child sexual abuse, 26(1), 3-22. 